\title{
Exposure factors for marine eutrophication impacts assessment based on a mechanistic biological model
}

\author{
Cosme, Nuno Miguel Dias; Koski, Marja; Hauschild, Michael Zwicky
}

Published in:

Ecological Modelling

Link to article, DOI:

10.1016/j.ecolmodel.2015.09.005

Publication date:

2015

Document Version

Peer reviewed version

Link back to DTU Orbit

Citation (APA):

Cosme, N. M. D., Koski, M., \& Hauschild, M. Z. (2015). Exposure factors for marine eutrophication impacts assessment based on a mechanistic biological model. Ecological Modelling, 317, 50-63.

https://doi.org/10.1016/j.ecolmodel.2015.09.005

\section{General rights}

Copyright and moral rights for the publications made accessible in the public portal are retained by the authors and/or other copyright owners and it is a condition of accessing publications that users recognise and abide by the legal requirements associated with these rights.

- Users may download and print one copy of any publication from the public portal for the purpose of private study or research.

- You may not further distribute the material or use it for any profit-making activity or commercial gain

- You may freely distribute the URL identifying the publication in the public portal 


\title{
Exposure factors for marine eutrophication impacts assessment based on a mechanistic biological model
}

\author{
Nuno Cosme $^{\text {a,*, }}{ }^{\text {, Marja Koski }}{ }^{\text {b }}$, Michael Z. Hauschild ${ }^{\text {a }}$ \\ ${ }^{a}$ Division for the Quantitative Sustainability Assessment, Department of Management Engineering, \\ Technical University of Denmark, Produktionstorvet 424, DK-2800 Kgs. Lyngby, Denmark \\ ${ }^{\mathrm{b}}$ Section of Marine Ecology and Oceanography, Technical University of Denmark, Kavalergården 6, DK- \\ 2920 Charlottenlund, Denmark \\ *Corresponding author. Tel.: +45 45254729.E-mail address: nmdc@ dtu.dk
}

\begin{abstract}
Emissions of nitrogen $(\mathrm{N})$ from anthropogenic sources enrich marine waters and promote planktonic growth. This newly synthesised organic carbon is eventually exported to benthic waters where aerobic respiration by heterotrophic bacteria results in the consumption of dissolved oxygen (DO). This pathway is typical of marine eutrophication. A model is proposed to mechanistically estimate the response of coastal marine ecosystems to $\mathrm{N}$ inputs. It addresses the biological processes of nutrient-limited primary production (PP), metazoan consumption, and bacterial degradation, in four distinct sinking routes from primary (cell aggregates) and secondary producers (faecal pellets, carcasses, and active vertical transport). Carbon export production $\left(P_{\mathrm{E}}\right)$ and ecosystems eXposure Factors $(\mathrm{XF})$, which represents a nitrogen-to-oxygen 'conversion' potential, were estimated at a spatial resolution of 66 large marine ecosystem (LME), five climate zones, and site-generic. The XFs obtained range from 0.45 (Central Arctic Ocean) to $15.9 \mathrm{kgO}_{2} \cdot \mathrm{kgN}^{-1}$ (Baltic Sea).

While LME resolution is recommended, aggregated $P_{\mathrm{E}}$ or XF per climate zone can be adopted, but not global aggregation due to high variability. The $\mathrm{XF}$ is essential to estimate a marine eutrophication impacts indicator in Life Cycle Impact Assessment (LCIA) of anthropogenic-N emissions. Every relevant process was modelled and the uncertainty of the driving parameters considered low suggesting valid applicability in characterisation modelling in LCIA.
\end{abstract}

Keywords: Nitrogen; Carbon export; Oxygen depletion; Marine eutrophication; Exposure factor; Life cycle impact assessment.

\section{Table of Contents}

1. Introduction 2

2. Methodology 3

2.1. Spatial differentiation 4

2.2. Biological model pathway and major fluxes 4

2.3. Photosynthesis and C:N conversion 5

2.4. Production and export of organic material from the euphotic zone 5

2.5. Consumption and degradation of sinking organic material $\quad 7$

2.6. Benthic respiration and $\mathrm{O}_{2}: \mathrm{C}$ conversion 9

2.7. Estimation of export production 10

3. Results 11

3.1. Contributions from sinking routes 13

3.2. Sensitivity analysis 13

4. Discussion 14

4.1. Model sensitivity and parameters uncertainty 14

4.2. Spatial units and differentiation 16

4.3. From primary production to export production 16

4.4. From export production to exposure factor 18

4.5. Limitations and future research $\quad 19$

$\begin{array}{ll}\text { 5. Conclusions } & 20\end{array}$

6. References 20 


\section{Introduction}

The ecological equivalent for the photosynthesis rate in marine systems is the primary production (PP) rate (Platt et al., 1989). Marine photosynthetic primary producers assimilate nutrients dissolved in seawater: nitrogen $(\mathrm{N})$, phosphorus $(\mathrm{P})$, silicon $(\mathrm{Si})$, and micronutrients, along with carbon $(\mathrm{C})$ available from dissolution of atmospheric carbon dioxide, to synthesise organic compounds necessary for their metabolism and growth. The Redfield ratio (Redfield, 1958) is usually adopted to describe the average uptake of the various nutrients, i.e. C:N:P with molar ratios of 106:16:1 - see Ho et al. (2003) on elemental composition of phytoplankton. We assume $\mathrm{N}$ as the limiting nutrient in marine waters, or more precisely, in most of the marine waters and for most of the time to account for possible spatial and temporal exceptions. Studies and reviews support this assumption (e.g. Howarth and Marino (2006); Vitousek et al. (2002)), but we acknowledge that spatial and seasonal limitation by P or Si (e.g. Elser et al. (2007); Turner et al. (1998)) and cases of co-limitation (Arrigo, 2005) may occur. For modelling purposes we consider the 'limiting nutrient' concept a necessary and justifiable simplification.

Phytoplankton blooms occur when optimal light and temperature conditions, nutrient availability, and limited grazing pressure exist, so that growth rates may exceed losses from respiration, sinking, grazing, and other causes for mortality (Behrenfeld and Boss, 2014; Huisman et al., 1999). The timing and duration of phytoplankton blooms relative to the life-histories of secondary producers (SP, mainly zooplankton) are crucial to the match-mismatch hypothesis (Cushing, 1975) and the application in the present method. Under 'match' events zooplankton typically graze on phytoplankton, whose growth and sink are contained, and the export production is based on zooplankton's faecal pellets and carcasses. In opposition, the 'mismatch' occurs when the grazing pressure of the zooplankton community is not sufficient to balance the increase in phytoplankton growth and a larger fraction of these is left ungrazed. The mismatched fraction sinks off the euphotic zone facilitated by advection, aggregation, and coagulation (Kiørboe et al., 1996; Wassmann, 1998). At higher latitudes mismatch events are usually more intense, as environmental conditions turn favourable, defining the vertical flux. In the tropics a closer match between phyto- and zooplankton growth results in higher nutrients regeneration and retention food webs (Wassmann, 1998) with lower contributions to vertical export.

The downward export is composed of 'marine snow' (Alldredge and Silver, 1988; Kiørboe, 2001, 1996), the term used to describe the particulate organic carbon (POC) flux of sinking aggregates of phytoplankton cells, faecal pellets, zooplankton carcasses, and other organic material from dead or dying microorganisms (extensively reviewed by Fowler and Knauer (1986)). An additional contribution to this flux is given by active vertical transport (AVT) mediated by diel vertical migration of zooplankton (Lampert, 1989): zooplankton ingests organic particles at night from surface waters and excretes/egests the metabolites during the day below the mixed layer (Longhurst and Harrison, 1988). Sinking POC may be consumed or dissolved in the water column and only a fraction gets oxidised or consumed by benthic microbial and metazoan communities, respectively (Ducklow et al., 2001). Respiration in bottom strata is responsible for the remineralisation of nutrients but also for the consumption of dissolved oxygen (DO). In a principle of linearity of cause-effect, and modulated by site-dependent conditions, the higher the load of the limiting nutrient the higher the carbon flux and DO consumption. Under low ventilation conditions and excessive N input, DO can be depleted down to hypoxic and anoxic levels (Elmgren, 2001; Keeling et al., 2010).

Globally, anthropogenic N-loadings to the environment have increased more than 10-fold in the last 150 years, mainly due to the growing need for reactive nitrogen use in agriculture and to emissions from energy production (Galloway et al., 2008). Fertilizers applied in agricultural production emits N, mainly in the form of $\mathrm{NH}_{4}{ }^{+}$and $\mathrm{NO}_{3}{ }^{-}$to soil and water, or $\mathrm{NH}_{3}$ to air, whereas fossil fuels combustion emits nitrogen oxides $\left(\mathrm{NO}_{\mathrm{x}}\right)$ resulting from the oxidation of atmospheric $\mathrm{N}_{2}$ or organic $\mathrm{N}$ content of the fuel (mainly coal) (Galloway et al., 2002; Socolow, 1999). Run-off, leaching, and atmospheric deposition of these N-forms eventually enrich coastal marine ecosystems with biologically available N. Marine eutrophication can be one of the consequences after planktonic growth (Nixon, 1995; NRC, 2000; Smith et al., 1999), for which important impacts may arise from (i) decrease in water quality, by high turbidity, colour, and smell, hindering water uses, fish production, and reducing the aesthetic value, (ii) depletion of DO in bottom waters 
down to hypoxic or anoxic levels that may affect exposed species, and (iii) change in species composition and interaction that may enhance the growth of toxic and harmful algal species (Diaz and Rosenberg, 2008; Gray et al., 2002; Kelly, 2008; Levin et al., 2009). High biological oxygen demand (BOD) effluents may share similar DO consumption pathways via biologically-mediated degradation, but these are outside the scope of the present work.

The PP rate provides useful information on the ecological condition (Niemi et al., 2004; Smith, 2007), but is unable to predict distinct responses thus missing the explanatory power for the impacts. We propose a novel indicator, the ecosystem eXposure Factor (XF), to add a mechanistic explanation for ecosystem responses, potential impacts, and the reasons for its variability. Aiming at the quantification of such responses to anthropogenic-N loadings, we set the following objectives:

- Identify and parameterise the relevant biological processes of organic carbon production, export, and consumption/degradation to cover the entire ecosystem response pathway in a mechanistic manner;

- Spatially differentiate the parameterisation to ensure the model output is representative of distinct receiving ecosystems in support of a comparative assessment of exposure locations;

- Produce site-dependent exposure factors with a global coverage that express how much oxygen is consumed via respiration of sunken organic carbon as a function of $\mathrm{N}$ assimilated per specific spatial unit.

This approach seems relevant and useful for predictive advice, ecosystems management, and eutrophication modelling. It may therefore contribute to comparative assessments of environmental impact of human activities or vulnerability of coastal areas.

\section{Methodology}

Life Cycle Assessment (LCA) is an environmental analysis tool used to systematically evaluate the potential environmental impacts that arise from the consumption of resources or emission of substances to the environment throughout the entire life cycle of a product or service (Hauschild, 2005). In the Life Cycle Impact Assessment (LCIA) phase the inventoried emissions are multiplied by substance-specific characterisation factors $(\mathrm{CF})$ that represent the ability of those to impact on representative indicators. In brief, CFs convert an emission or consumption into a potential impact to the environment. In the present case, the impact category is marine eutrophication and the metric is a potential loss of species diversity in an ecosystem exposed to an $\mathrm{N}$ emission from anthropogenic sources.

The estimation of aquatic eutrophication CFs for LCIA applications has been reviewed recently and research needs identified (Henderson, 2015). Generically, the characterisation of marine eutrophication impacts involves the calculation of (i) fate factors (FF) expressing the availability of $\mathrm{N}$ in the euphotic zone of coastal waters, (ii) ecosystem exposure factors (XF) for the 'conversion' of the available $\mathrm{N}$ into organic matter (biomass) and oxygen consumed after its aerobic respiration, and (iii) effect factors (EF) to quantify the impact of DO depletion on exposed species (modelled as time- and volume-integrated Potentially Affected Fraction of species, PAF). Eq. (1) summarises the calculation of CFs as the product of these factors:

$C F\left[P A F \cdot m^{3} \cdot y r \cdot k g N^{-1}\right]=F F[y r] \times X F\left[k g O_{2} \cdot k g N^{-1}\right] \times E F\left[P A F \cdot m^{3} \cdot k g O_{2}{ }^{-1}\right]$

The present work introduces and discusses a method to estimate XFs. It contributes with a central element for the impact modelling of marine eutrophication in LCIA. The framework fits a mechanistic approach as it uses existing scientific knowledge about the relevant biological processes by means of equations that express the systems' response. Such approach allows some extrapolation of the results beyond the intrinsic limitations of the experimental data and evidence available (Duarte et al., 2004). In practice, we build a cause-effect pathway of cascading biological processes to deliver an overall conversion of $\mathrm{N}$ into DO consumption. Environmental relevance is ensured by describing every relevant parameter based on state of the art science. 


\subsection{Spatial differentiation}

The model focuses on coastal and shelf waters as these receive the majority of the anthropogenic emissions to the marine compartment and it is where the potential effects have the highest impact. Occurring biological populations and physical features are distinct from the adjacent pelagic open ocean and deep benthic systems (Spalding et al., 2007; UNESCO, 2009). They also comprise most of the marine biodiversity and human interest, as well as higher productivity and vulnerability to human interventions, including marine eutrophication (UNEP, 2006).

The modelled processes are nutrient-limited PP, metazoan consumption, and bacterial degradation of sunken organic carbon. A short description of these processes will be given in the sections ahead, focusing on the relevant limitations and interactions of the proposed approach. Some of the modelled parameters show significant spatial variation (e.g. PP rate). Spatial units are needed in an adequate and manageable scale and number to capture this variability and its contribution to the model results. Considering the scale at which the described processes occur, the large marine ecosystems (LME) biogeographical classification system (Sherman and Alexander, 1986) was adopted. It divides the coastal waters of the planet into 66 spatial units, from river basins and estuaries to the seaward boundaries of continental shelves (average depth of $200 \mathrm{~m}$ as a model assumption) and the outer margins of the major ocean current systems (Sherman et al., 2009). For parameters varying (mainly) with latitude, LMEs were grouped into five climate zones (polar, subpolar, temperate, subtropical, and tropical - Figures S.1 and S.2). The classification criteria were based on the mean annual sea surface temperature and latitudinal distribution (details in Section S.2.1). In other cases, sitegeneric parameters based on best estimates or global mean values from available empirical data were given preference when no relevant spatial differentiation was to consider, or when data on spatial variability were missing (e.g. respiration rates of sinking organic material, zooplankton ingestion rates, or carbon transported by AVT).

\subsection{Biological model pathway and major fluxes}

As mentioned earlier, nutrients assimilation by primary producers is followed by sinking of organic carbon to bottom layers facilitated by phytoplankton cells aggregation, compaction into zooplankton faecal pellets and carcasses, and AVT. Aerobic respiration by heterotrophic bacteria near the bottom leads to the consumption of DO. Figure 1 shows a simplified illustration of this pathway.

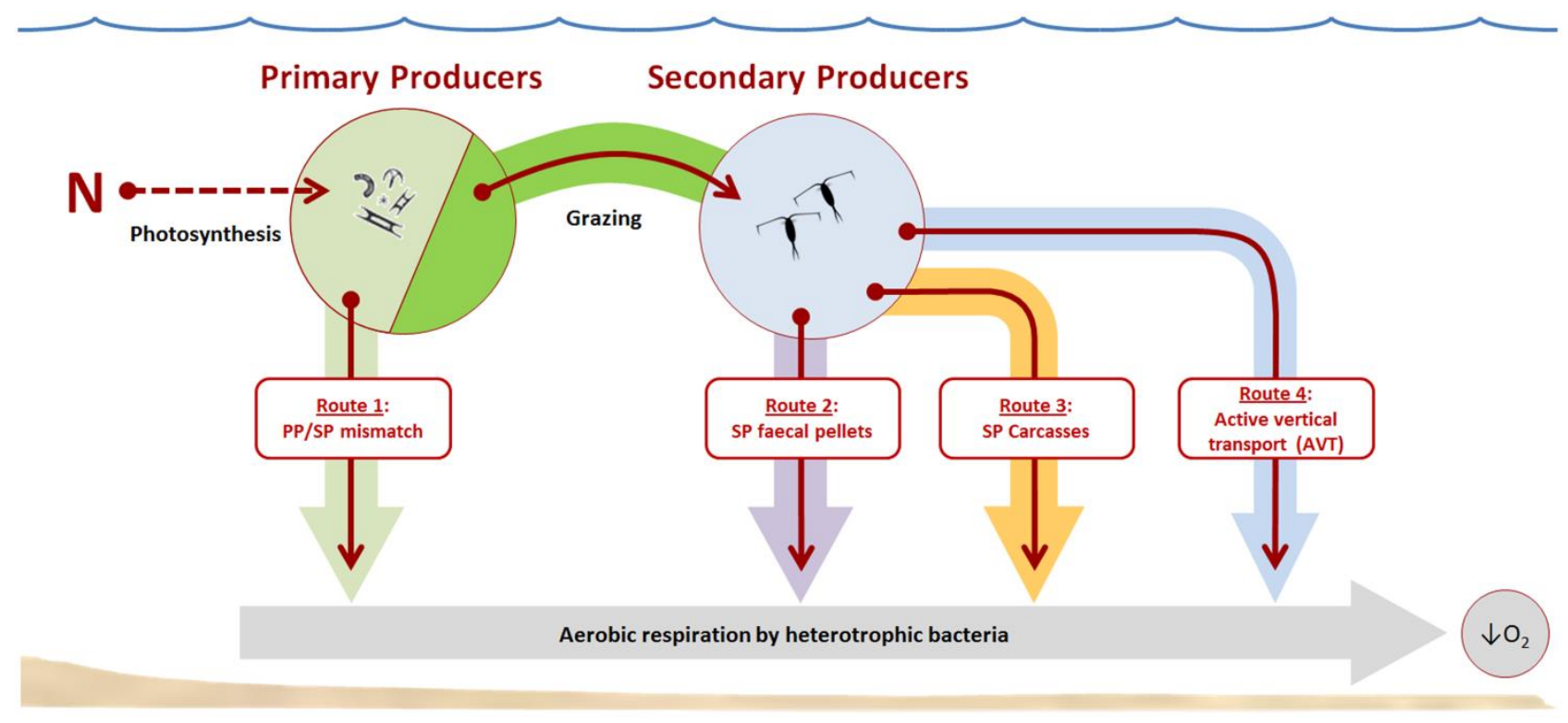

Figure 1 Simplified pathway of the ecosystem response to nitrogen $(\mathrm{N})$ inputs showing the four carbon export routes from the upper euphotic zone to the bottom water layer: route 1 (light green arrow) for sinking primary production (PP) biomass, route 2 (purple arrow) for sinking particulate organic carbon as faecal pellets from secondary production (SP), 
route 3 (orange arrow) for sinking zooplankton carcasses, and route 4 (light blue arrow) for active vertical transport $(\mathrm{AVT})$ - see text for process description. Dashed brown arrow represents assimilation of $\mathrm{N}$ and solid brown arrows represent organic carbon flows. Grey horizontal arrow refers to bacterial respiration in bottom waters that leads to dissolved oxygen $\left(\mathrm{O}_{2}\right)$ consumption.

Total PP consists of new production $\left(P_{\text {new }}\right)$, which uses allochthonous $\mathrm{N}$ (externally supplied, mainly nitrate), and regenerated production $\left(P_{\mathrm{r}}\right)$ fuelled by autochthonous $\mathrm{N}$ in the surface mixed layer (from heterotrophic recycling of organic matter, e.g. ammonia and urea) (Dugdale and Goering, 1967; Wassmann, 1990a). At steady-state (or long-term average) $P_{\mathrm{r}}$ is the component of PP that meets the metabolic demands of the pelagic community (Platt and Sathyendranath, 1988) and $P_{\text {new }}$ the component that can be exported without compromising the long-term integrity of the community (Vézina and Platt, 1987). The organic carbon that sinks off the mixed layer is referred to as export production $\left(P_{\mathrm{E}}\right)$. Its rate is, on an annual time scale and assuming $\mathrm{N}$ as the limiting nutrient, equivalent to the allochthonous $\mathrm{N}$ input rate as the downward flux of sinking $P_{\mathrm{E}}$ is equivalent to $P_{\text {new }}$ (Eppley et al., 1983). For this reason $P_{\mathrm{E}}$ is expected to increase (and so the impacts that may result from it) if $P_{\text {new }}$ increases due to additional $\mathrm{N}$-loadings to the coastal marine system from anthropogenic sources. Therefore, an increase of $\mathrm{N}$ input is expected to correspond to an increase in DO consumption in the proportionality defined by some factor. This attests the relevance for the management of N-emitting human activities and for the assessment of ecosystems health of a model capable of quantifying such a factor. This factor (i.e. XF) is described ahead.

The modelled biological processes can be related to (i) photosynthesis, determining the assimilation of $\mathrm{N}$ into biomass (organic carbon), (ii) production and export of organic material from the euphotic layer, (iii) consumption and degradation of sinking organic material, and (iv) the quantitative conversion of organic carbon into oxygen consumed by means of aerobic respiration by benthic heterotrophic bacteria, in agreement with the carbon fluxes as defined by the biological pump concept (Ducklow et al., 2001). The specific model parameters are described in the following sections and their inclusion in the response pathway is detailed in Figure 2. Processes in categories (i) and (ii) are also used to model $P_{\mathrm{E}}$.

\subsection{Photosynthesis and $C: N$ conversion}

Photosynthesis governs nutrients assimilation by primary producers. From thereon $\mathrm{N}$ relates to $\mathrm{C}$ by means of the Redfield ratio (Redfield, 1958) (molar mass ratio $C: N=106: 16$ ) based on the stoichiometry of the photosynthesis equation:

$\underline{106} \mathrm{CO}_{2}+16 \mathrm{HNO}_{3}+\mathrm{H}_{3} \mathrm{PO}_{4}+122 \mathrm{H}_{2} \mathrm{O} \Rightarrow \mathrm{C}_{106} \mathrm{H}_{263} \mathrm{O}_{110} \mathrm{~N}_{16} \mathrm{P}+138 \mathrm{O}_{2}$

The $C: N$ molar mass ratio estimates the mass of $\mathrm{C}$ fixed into biomass per mass of $\mathrm{N}$ assimilated, calculated by:

$C: N=(\underline{106} \mathrm{molC} * 12.0107 \mathrm{gC} / \mathrm{molC}) /(\underline{16} \mathrm{molN} * 14.0067 \mathrm{gN} / \mathrm{molN})=5.681 \mathrm{gC} / \mathrm{gN}$

\subsection{Production and export of organic material from the euphotic zone}

$\left(\boldsymbol{P P}_{\boldsymbol{P o t}}\right)$ PP rate $\left[\mathrm{gC} \cdot \mathrm{m}^{2} \cdot \mathrm{yr}^{-1}\right]$ (organic carbon synthesis rate) data are available at a LME spatial resolution from the Sea Around Us project (http://www.seaaroundus.org) (Lai, 2004; UBC, 1999). For comparative purposes, the PP rates of every LME $\left(P P_{L M E}\right)$ were normalised by the average PP rate $\left(P P_{\text {Avg_66LME }}\left[\mathrm{gC} \cdot \mathrm{m}^{2} \cdot \mathrm{yr}^{-1}\right]\right)$ to deliver the relative potential primary production in each spatial unit $\left(P P_{\text {Pot_LME }}[-]\right)$ by:

$P P_{P o t \_L M E}=P P_{L M E} / P P_{A v g_{-} 66 L M E}$

$\left(\boldsymbol{f}_{\boldsymbol{P P s i n k}}\right.$ and $\left.\boldsymbol{f}_{\boldsymbol{P P g r z}}\right)$ A fraction of the PP is grazed by zooplankton $\left(f_{P P g r z}[-]\right)$ while the remaining fraction $\left(f_{P P \operatorname{sink}}[-]\right)$ avoids it by sinking. The overlapping of occurrence of phyto- and zooplankton 
populations determines the grazed fraction while its mismatch represents the ungrazed sinking fraction, which varies with the production cycles in different regions (Cushing, 1975). Adopting the five climate zones $(\mathrm{CZ})$, these regionally-differentiated mismatch events result in a mean annual sinking fraction $\left(f_{\text {PPsink_cZ }}\right)$ of 0.67 of the phytoplankton biomass in the polar CZ (dominated by large phytoplankton cells, e.g. diatoms), 0.30 in the temperate $\mathrm{CZ}$ (dominated by diatoms in spring and dinoflagellates in autumn), and 0.15 in the tropical CZ (dominated by picoplankton, flagellates, and ciliates). These coefficients were estimated according to Cushing's principles for typical growth and grazing response, and the export production response modelled by Laws et al. (2000). Intermediate subpolar and subtropical CZs adopted mean values of the adjacent zones, i.e. 0.49 and 0.23 respectively (Table S.1). Complementarily, the fraction not sinking represents the standing crop of primary producers grazed by zooplankton, obtained by:

$f_{P P g r z_{-} C Z}=1-f_{P P S i n k_{-} C Z}$

Microzooplankton may also graze on phytoplankton, removing ca. 60-70\% of PP biomass on a global scale (Calbet and Landry, 2004) from the downward export flux of organic carbon due to remineralisation within the euphotic zone (Calbet, 2001). However, we assume that microzooplankton typically do not pose significant grazing pressure on large-celled phytoplankton blooms that constitute the mismatched fraction of the sinking PP biomass aggregates $\left(f_{P \text { Psink }}\right)$. The grazing pressure by microzooplankton is thus assumed to be included in the grazed fraction $\left(f_{P P g r z}\right)$. The ingestion, assimilation, and egestion (defecation) rates of the heterotrophs are then determinant in estimating the carbon export flux from SP (Besiktepe and Dam, 2002) (route 2 in Figure 1).

$\left(\boldsymbol{f}_{\text {SPingest }}\right)$ Phytoplankton's biomass grazed by SP is either ingested $\left(f_{\text {SPingest }}[-]\right)$ or dispersed (1 $f_{\text {SPingest }}$ ) as dissolved organic carbon (DOC) via sloppy feeding (Lampert, 1978; Møller, 2007). Mean ingestion fractions of the grazed biomass of 0.64 (relative standard deviation (rel.SD) $\approx 21 \%$ ) were obtained from different species and estimation methods (Møller and Nielsen, 2001; Møller, 2007; Saba et al., 2011, 2009) (see also Section S.2.3). Although DOC production may vary with the predator-prey size ratio (Møller, 2007) we do not expect a consistent biased variation per $C Z$ and thus a generic coefficient was adopted. The fate of this ingested fraction is further modelled by predation $\left(f_{\text {plfish }}\right)$, egestion $\left(f_{S P e g e s t}\right)$, non-consumptive mortality $\left(f_{\text {SPCarc }}\right)$, and active vertical transport $\left(f_{\text {AVT grz }}\right)$.

$\left(\boldsymbol{f}_{\text {plfish }}\right)$ Zooplankton biomass may be consumed by planktivorous fish (plfish) and therefore abstracted from the sinking flux. The concept of Primary Production Required (PPR, [-]) explains how much PP is required to sustain the reported fisheries per LME (Pauly and Christensen, 1995; UBC, 1999) and is used here as a proxy to estimate the predated fraction of zooplankton.

( $\boldsymbol{f}_{\text {SPassimil }}$ and $\boldsymbol{f}_{\text {SPegest }}$ ) Assimilation efficiency (AE) is the ratio of assimilation to consumption (Odum, 1971 ) or the proportion of the ingested material that is actually absorbed rather than egested (Besiktepe and Dam, 2002). AE coefficients for zooplankton ( $\left.f_{\text {SPassimil }}[-]\right)$ were estimated from Besiktepe and Dam (2002) for the polar $(0.30$, rel.SD $\approx 74 \%)$, temperate $(0.50$, rel.SD $\approx 25 \%)$, and tropical $(0.80$, rel.SD $\approx 9 \%)$ CZs based on the expected dominance of diatoms (polar), diatoms/flagellates (temperate), and flagellates/ciliates (tropical) in their diet. $f_{\text {SPassimil }}$ for the subpolar $(0.40$, rel.SD $\approx 57 \%)$ and subtropical $(0.65$, rel.SD $\approx 19 \%)$ CZs are mean values of the adjacent zones (see Table S.1). We used diet-specific AE coefficients instead of generic values from e.g. Saba et al. (2011) or Møller et al. (2003) after Conover (1966), to add environmental relevance and spatial differentiation to the parameter. Egestion refers to the ingested food that is not assimilated in the gut of zooplankton and therefore is eliminated as faecal pellets. The egested organic carbon fractions from SP were calculated for the five CZs by:

$f_{\text {SPegest_CZ }}=1-f_{\text {SPassimil_CZ }}$

$\left(\boldsymbol{f}_{\text {SPcarc }}\right)$ Zooplankton carcasses, i.e. dead organisms and body parts (Tang and Elliott, 2013) due to nonconsumptive mortality, are also part of sinking marine snow (as POC) following route 3 in Figure 1, which 
can further be consumed or respired in the water column or at the bottom. Non-consumptive mortality $\left(f_{\text {SPmort }},[-]\right)$ was estimated to be $29 \%$ of the predation mortality by plfish and constant regardless of temperature (Hirst and Kiørboe, 2002). A site-generic value was therefore used. PP's biomass in SP carcasses is then obtained per LME by:

$f_{\text {SPCarc_LME }}=f_{\text {SPMort }} * f_{\text {plfish_LME }}=0.29 * f_{\text {plfish_LME }}$

$\left(\boldsymbol{f}_{\text {AVT grz }}\right)$ Active vertical transport (AVT) due to diel vertical migration of zooplankton (route 4 in Figure 1 ) is an additional contribution to the downward carbon flux. The grazing pressure from migrating zooplankton (i.e. biomass removed from suspension) is assumed to be $10 \%$ of that of the zooplankton residing permanently in the surface layer $\left(f_{P P g r z}\right)$ and assumed constant for the five CZs. This assumption is based on findings of $<10 \%$ by Morales et al. (1993), roughly the proportion of migrating vs. non-migrating species in the North Sea (Koski et al., 2011), the mean value of $12 \%$ by Besiktepe et al. (1998), and also $15 \%$ by Roman et al. (1990) but including both pelagic and demersal zooplankton. Only the ingested fraction of the grazed biomass is modelled by AVT $\left(f_{\text {AVT grz }}[-]\right)$ as:

$f_{\text {AVTgrz } C Z}=0.10 * f_{P P g r z_{-} C Z} * f_{\text {SPingest }}$

\subsection{Consumption and degradation of sinking organic material}

$\left(\boldsymbol{f}_{\boldsymbol{P P s i n k G Z}}\right.$ and $\left.\boldsymbol{f}_{\boldsymbol{P P s i n k N G}}\right)$ Sinking aggregates may be grazed by zooplankton (sinkGZ) residing below the photic depth (Alldredge and King, 1980). We assumed that the zooplankton community in the aphotic zone crops ca. $15 \%$ of the sinking aggregates from PP $\left(f_{P P \operatorname{sink}}\right)$ supported by Roman et al. (1990), similar to mean values $(\approx 13.6 \%$ ) obtained by Roman et al. (2002), and roughly 1 out of $6(\approx 16.7 \%)$ dominant species of copepods occurring in the North Sea below the thermocline (Koski et al., 2011). The sinking non-grazed fraction of $\mathrm{PP}\left(f_{P P \operatorname{sinkNG}}[-]\right)$ per $\mathrm{CZ}$ is calculated by:

$f_{P P \operatorname{sinkNG} C Z}=1-f_{P P \operatorname{sinkGZ} C Z}=1-0.15 * f_{P P \sin k_{-} C Z}$

$\left(\boldsymbol{f}_{\text {FPleach }}\right)$ Organic carbon leached from faecal pellets (FP) contributes to the production of DOC (Møller and Nielsen, 2001), which is assumed to be recycled in the surface mixed layer and thus not contribute to the organic carbon flux reaching the bottom (contrary to POC). Here we included the losses by leaching and dissolution caused by the disruption of FP's periotrophic membrane by bacteria and protists (coprochaly) and manipulation by zooplankton with fragmentation (coprorhexy) (Wassmann, 1998). The organic carbon 'lost' to leaching $\left(f_{\text {FPleach }}[-]\right)$ was adopted from Møller et al. (2003) as $28 \%$ of the sinking flux of FP and assumed constant for the five CZs.

$\left(\boldsymbol{f}_{\boldsymbol{F P s i n k G Z}}\right.$ and $\left.\boldsymbol{f}_{\boldsymbol{F P s i n k N G}}\right)$ Zooplankton can also graze on sinking FP (coprophagy) (Wassmann, 1998) though much less efficiently than on sinking algal aggregates. The maximum feeding rate of particlecolonising copepods on FP $\left(f_{F P s i n k G Z}\right)$ is assumed to be ca. $20 \%$ of that of algae aggregates $\left(f_{P P \operatorname{sinkGZ}}\right)$ (Koski, unpublished) per climate zone, as:

$f_{F P \operatorname{sinkGZ} C Z}=0.20 * f_{P P \sin k G Z_{-} C Z}$

The remaining organic material sinking as FP not grazed $\left(f_{F P \sin k N G}[-]\right)$ is therefore obtained from deducting the losses of leaching and consumption, per climate zone, by:

$f_{\text {FPsinkNG_CZ }}=\left(1-f_{\text {FPleach }}\right) *\left(1-f_{\text {FPsinkGZ_CZ }}\right)$

$\left(\boldsymbol{f}_{\boldsymbol{B R} \operatorname{sinkPP}}\right.$ and $\boldsymbol{f}_{\boldsymbol{B R} \text { sinkSP }}$ ) Sinking POC is a component of marine snow (marsnow) and as such is respired by heterotrophic bacteria (bacterial respiration, BR) at a rate of $f_{B R \text { marsnow }}=0.13 d^{-1}$ (Iversen and Ploug, 2010). Sinking rates $(U)$ of organic material from PP and SP were adopted from Turner (2002) as $U_{P P}=150 \mathrm{~m} \cdot d^{-1}$ (phytodetritus and marine snow) and $U_{S P}=200 \mathrm{~m} \cdot d^{-1}$ (marine snow and faecal 
pellets). Mean depth $\left(Z_{\text {mean }}=100 \mathrm{~m}\right)$ was also used. The fractions of respired sinking $\operatorname{PP}\left(f_{B R \operatorname{sinkPP}}[-]\right)$ and sinking $\mathrm{SP}\left(f_{B R \sin k S P}[-]\right)$ are calculated by:

$$
\begin{aligned}
& f_{B R \operatorname{sinkPP}}=f_{B R \text { marsnow }} / U_{P P} * Z_{\text {mean }}=0.13 \mathrm{~d}^{-1} / 150 \mathrm{~m} \cdot \mathrm{d}^{-1} * 100 \mathrm{~m}=0.087 \\
& f_{B R \operatorname{sinkSP}}=f_{B R \text { marsnow }} / U_{S P} * Z_{\text {mean }}=0.13 \mathrm{~d}^{-1} / 200 \mathrm{~m} \cdot \mathrm{d}^{-1} * 100 \mathrm{~m}=0.065
\end{aligned}
$$

SP carcasses are assumed equivalent to detritus entangled in sinking marine snow and respired as such (Iversen and Ploug, 2010; Tang and Elliott, 2013). We assumed a consumption rate similar to that of sinking faecal pellets $\left(f_{F P \sin k G Z_{-} C Z}\right.$, from Eq. 10$)$ and bacterial respiration as SP marine snow $\left(f_{B R \operatorname{sinkSP}}\right.$, from Eq. 13) (Turner, 2002).

$\left(\boldsymbol{f}_{\text {AVToc }}\right)$ By AVT some zooplankton excretes and egests organic carbon (oc) as DOC and POC, respectively, in aphotic layers. Contributions to DOC $\left(f_{\text {AVTdoc }}[-]\right)$ from excretion and FP leaching are estimated as described for surface resident copepods and assuming that $15 \%$ of the ingested carbon is excreted (Saba et al., 2011), plus the FP leaching $\left(f_{\text {GRZdoc }}\right.$ [-], Eq. 15) and ingestion of grazed sinking PP $\left(f_{P P \operatorname{sinkGZ} C Z}\right)$ and FP $\left(f_{F P \operatorname{sinkGZ} C Z}\right)$ fractions (marked in Figure 2 as "- to $f_{\mathrm{AVTdoc} / \text { poc }}$ " and denoted grazed fraction, $f_{G R Z}$ [-], Eq. 16). Only a fraction of this DOC pool is respired in the bottom layer as a function of the proportion of vertical distance covered by emergent copepods $\left(Z_{A V T}\right.$, assumed to be $20 \mathrm{~m}$ (Atkinson et al., 1992; Puelles et al., 1996)) of the water column below the photic depth $\left(Z_{\text {photic_LME }}\right.$ from Longhurst (1998), Table S.4) to the bottom, with mean depth $\left(Z_{\text {mean }}\right)$ of $100 \mathrm{~m}$ (see Table 1 and $f$ of $Z_{\text {aphotic }}$ in Table S.4). The calculation of $f_{A V T d o c}$ per $\mathrm{CZ}$ is then:

$f_{\text {AVTdoc_CZ }}=\left(f_{\text {AVTgrz_CZ }} * f_{\text {SPassimil_CZ }} * 0.15+f_{\text {AVTgrz_CZ }} * f_{\text {SPegest_CZ }} * f_{\text {FPleach }}+f_{\text {GRZdoc_CZ }}\right) * Z_{\text {AVT }} / Z_{\text {aphotic_LME }}$

where:

$$
\begin{aligned}
& f_{G R Z d o c_{-} C Z}=f_{G R Z_{-} C Z} *\left(f_{\text {SPassimil_CZ }} * 0.15+f_{\text {SPegest_CZ }} * f_{F P l e a c h}\right)
\end{aligned}
$$

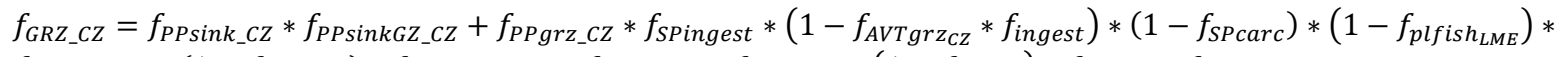

$$
\begin{aligned}
& f_{\text {SPegest_CZ }} *\left(1-f_{\text {FPleach }}\right) * f_{\text {FPsinkGZ_CZ }}+f_{\text {PPgrz_CZ }} * f_{\text {SPingest }} *\left(1-f_{\text {plfish }}\right) * f_{\text {SPcarc }} * f_{\text {FPsinkgz_CZ }}
\end{aligned}
$$

Contributions to the POC pool as FP $\left(f_{\text {AVTpoc }}[-]\right)$ include egestion from migrating copepods plus egestion from ingested grazed sinking PP, sinking FP, and sinking SP carcasses ( $f_{G R Z}[-]$, Eq. 16). Such egested FPs are also grazed as described for $f_{F P s i n k G Z}$ and respired by bacteria (see description and calculations of $f_{B R m a r s n o w}$ and $U_{S P}$ ) as a function of $Z_{\text {aphotic_LME }}$ (Table S.3). The calculation of $f_{A V T p o c}$ per $\mathrm{CZ}$ is then:

$f_{\text {AVTpoc_CZ }}=\left(f_{\text {AVTgrz_CZ }}+f_{G R Z}\right) * f_{\text {SPegest_CZ }} *\left(1-f_{\text {FPleach }}\right) *\left(1-f_{\text {FPsinkGZ_CZ }}\right) * f_{\text {BRsinkSPaphotic_LME }}$

where:

$f_{\text {BRsinkSPaphotic_LME }}=f_{\text {BRmarsnow }} / U_{S P} * Z_{\text {aphotic }}$

The total organic carbon transported by AVT $\left(f_{A V T o c}\right)$ per $\mathrm{CZ}$ is then obtained from:

$$
f_{\text {AVToc_CZ }}=f_{\text {AVTdoc_CZ }}+f_{\text {AVTpoc_CZ }}
$$

The remaining sinking fractions reach the bottom layer and are respired there. 


\subsection{Benthic respiration and $\mathrm{O}_{2}$ :C conversion}

$\left(\boldsymbol{f}_{\boldsymbol{B R b o t t}}\right)$ Organic carbon reaching bottom layers is assimilated by heterotrophic bacteria to produce new bacterial biomass (secondary bacterial production, BP) and to meet metabolic requirements (bacterial respiration, $\mathrm{BR})$. The amount of bacterial biomass produced per unit carbon substrate assimilated is defined as Bacterial Growth Efficiency $(B G E[-])$, i.e. the fraction not respired or $B P /(B P+B R)$ (del Giorgio and Cole, 1998). Comparative studies of natural aquatic systems show that BP is correlated with PP and averaging ca. 30\% of PP (Cole et al., 1988; del Giorgio and Cole, 1998; Ducklow and Carlson, 1992). Instead of using such a generic coefficient, and to further add spatial differentiation and relevance, we estimated spatially differentiated BP values for the $66 \mathrm{LMEs}\left(B P_{L M E}\left[\mu \mathrm{gC} \cdot \mathrm{L} \cdot \mathrm{h}^{-1}\right]\right)$ using the empirical equation by Cole et al. (1988) for marine systems $\left(R^{2}=0.77\right)$ with the available PP rates:

$B P_{L M E}=0.249 * P P_{L M E}^{0.86}$

Spatially differentiated $B G E$ values $\left(B G E_{L M E}[-]\right)$ were then estimated with the empirical equation by del Giorgio and Cole (1998) relating BP and BGE:

$B G E_{L M E}=\left(0.037+0.65 * B P_{L M E}\right) /\left(1.8+B P_{L M E}\right)$

$B G E_{L M E}$ values range from 0.03 (oligotrophic LME\#64 Central Arctic Ocean) to 0.37 (eutrophic LME\#23 Baltic Sea) (Table S.4). This range is close to reported direct measurements in ocean (0.10-0.31) and coastal waters $(0.18-0.42)$ and follows the systematic variation with productivity shown by del Giorgio and Cole (1998). The fraction of organic carbon that is actually respired contributing to DO consumption $\left(f_{B R b o t t}\right)$ is then defined per LME by:

$f_{B R b o t t_{-} L M E}=1-B G E_{L M E}$

As mentioned before, the aerobic respiration by heterotrophic bacteria is responsible for the consumption of DO. The $\mathrm{O}_{2}: \mathrm{C}$ molar mass ratio delivers the conversion of sunken carbon into respired dioxygen, by:

$\mathrm{O}_{2}: \mathrm{C}=\left(\underline{138} \mathrm{molO}_{2} * 2 * 15.9994 \mathrm{gO}_{2} / \mathrm{molO}_{2}\right) /(\underline{106} \mathrm{molC} * 12.0107 \mathrm{gC} / \mathrm{molC})=3.468 \mathrm{gO}_{2} / \mathrm{gC}$

obtained from the stoichiometry of the aerobic respiration equation:

$\left(\mathrm{CH}_{2} \mathrm{O}\right)_{\underline{106}}\left(\mathrm{NH}_{3}\right)_{16} \mathrm{H}_{3} \mathrm{PO}_{4}+\underline{138} \mathrm{O}_{2} \Rightarrow 106 \mathrm{CO}_{2}+122 \mathrm{H}_{2} \mathrm{O}+16 \mathrm{HNO}_{3}+\mathrm{H}_{3} \mathrm{PO}_{4}$

The elemental flows can ultimately be simplified by combining $C: N$ and $O_{2}: C$ (Eqs. 3 and 23) as the molar mass ratio of $\mathrm{O}_{2}: \mathrm{N}$ as:

$\mathrm{O}_{2}: \mathrm{N}=\left(138 \mathrm{molO}_{2} * 2 * 15.9994 \mathrm{gO}_{2} / \mathrm{molO}_{2}\right) /(16 \mathrm{molN} * 14.0067 \mathrm{gN} / \mathrm{molN})=19.704 \mathrm{gO}_{2} / \mathrm{gN}$

In summary, DO consumption is estimated from the respiration of the organic carbon reaching the bottom layer. The organic carbon export is modelled in four distinct routes: route 1, POC exported as algal cell

aggregates (sinking of PP biomass); route 2, POC exported as faecal pellets (egestion from SP); route 3, POC from non-predatory mortality of zooplankton (sinking SP carcasses); and route 4, POC and DOC exported by active vertical transport (zooplankton-mediated export). The model equations quantifying DO consumption as a function of $\mathrm{N}$ input per export route are (see also Figure 2 for illustration):

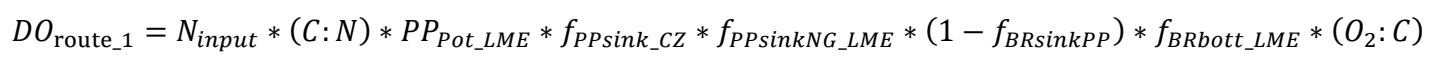

$$
\begin{aligned}
& D O_{\text {route } 2}=N_{\text {input }} *(C: N) * P P_{\text {Pot_LME }} * f_{P P g r z_{-} C Z} * f_{\text {SPingest }} *\left(1-f_{\text {AVTgrz_CZ }}\right) *\left(1-f_{\text {plfish_LME }}\right) *\left(1-f_{\text {SPcarc }}\right) * \\
& f_{\text {SPegest_CZ }} * f_{\text {FPsinkNG_CZ }} *\left(1-f_{B R \text { sinkSP }}\right) * f_{B R \text { Bott_LME }} *\left(O_{2}: C\right)
\end{aligned}
$$


$D O_{\text {route } \_3}=N_{\text {input }} *(C: N) * P P_{\text {Pot_LME }} * f_{P P g r z_{-} C Z} * f_{\text {SPingest }} *\left(1-f_{\text {AVTgrz } \_C Z}\right) * f_{\text {SPcarc }} *\left(1-f_{F P \operatorname{sinkGZ} \_Z}\right) *(1-$

$\left.f_{B R \operatorname{sinkSP}}\right) * f_{B R \text { bott_LME }} *\left(\mathrm{O}_{2}: C\right)$

$D O_{\text {route } \_4}=N_{\text {input }} *(C: N) * P P_{\text {Pot_LME }} * f_{\text {AVTgrz } \_ \text {CZ }} * f_{\text {AVToc_CZ }} *\left(1-f_{\text {BRsinkSPaphot_LME }}\right) * f_{\text {BRbott_LME }} *\left(O_{2}: C\right)$

Finally, the combination of these four equations (Eqs. 26-29) deliver the XF per LME, i.e. the mass of DO consumed in the bottom layer as a function of the mass of $\mathrm{N}$ input to the $\mathrm{LME}, \operatorname{in}\left[\mathrm{kgO}_{2} \cdot \operatorname{kgN} \mathrm{N}^{-1}\right]$ :

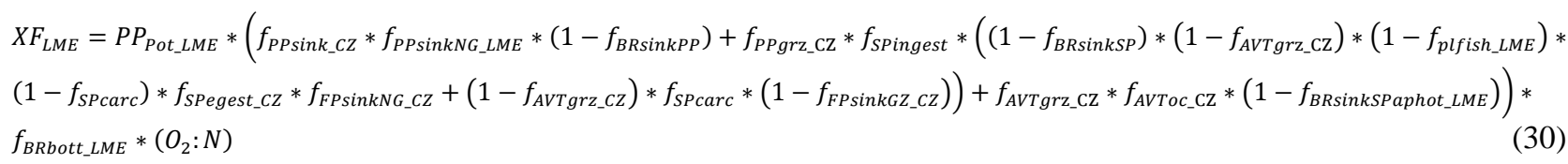

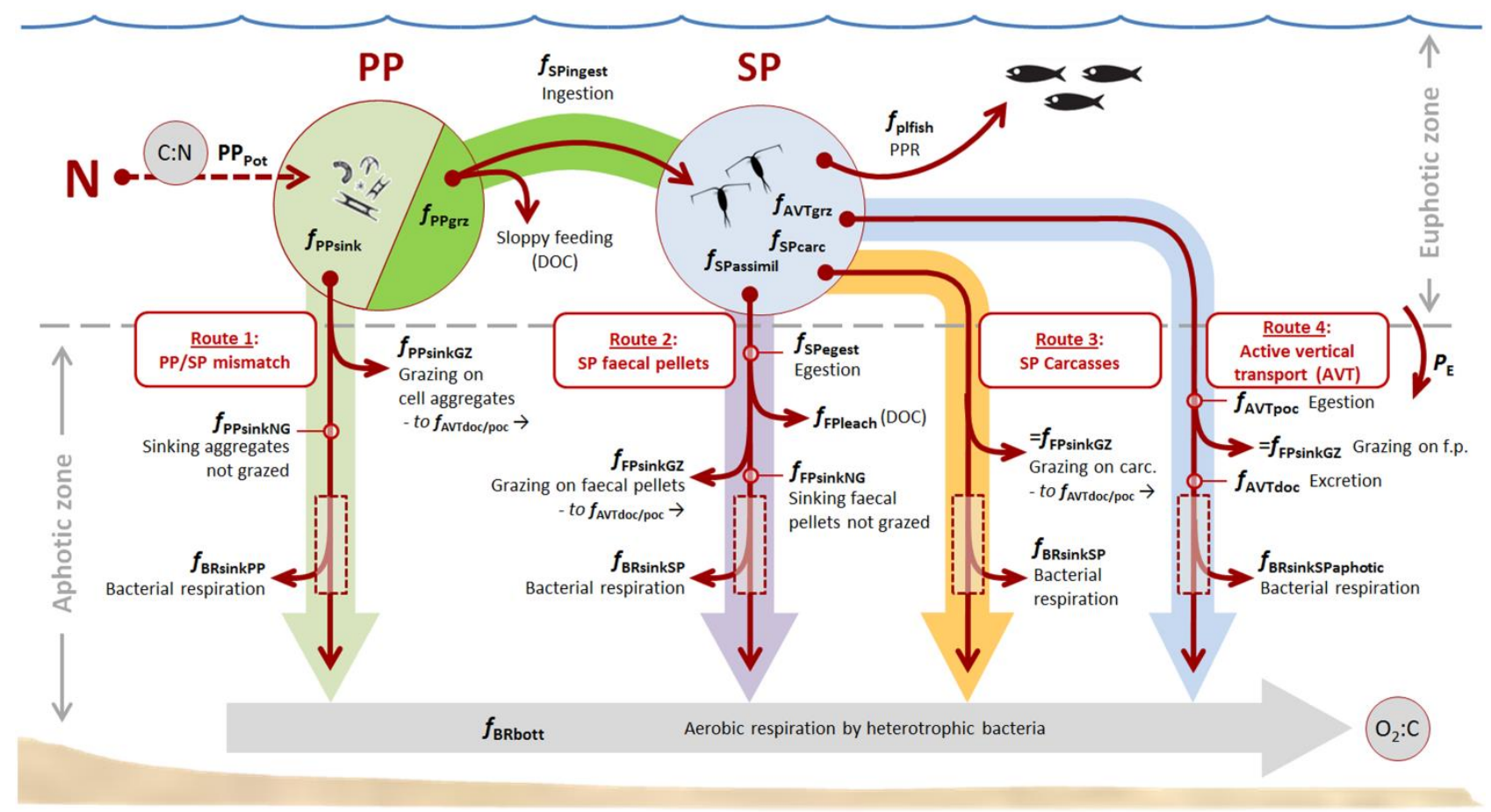

Figure 2 Summary of the ecosystem response model to nitrogen $(\mathrm{N})$ inputs and the resulting consumption of dissolved oxygen $\left(\mathrm{O}_{2}\right)$ in the bottom water layer. Four export routes are modelled: sinking of primary production (PP) biomass (route 1, light green arrow), sinking particulate organic carbon (POC) from secondary production (SP) as faecal pellets (FP) (route 2, purple arrow), sinking zooplankton carcasses (route 3, orange arrow), and active vertical transport (AVT) as dissolved and particulate organic carbon (DOC and POC) (route 4, light blue arrow). Transfer to planktivorous fish (plfish) estimated by Primary Production Required (PPR) to sustain fisheries represents predation by upper trophic levels. The photic depth (grey horizontal dashed line) divides the surface euphotic zone and the bottom aphotic zone (not to scale). The organic carbon moving below this line represents the export production $\left(P_{\mathrm{E}}\right)$. Dashed brown arrow represents $\mathrm{N}$ assimilation and solid brown arrows represent organic carbon flows. Grey horizontal arrow refers to bacterial respiration (BR) at bottom waters leading to dissolved $\mathrm{O}_{2}$ consumption. Grey small circles represent the molar mass conversions of $\mathrm{C}: \mathrm{N}$ and $\mathrm{O}_{2}: \mathrm{C}$. Also consult Table 1 and text for details on model parameters.

\subsection{Estimation of export production}

To quantify the organic carbon exported $\left(P_{\mathrm{E}}\left[\mathrm{gC} \cdot \mathrm{m}^{2} \cdot \mathrm{yr}^{-1}\right]\right)$ from the euphotic zone (as POC) we used the actual PP rates per LME ( $P P_{L M E}$ and not $\left.P P_{P o t_{-} L M E}\right)$ and Eqs. 3 and 5-8, i.e. PP, its sinking fraction, and the SP-related export fractions, by:

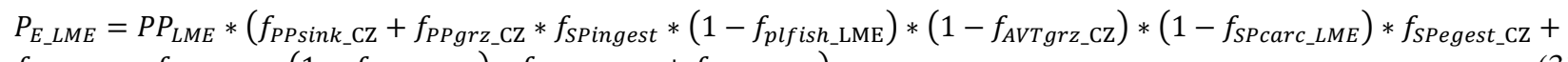
$\left.f_{P P g r Z_{-} C Z} * f_{\text {SPingest }} *\left(1-f_{\text {AVTgrz }} \mathrm{CZ}\right) * f_{\text {SPCarc } \_L M E}+f_{\text {AVTgrz }} C Z\right)$ 
Table 1 Spatial resolution of the modelled parameters, their values, and reference sources/calculation method (see Table S.1 for an extended version). (LME, large marine ecosystem, and CZ, climate zone).

\begin{tabular}{|c|c|c|c|c|}
\hline Input parameter & Spatial resolution & Value & Unit & Source (reference or calculation) \\
\hline $\mathrm{C}: \mathrm{N}$ & Global & 5.681 & {$\left[\mathrm{kgC} \cdot \mathrm{kgN}^{-1}\right]$} & Stoichiometry of the photosynthesis equation \\
\hline $\mathrm{O}_{2}: \mathrm{C}$ & Global & 3.468 & {$\left[\mathrm{kgO}_{2} \cdot \mathrm{kgC}^{-1}\right]$} & Stoichiometry of the respiration equation \\
\hline $\mathrm{O}_{2}: \mathrm{N}$ & Global & 19.704 & {$\left[\mathrm{kgO}_{2} \cdot \mathrm{kgN}^{-1}\right]$} & Calculation: $\left(\mathrm{O}_{2}: \mathrm{N}\right)=(\mathrm{C}: \mathrm{N})^{*}\left(\mathrm{O}_{2}: \mathrm{N}\right)$ \\
\hline$P P_{\text {Pot }}$ & LME & $0.033 \leftrightarrow 2.707$ & {$[-]$} & Calculation: $\mathrm{PP}_{\mathrm{Pot}}=\mathrm{PP}_{\mathrm{LME}} / \mathrm{PP}_{\text {Avg_66ME }}$ \\
\hline$f_{\text {PPsink }}$ & $\mathrm{CZ}$ & $0.150 \leftrightarrow 0.670$ & {$[-]$} & Cushing (1975), Laws et al. (2000) and average CZs \\
\hline$f_{\text {PPgrz }}$ & $\mathrm{CZ}$ & $0.330 \leftrightarrow 0.850$ & {$[-]$} & Calculation: $f_{\text {PPgrz_CZ }}=1-f_{\text {PPsink_CZ }}$ \\
\hline$f_{\text {SPingest }}$ & Global & 0.643 & {$[-]$} & Møller and Nielsen (2001); Møller (2007); Saba et al. (2011) \\
\hline$f_{\text {SPassimil }}$ & $\mathrm{CZ}$ & $0.300 \leftrightarrow 0.900$ & {$[-]$} & Besiktepe and Dam (2002) and average CZs \\
\hline$f_{\text {SPegest }}$ & $\mathrm{CZ}$ & $0.100 \leftrightarrow 0.700$ & {$[-]$} & Calculation: $f_{\text {SPegest_CZ }}=1-f_{\text {SPassimil_CZ }}$ \\
\hline$f_{\text {plfish }}$ & LME & $2 \mathrm{E}-04 \leftrightarrow 1.000$ & {$[-]$} & SP consumption by planktivorous fish \\
\hline$f_{\mathrm{AVTgrz}}$ & $\mathrm{CZ}$ & $0.033 \leftrightarrow 0.085$ & {$[-]$} & Calculation: $f_{\text {AVTgrz_CZ }}=0.10^{*} f_{\text {PPgrz_CZ }} * f_{\text {SPingest }}$ \\
\hline$f_{\text {PPsinkGZ }}$ & $\mathrm{CZ}$ & $0.023 \leftrightarrow 0.101$ & {$[-]$} & Calculation: $f_{\text {PPsinkGZ_CZ }}=0.15^{*} f_{\text {PPsink_CZ }}$ \\
\hline$f_{\text {PPsinkNG }}$ & $\mathrm{CZ}$ & $0.900 \leftrightarrow 0.978$ & {$[-]$} & Calculation: $f_{\text {PPsinkNG_CZ }}=1-f_{\text {PPsinkGZ_CZ }}$ \\
\hline$f_{\text {FPleach }}$ & Global & 0.280 & {$[-]$} & Møller et al. (2003) \\
\hline$f_{\text {FPsinkGZ }}$ & $\mathrm{CZ}$ & $0.007 \leftrightarrow 0.017$ & {$[-]$} & Calculation: $f_{\text {FPsinkGZ_CZ }}=0.20 * f_{\text {PPsinkGZ_CZ }}$ \\
\hline$f_{\text {FPsinkNG }}$ & $\mathrm{CZ}$ & $0.708 \leftrightarrow 0.715$ & {$[-]$} & Calculation: $f_{\text {FPsinkNG_CZ }}=\left(1-f_{\text {FPleach }}\right) *\left(1-f_{\text {FPsinkGZ_CZ }}\right)$ \\
\hline$f_{\text {SPmort }}$ & Global & 0.290 & {$[-]$} & Hirst and Kiørboe (2002) \\
\hline$f_{\text {SPcarc }}$ & LME & $0.000 \leftrightarrow 0.290$ & {$[-]$} & Calculation: $f_{\text {SPcarc_LME }}=f_{\text {SPmort }} * f_{\text {plfish_LME }}$ \\
\hline$Z_{\text {mean }}$ & Global & 100 & {$[\mathrm{~m}]$} & Mean depth of continental shelf \\
\hline$Z_{\mathrm{AVT}}$ & Global & 20 & {$[\mathrm{~m}]$} & Atkinson et al. (1992); Puelles et al. (1996) \\
\hline$Z_{\text {photic }}$ & LME & $12 \leftrightarrow 68$ & {$[\mathrm{~m}]$} & Longhurst (1998) \\
\hline$Z_{\text {aphotic }}$ & LME & $32 \leftrightarrow 88$ & {$[\mathrm{~m}]$} & Calculation: $Z_{\text {aphotic_LME }}=Z_{\text {mean }}-Z_{\text {photic_LME }}$ \\
\hline$U_{\mathrm{PP}}$ & Global & 150 & {$\left[\mathrm{~m} \cdot \mathrm{d}^{-1}\right]$} & Turner (2002) \\
\hline$U_{\mathrm{SP}}$ & Global & 200 & {$\left[\mathrm{~m} \cdot \mathrm{d}^{-1}\right]$} & Turner (2002) \\
\hline$f_{\mathrm{BRmarsnow}}$ & Global & 0.130 & {$\left[\mathrm{~d}^{-1}\right]$} & Iversen and Ploug (2010) \\
\hline$f_{\text {BRsinkSPaphotic_LME }}$ & LME & $0.021 \leftrightarrow 0.051$ & {$[-]$} & Calculation: $f_{\text {BRsinkSPaphotic_LME }}=f_{\text {BRmarsnow }} U_{\mathrm{SP}} *\left(Z_{\text {mean }}-Z_{\text {photic_LME }}\right)$ \\
\hline$f_{\mathrm{BR} \operatorname{sinkPP}}$ & Global & 0.087 & {$[-]$} & Calculation: $f_{\mathrm{BRsinkPP}}=f_{\mathrm{BRmarsnow}} / \mathrm{U}_{\mathrm{PP}} * \mathrm{Z}_{\text {meanLME }}$ \\
\hline$f_{\mathrm{BRsinkSP}}$ & Global & 0.065 & {$[-]$} & Calculation: $f_{\mathrm{BRsinkSP}}=f_{\mathrm{BRmarsnow}} / \mathrm{U}_{\mathrm{SP}} * \mathrm{Z}_{\text {meanLME }}$ \\
\hline$B G E$ & LME & $0.039 \leftrightarrow 0.464$ & {$[-]$} & Cole et al. (1988); del Giorgio and Cole (1998) \\
\hline$f_{\text {BRbott }}$ & LME & $0.536 \leftrightarrow 0.961$ & {$[-]$} & Calculation: $f_{\text {BRbott_LME }}=1-\mathrm{BGE}_{\mathrm{LME}}$ \\
\hline
\end{tabular}

\section{Results}

The results of the normalisation of primary productivity per spatial unit (potential primary production, $P P_{\text {Pot_LME }}$ ) are shown in Table 2. $P P_{\text {Pot_LME }}$ range from 0.03 (LME\#64. Central Arctic Ocean) to 2.71 (LME\#23. Baltic Sea), with a mean rate $\left(P P_{\text {Avg_66LME }}\right)$ of $257.7 \mathrm{gC} \cdot \mathrm{m}^{-2} \cdot \mathrm{yr}^{-1}$.

The estimation of XFs (from Eq. 30) per LME delivers the set of results included in Table 2 and depicted in Figure 3. $X F_{L M E}$ range from 0.45 (LME \#64 Central Arctic Ocean) to $15.9 \mathrm{kgO}_{2} \cdot \mathrm{kgN}^{-1}$ (LME \#23 Baltic Sea). The results of the estimation of export production $\left(P_{\mathrm{E}}\right)$ per LME (from Eq. 31) are also shown in Table 2. $P_{E_{-} L M E}$ range from 7.026 (LME \#64 Central Arctic Ocean) to $484.8 \mathrm{gC} \cdot \mathrm{m}^{-2} \cdot \mathrm{yr}^{-1}$ (LME \#23 Baltic Sea). The geographic distribution of $X F_{L M E}$ is consistent with the annual distribution of PP in coastal areas (e.g. Behrenfeld and Falkowski (1997); Chassot et al. (2010)). $X F_{L M E}$ hotspots in Figure 3 match highly productive coastal areas fuelled by e.g. coastal upwelling or otherwise resulting from the interaction of light and nutrients availability, and low grazing pressure. 
Table 2 Results of the calculated export production $\left(P_{\mathrm{E}},\left[\mathrm{gC} \cdot \mathrm{m}^{-2} \cdot \mathrm{yr}^{-1}\right]\right)$ and exposure factors $\left(\mathrm{XF},\left[\mathrm{kgO}_{2} \cdot \mathrm{kgN}^{-1}\right]\right)$ for the 66 large marine ecosystems (LME) grouped into climate zones (see extended version in Table S.4).

\begin{tabular}{|c|c|c|c|c|c|}
\hline $\begin{array}{l}\text { Large Marine Ecosystem } \\
\text { [\#. name] }\end{array}$ & $\begin{array}{l}\text { Climate zone } \\
\text { [name] }\end{array}$ & $\begin{array}{r}\mathrm{PP} \\
{\left[\mathrm{gC} \cdot \mathrm{m}^{-2} \cdot \mathrm{yr}^{-1}\right]}\end{array}$ & $\begin{array}{r}\text { PP }_{\text {Pot_LME }} \\
{[-]} \\
\end{array}$ & $\begin{array}{r}P_{\mathrm{E}} \\
{\left[\mathrm{gC} \cdot \mathrm{m}^{-2} \cdot \mathrm{yr}^{-1}\right]}\end{array}$ & $\begin{array}{r}\mathrm{XF}_{\mathrm{LME}} \\
{\left[\mathrm{kgO}_{2} \cdot \mathrm{kgN}^{-1}\right]} \\
\end{array}$ \\
\hline 18. Canadian Eastern Arctic - West Greenland & Polar & 151.9 & 0.59 & 125.4 & 6.80 \\
\hline 19. Greenland Sea & Polar & 174.2 & 0.68 & 130.9 & 7.25 \\
\hline 20. Barents Sea & Polar & 151.2 & 0.59 & 120.0 & 7.05 \\
\hline 54. Northern Bering - Chukchi Seas & Polar & 90.95 & 0.35 & 76.06 & 4.57 \\
\hline 55. Beaufort Sea & Polar & 119.1 & 0.46 & 99.60 & 5.87 \\
\hline 56. East Siberian Sea & Polar & 54.42 & 0.21 & 45.51 & 2.81 \\
\hline 57. Laptev Sea & Polar & 156.7 & 0.61 & 131.0 & 7.54 \\
\hline 58. Kara Sea & Polar & 126.7 & 0.49 & 106.0 & 6.22 \\
\hline 61. Antarctic & Polar & 99.71 & 0.39 & 83.40 & 4.91 \\
\hline 63. Hudson Bay Complex & Polar & 152.7 & 0.59 & 127.7 & 6.96 \\
\hline 64. Central Arctic Ocean & Polar & 8.401 & 0.03 & 7.026 & 0.45 \\
\hline 66. Canadian High Arctic - North Greenland & Polar & 58.81 & 0.23 & 48.98 & 2.99 \\
\hline 01. East Bering Sea & Subpolar & 285.6 & 1.11 & 196.4 & 9.86 \\
\hline 02. Gulf of Alaska & Subpolar & 330.9 & 1.28 & 228.1 & 11.1 \\
\hline 09. Newfoundland-Labrador Shelf & Subpolar & 295.5 & 1.15 & 206.6 & 10.3 \\
\hline 21. Norwegian Sea & Subpolar & 179.3 & 0.70 & 113.0 & 6.35 \\
\hline 23. Baltic Sea & Subpolar & 697.6 & 2.71 & 484.8 & 15.9 \\
\hline 51. Oyashio Current & Subpolar & 261.5 & 1.01 & 178.5 & 9.25 \\
\hline 52. Sea of Okhotsk & Subpolar & 297.7 & 1.16 & 198.7 & 10.0 \\
\hline 53. West Bering Sea & Subpolar & 214.0 & 0.83 & 148.7 & 7.80 \\
\hline 59. Iceland Shelf and Sea & Subpolar & 201.3 & 0.78 & 140.7 & 7.34 \\
\hline 60. Faroe Plateau & Subpolar & 154.1 & 0.60 & 94.16 & 5.58 \\
\hline 65. Aleutian Islands & Subpolar & 285.6 & 1.11 & 199.5 & 10.0 \\
\hline 03. California Current & Temperate & 223.9 & 0.87 & 120.8 & 6.09 \\
\hline 07. Northeast U.S. Continental Shelf & Temperate & 561.0 & 2.18 & 303.0 & 12.2 \\
\hline 08. Scotian Shelf & Temperate & 509.5 & 1.98 & 280.6 & 11.6 \\
\hline 13. Humboldt Current & Temperate & 320.0 & 1.24 & 170.9 & 8.38 \\
\hline 14. Patagonian Shelf & Temperate & 509.5 & 1.98 & 272.1 & 11.5 \\
\hline 22. North Sea & Temperate & 407.3 & 1.58 & 209.8 & 9.11 \\
\hline 24. Celtic-Biscay Shelf & Temperate & 349.2 & 1.35 & 180.9 & 8.15 \\
\hline 25. Iberian Coastal & Temperate & 276.9 & 1.07 & 145.6 & 7.38 \\
\hline 42. Southeast Australian Shelf & Temperate & 187.0 & 0.73 & 104.3 & 5.41 \\
\hline 43. Southwest Australian Shelf & Temperate & 180.8 & 0.70 & 100.9 & 5.28 \\
\hline 46. New Zealand Shelf & Temperate & 208.2 & 0.81 & 110.4 & 5.69 \\
\hline 48. Yellow Sea & Temperate & 589.1 & 2.29 & 284.4 & 12.0 \\
\hline 50. Sea of Japan/East Sea & Temperate & 220.6 & 0.86 & 114.8 & 5.92 \\
\hline 62. Black Sea & Temperate & 376.6 & 1.46 & 207.1 & 8.83 \\
\hline 04. Gulf of California & Subtropical & 437.9 & 1.70 & 191.8 & 7.97 \\
\hline 05. Gulf of Mexico & Subtropical & 208.2 & 0.81 & 90.95 & 4.49 \\
\hline 06. Southeast U.S. Continental Shelf & Subtropical & 263.3 & 1.02 & 115.6 & 5.26 \\
\hline 15. South Brazil Shelf & Subtropical & 283.1 & 1.10 & 123.9 & 5.84 \\
\hline 26. Mediterranean & Subtropical & 157.8 & 0.61 & 67.78 & 3.45 \\
\hline 27. Canary Current & Subtropical & 436.8 & 1.70 & 188.8 & 7.73 \\
\hline 29. Benguela Current & Subtropical & 506.6 & 1.97 & 219.9 & 9.09 \\
\hline 30. Agulhas Current & Subtropical & 221.0 & 0.86 & 96.51 & 4.76 \\
\hline 41. East-Central Australian Shelf & Subtropical & 157.4 & 0.61 & 69.22 & 3.51 \\
\hline 44. West-Central Australian Shelf & Subtropical & 173.9 & 0.67 & 76.43 & 3.85 \\
\hline 47. East China Sea & Subtropical & 325.4 & 1.26 & 133.5 & 6.45 \\
\hline 49. Kuroshio Current & Subtropical & 154.1 & 0.60 & 66.10 & 3.37 \\
\hline 10. Insular Pacific-Hawaiian & Tropical & 84.74 & 0.33 & 26.10 & 1.33 \\
\hline 11. Pacific Central-American & Tropical & 244.0 & 0.95 & 75.33 & 3.33 \\
\hline 12. Caribbean Sea & Tropical & 174.6 & 0.68 & 53.83 & 2.51 \\
\hline 16. East Brazil Shelf & Tropical & 130.4 & 0.51 & 40.26 & 1.94 \\
\hline 17. North Brazil Shelf & Tropical & 442.3 & 1.72 & 136.5 & 5.26 \\
\hline 28. Guinea Current & Tropical & 357.9 & 1.39 & 110.5 & 4.31 \\
\hline 31. Somali Coastal Current & Tropical & 249.5 & 0.97 & 76.85 & 3.36 \\
\hline 32. Arabian Sea & Tropical & 390.5 & 1.52 & 121.7 & 4.99 \\
\hline 33. Red Sea & Tropical & 298.4 & 1.16 & 92.34 & 3.89 \\
\hline 34. Bay of Bengal & Tropical & 265.2 & 1.03 & 82.83 & 3.71 \\
\hline 35. Gulf of Thailand & Tropical & 284.9 & 1.11 & 91.10 & 4.17 \\
\hline 36. South China Sea & Tropical & 174.2 & 0.68 & 55.55 & 2.70 \\
\hline 37. Sulu-Celebes Sea & Tropical & 209.3 & 0.81 & 66.56 & 3.18 \\
\hline 38. Indonesian Sea & Tropical & 263.7 & 1.02 & 82.42 & 3.69 \\
\hline 39. North Australian Shelf & Tropical & 328.7 & 1.28 & 101.3 & 4.26 \\
\hline 40. Northeast Australian Shelf & Tropical & 130.8 & 0.51 & 40.29 & 1.93 \\
\hline 45. Northwest Australian Shelf & Tropical & 185.9 & 0.72 & 57.31 & 2.66 \\
\hline
\end{tabular}




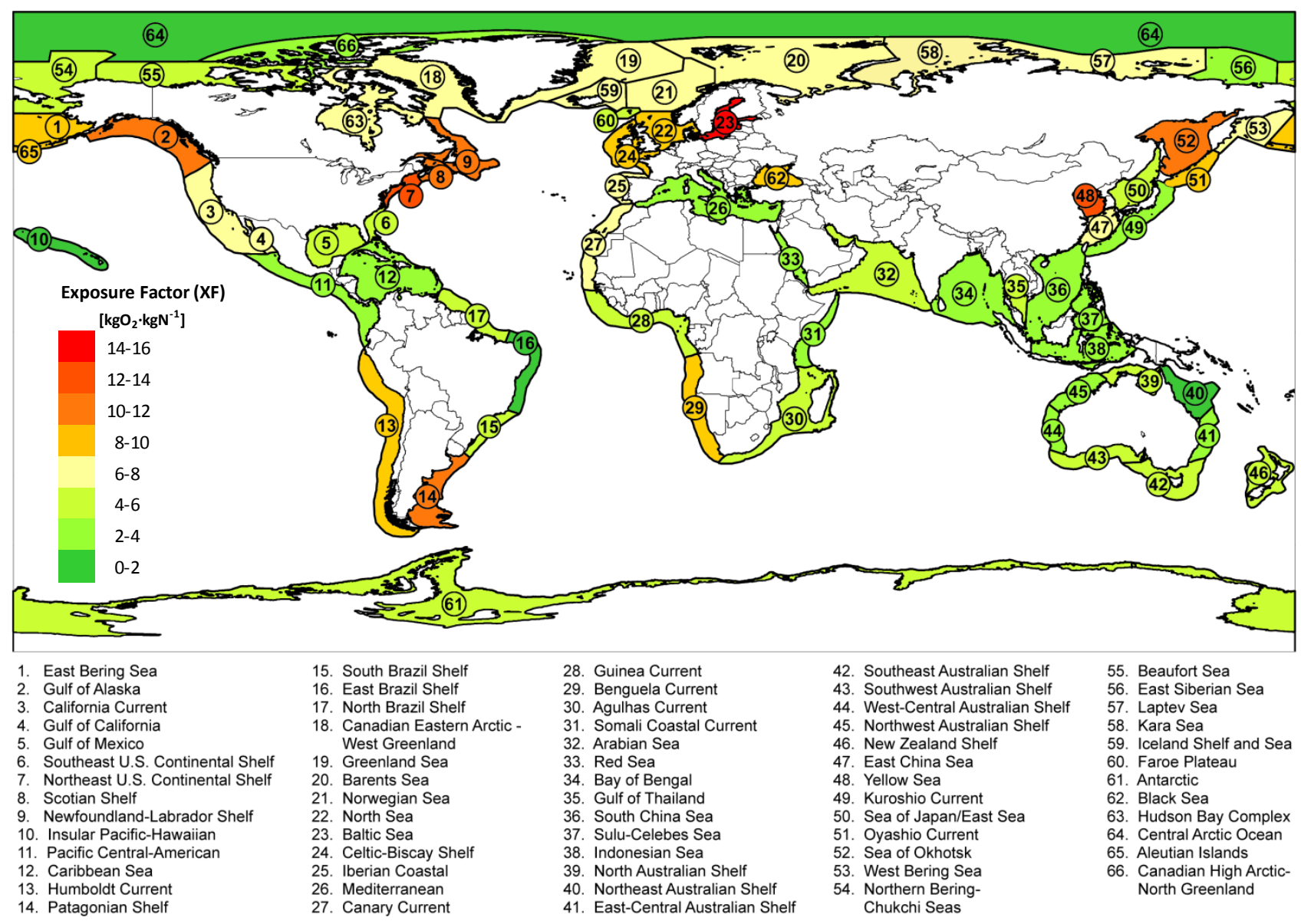

Figure 3 Global distribution of the exposure factors (XF, $\left[\mathrm{kgO}_{2} \cdot \mathrm{kgN}^{-1}\right]$ ) estimated for the 66 large marine ecosystems (spatial units coloured from the original digital map available at http://lme.edc.uri.edu/).

\subsection{Contributions from sinking routes}

The relative contributions of each sinking carbon route to the export production $\left(P_{\mathrm{E}}\right)$ and DO consumption were grouped into climate zones (Table S.3), as most of the spatial differentiation is originated from this resolution, based on the results per LME (Table S.4). Route 1 consistently contributes more to both $P_{\mathrm{E}}(61 \%)$ and XF (63\%) (route 2: $26 \%$ and 23\%, route 3: $4 \%$ and 5\%, and route $4,10 \%$ and $9 \%$, respectively) (more details in Section S.3.1). These results are significantly correlated with the PP-SP mismatch and biomass sinking $\left(f_{P P \text { sink_CZ }}\right)$, except for the contributions of routes 3 and 4 to $\mathrm{XF}$ as its modelling extends to include the loss processes in the aphotic zone that act on $P_{\mathrm{E}}$ (consumption, leaching, and respiration).

\subsection{Sensitivity analysis}

The model sensitivity to the 18 primary input parameters was assessed by calculating sensitivity ratios (SR) for each combination of input parameter and resulting $X F_{L M E}$, as described by Strandesen et al. (2007). The SR is the ratio between the relative change in the model output and the relative change in the model input. Figure 4 shows the mean SR values and the respective range of variation among LMEs (see also Table S.6). 


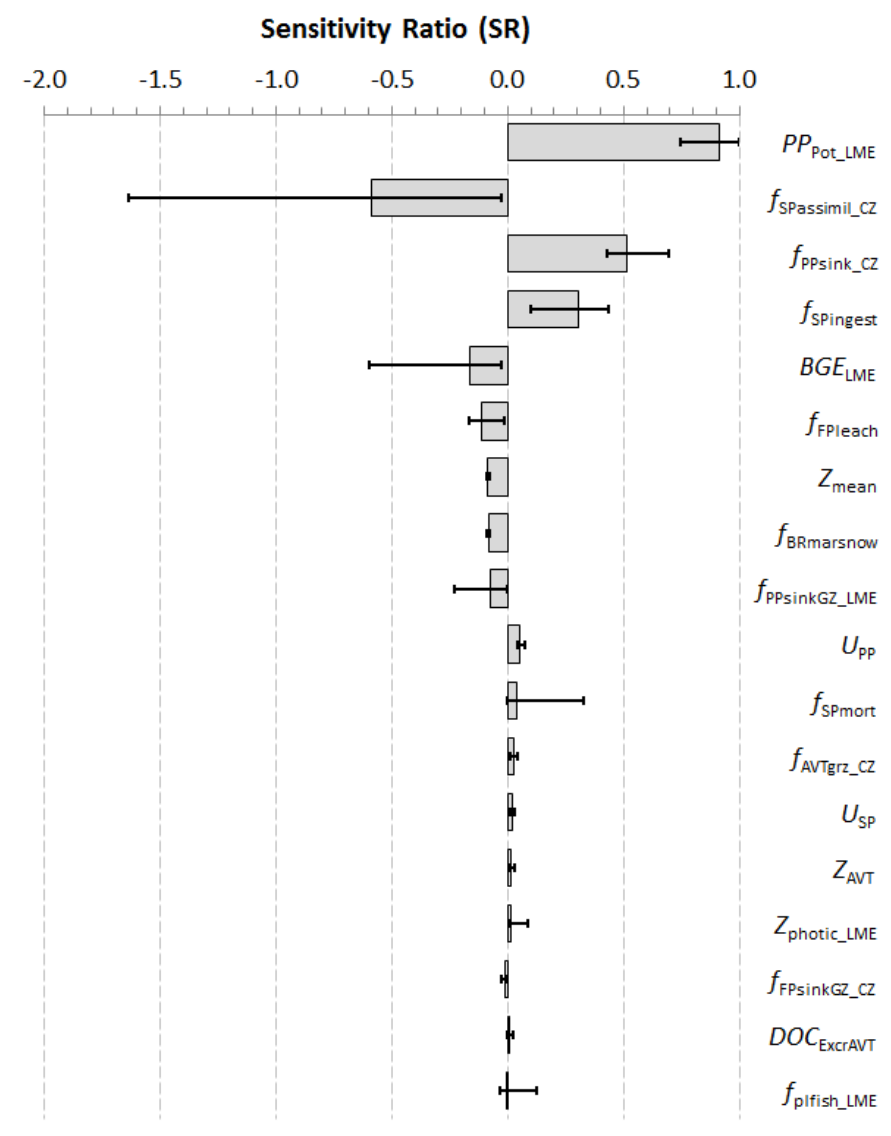

Figure 4 Sensitivity ratios (SRs) for the 18 modelled input parameters. The grey bars represent the mean SR values and the variation ranges represent the lower and upper values of the 66 large marine ecosystems. Absolute SR values of 1.00 mean direct proportionality of input and output; negative SR values indicate that input and output are inversely related, meaning that an increase in the input value decreases the output.

\section{Discussion}

The model covers the entire response pathway by a spatially differentiated parameterisation that supports the interpretation and the application of the resulting exposure indicator. Model sensitivity and parameters uncertainty were analysed to assess robustness. We further compare $P_{\mathrm{E}}$ estimated by our model with predicted curves by others in order to validate the processes occurring in the euphotic zone. This 'euphotic component' determines the input of organic matter to the biologically-mediated processes of consumption, degradation, and respiration that occur in the water column and benthic layers and for which there is no comparable spatially differentiated model with global coverage. Finally, we discuss the spatial differentiation and resolution of the results, the framework and its application in LCIA.

\subsection{Model sensitivity and parameters uncertainty}

The site-dependent parameter $P P_{P o t} L M E$ (model input) shows the highest individual contribution to the resulting XFs (model output) with a mean SR value of 0.92 (range 0.75-1.00, Figure 4 and Table S.6). LMEdependent $\mathrm{PP}$ rates modulate $\mathrm{N}$ assimilation and the carbon fluxes thereafter thus justifying such influence on the results. Sensitivity to $f_{S P a s s i m i l} C Z$ range up to -1.64 but only in the tropical LMEs where the assimilation rate acts upon a larger grazed biomass fraction by routes 2 to 4 . Other two site-dependent parameters may range to relevant SR values: $f_{P P s_{i n k} C Z}$ in LMEs with high SP consumption by planktivorous fish (PPR, Table S.4); and $B G E_{L M E}$ in highly productive LMEs. The analysis further suggests that the remaining site-dependent parameters $\left(f_{P P \operatorname{sinkGZ} L M E E}, f_{\text {AVTgrz } C Z}, Z_{\text {photic_LME }}, f_{F P \text { sinkGZ_LME }}\right.$, $f_{\text {plfish_LME }}$ ) may adopt site-generic coefficients since any uncertainty associated with their estimation 
renders little impact on the quality of the XFs obtained. Sensitivity to the site-generic parameter $f_{\text {SPingest }}$ may range up to 0.43 in tropical LMEs as it affects a larger relative fraction of the grazed PP biomass. The remaining site-generic parameters $\left(f_{\text {FPleach }}, Z_{\text {mean }}, f_{B R \text { marsnow }}, U_{P P}, f_{S P \text { mort }}, U_{S P}, Z_{A V T}, D O C_{E x c r A V T}\right)$ show low contributions to output. The lack of spatial differentiation in site-generic parameters is deemed acceptable considering the low SRs, although adding spatial differentiation to $f_{\text {SPingest }}$ (possibly per climate zone) could be seen as a method improvement.

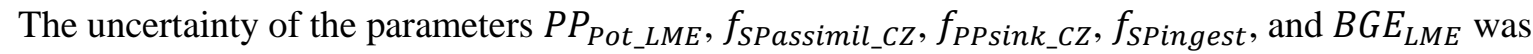

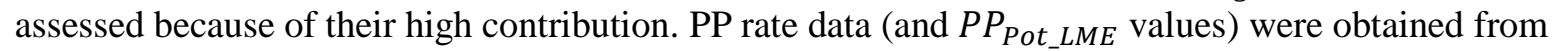
chlorophyll pigment concentrations derived from satellite data. The uncertainty of the underlying models by Bouvet et al. (2002) and Platt and Sathyendranath (1988) or the spatial integration method (Lai, 2004; Watson et al., 2014) is not discussed here. The PP dataset integrates monthly records from an approximately 12-year period. The variability of the dataset per LME was verified by Watson et al. (2014) and the majority of the PP data points have a coefficient of interannual variation below 5\%. Only the Arctic and near-Arctic LMEs show interannual variation of $20-25 \%$ possibly due to poorer satellite coverage. As such, it seems to us that the used PP dataset provides a reliable average PP value per LME with an acceptable (natural) variability. Furthermore, the choice for space and time integrated PP data is deemed appropriate and less uncertain than using PP data from any specific location or day (or even over a single year) inherently less representative.

We acknowledge the increase of uncertainty towards higher latitudes in the estimation of mean $f_{\text {SPassimil_CZ }}$ for the five CZs (in Section 2.4). However, this fact is tied in with a decrease in PP biomass, as the parameter is correlated with the grazed fraction transferred to route 2 (mainly) (Table S.3) in which the AE coefficient is embedded as egested fraction $\left(f_{\text {SPegest_CZ }}\right)$, thus minimizing the impact of the most uncertain CZs. This is also supported by SRs above 0.50 in the subtropical and tropical CZs only. As such, we consider that the estimated $\mathrm{AE}$ and egestion coefficients are valid for a spatially differentiated application and preferred over global generic values, which are otherwise available as of $18 \%$ for the coastal copepod Acartia tonsa (Saba et al., 2011) or 60\% but for the epipelagic Calanus spp. in Møller et al. (2003).

The match-mismatch hypothesis by Cushing (1975) determines the phytoplankton's sunken and grazed fractions. Mismatched growth of phyto- and zooplankton communities results in increased downward export of organic carbon. As a conceptual description of a natural phenomenon involving complex processes (Cushing, 1990; Durant et al., 2007) it has, not surprisingly, high variability associated. Any uncertainty estimation of this hypothesis is of questionable relevance and is therefore not discussed here, but the applicability of the concept has wide scientific acceptance. As a best estimate it is useful in the present context. Ideally, measured sunken and grazed PP fractions for every LME would be preferred, possibly carrying less uncertainty, but such results are not available. Still, Laws et al. (2000) quantifies that $86 \%$ of the variance of the expected sinking fraction (as used here) is explained by the water temperature effect (indirectly used when defining the climate zonation) but no direct quantification of further causes is discussed. Considering the above, the use of the match-mismatch concept for the estimation of globally applicable sinking PP fractions is deemed preferable over an extrapolation from available disparate empirical measurements.

The estimation of $f_{\text {SPingest }}$ as of $64.3 \%$ of the grazed phytoplankton biomass involves a rel.SD $\approx 1 \%$ due to the averaging from different sources and methods. We consider it preferable over the use of a single source in order to increase the representativeness of the coefficient adopted.

BGE is estimated from BP, which in turn is estimated from PP (Table S.5). The overall uncertainty of such BGE estimation depends on the variability of the PP dataset (addressed earlier) and the fit of the BP-PP correlation $\left(R^{2}=0.77\right)$. Alternatively, the coupling between BR and BP can be used, but its variance $\left(R^{2}=0.46\right.$, (del Giorgio and Cole, 1998)) is affected by high spatial and temporal variability of bacterial activity (not modelled). As BGE systematically increases with PP (Cole et al., 1988; del Giorgio and Cole, 1998) we 
therefore assumed (i) BGE estimated from BP as the best method available and that (ii) the natural variability is equivalent in every LME thus not adding significant bias to the estimation of $\mathrm{BGE}_{\mathrm{LME}}$.

The uncertainty of the parameters with higher contributions to the model results was assessed and their variability deemed acceptable or acknowledged. We therefore consider them as best available estimates that still suit the purpose of the model thus supporting our confidence in the robustness of the proposed method. Despite the complexity of the parameterisation and inherent calculations, potential users of the XFs in LCIA or ecosystems health assessment/management would only be required to identify the N-receiving LME and estimate environmental fate losses of the original $\mathrm{N}$ emission to feed the model.

\subsection{Spatial units and differentiation}

We adopted large spatial units of coastal ecosystems instead of a grid cell approach that would inherently presume a significant horizontal flow of organic carbon (or $\mathrm{N}$ or DO). We do not judge a grid-based approach to be feasible at the present stage of development of methods for the estimation of impacts to marine eutrophication. The immensity of data required for local parameterisation hinders the implementation of a finer spatial resolution beyond large spatial units such as the LMEs. In support of this reasoning also stands the temporal variability of the processes and (bio)(geo)chemical properties of the water masses, along with local advection and mixing patterns that contribute to some of the modelled parameters. As such, the temporal and spatial integration fits well the LCIA application, which adopts best estimates and an average approach. This seems most appropriate to represent potential conditions and coherence with the pursued objectives. Finally, when applied to the development of CFs in LCIA, XFs need to be combined with emission data, which will realistically not be reported with a resolution finer than the level of countries or discharging watersheds. However, the adoption of large spatial units has the drawback of masking potential peaks of organic carbon supply to bottom waters and of oxygen consumption that may occur either in time or space and cause severe hypoxia or anoxia events. As there is no temporal discrimination in the XFs estimation we assume for modelling purposes that the DO is consumed over a period of one year. This also means that if its depletion is sufficiently slow and system ventilation occurs then replenishment of DO from adjacent water masses may prevent the onset of hypoxia.

The adoption of the LME biogeographical classification system is a discrete choice in the model framework. Any other coastal classification system can be adopted provided that spatially integrated PP data is available and a coherent aggregation into climate zones is possible. These two aspects also advocate for the applicability and flexibility of the proposed method.

\subsection{From primary production to export production}

The model quantifies the ecosystem response to allochthonous-N inputs and does not include 'natural' external input sources like upwelling or resuspension. This choice is consistent with the desired application in LCIA of estimating the impacts of emissions originated from human activities.

The positive and non-linear correlation between $P_{\mathrm{E}}$ and PP has been shown and discussed elsewhere - see e.g. Vézina and Platt (1987) and Wassmann (1990a). However, as we deliberately strip the model of the regeneration and remineralization processes and respective feedbacks, the output expresses a maximum export capacity of the system and so linearity is expected. This is because, by definition, $P_{\text {new }}$ is equivalent to $P_{\mathrm{E}}$ on an annual time scale (Eppley et al., 1983) and so are their carbon equivalents. As $P_{\text {new }}$ is, in our model, exclusively fuelled by anthropogenic-N sources, the export production is directly related to the $\mathrm{N}$ input in the sense that the annual supply of $\mathrm{N}$ does not enter the regeneration loops of local pelagic food webs and, as such, is exported as $P_{\mathrm{E}}$. As described by Wassmann (1990b), when $P_{\mathrm{r}}$ is set to zero, a linear relationship is expected between the total PP and $P_{\mathrm{E}}$ (which would then be maximised). We chose a power regression model as best fit and significance for the $P_{\mathrm{E}}-\mathrm{PP}$ correlation (see Table S.7 and Figure S.3) and tested this relationship in the five CZs (Figure 5). 


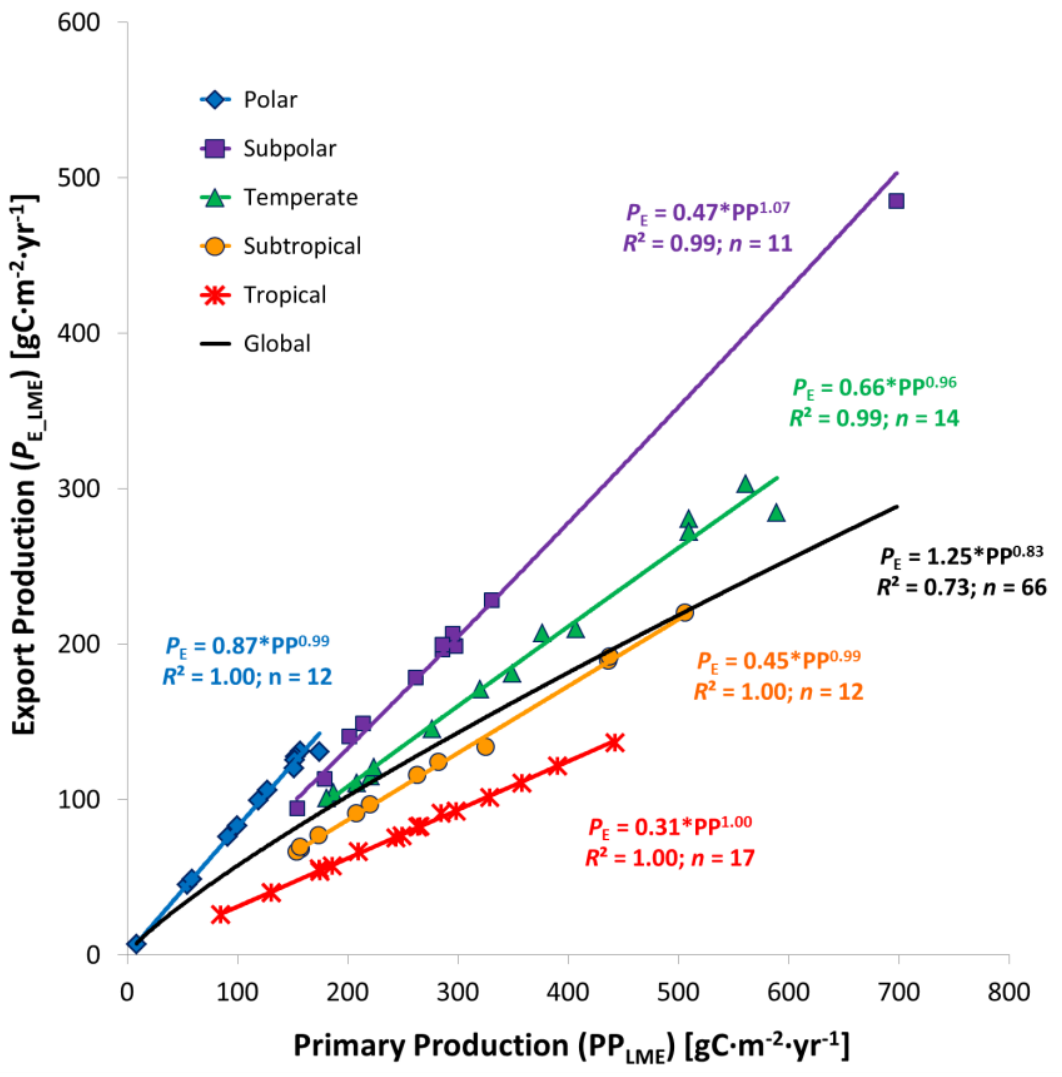

Figure 5 Export production $\left(P_{\mathrm{E}},\left[\mathrm{gC} \cdot \mathrm{m}^{-2} \cdot \mathrm{yr}^{-1}\right]\right)$ as a function of primary production $\left(\mathrm{PP},\left[\mathrm{gC} \cdot \mathrm{m}^{-2} \cdot \mathrm{yr}^{-1}\right]\right)$. Aggregation of $P_{\mathrm{E}}$ from 66 large marine ecosystems (LME) into five climate zones (polar, subpolar, temperate, subtropical, tropical) and global default. Power regression equations and coefficient of determination $\left(R^{2}\right)$ included.

The balance between $P_{\mathrm{E}}$ and PP is determined by the supply of nutrients and heterotrophic grazing/predation. The system is described by a 'top-down' control as the loss rates are determined by grazing pressure and assimilation efficiency, as suggested by Lehman (1991) and Wassmann (1993). The fit of the $P_{\mathrm{E}}-\mathrm{PP}$ curves per $\mathrm{CZ}$ is close to 1.00 and the power equations show linearity close to 1.00 (range 0.96 1.07). The five $\mathrm{CZ}$ export algorithms obtained from our model are therefore rather consistent with the linearity expected by not modelling $P_{\mathrm{r}}$ and $P_{\text {new }}$ supported by recycling and remineralization. The global default curve reveals higher variability, i.e. the fraction of variance of $P_{\mathrm{E}}$ explained by the variation of $\mathrm{PP}$ is only $0.73\left(R^{2}\right)$. This clearly shows that, in our model, $P_{\mathrm{E}}$ can be predicted per $\mathrm{CZ}$ with the respective algorithms, but the global algorithm shows a level of uncertainty that might hinder its application. The notion that there is no universal algorithm was already been noted by Wassmann (1998). Nevertheless, the $P_{\mathrm{E}}$ algorithms are valid for the $\mathrm{CZ}$ resolution and applicable if no information on spatial variability of the emission/exposure location is available at the LME scale (which is the preferable resolution). The global $P_{\mathrm{E}}$ algorithm should only be applied if the purpose of the study accepts the uncertainty reported. The model discriminates the effect of zooplankton on the suspended biomass of producers by different parameterisation of the grazing pressure and assimilation efficiency per CZ. It is clear that no LME (or intra-CZ) variability is originated from the heterotrophic control modelled as such, whereas the inter-CZ variability is an indication of the discriminatory power of the $P_{\mathrm{E}}$ model.

Figure 6 shows the correlation of our export algorithm to others found in literature (Betzer et al., 1984; Eppley and Peterson, 1979; Pace et al., 1987; Suess, 1980; Wassmann, 1990a) and reviewed by Wassmann (1990a) (see also Table S.8). The present PP and photic depth datasets (Table S.4) were applied to plot the curves. Our export algorithm seems consistent with others (Eppley and Peterson's to a lesser extent). The variation between export curves may originate from the inadequacy of the original algorithms for our global application. Those were derived from empirical data of the eastern Pacific Ocean (Eppley and Peterson, 1979), global ocean in 25 different locations but not coastal-specific (Suess, 1980), open ocean in equatorial 
Pacific Ocean (Betzer et al., 1984), deep ocean (not coastal) (Pace et al., 1987), and boreal north Atlantic coastal waters (Wassmann, 1990a). As empirical data were used to derive those algorithms, regeneration and remineralisation feedbacks may be included, justifying higher variation towards higher PP rates.

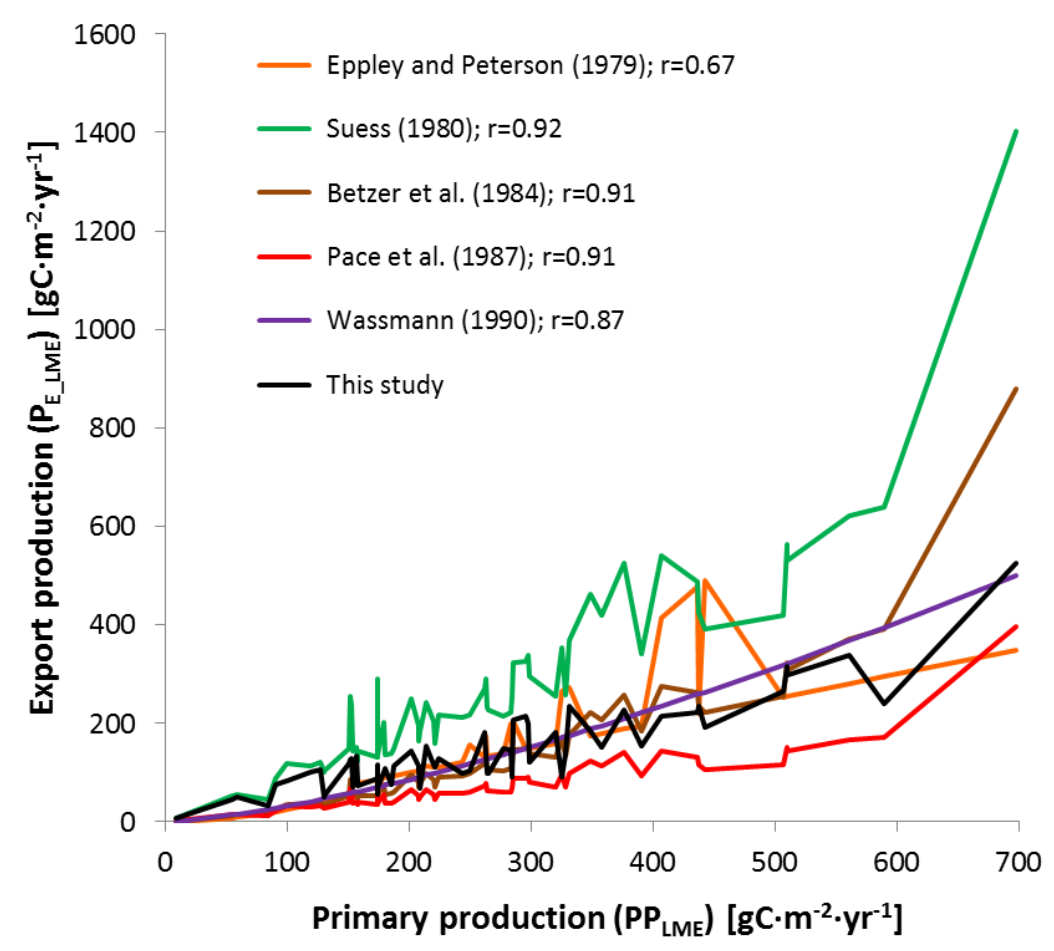

Figure 6 Comparison of the export productions $\left(P_{\mathrm{E}}\right)$ curves obtained from the proposed model and predictions by others (see legend box) with the current primary productivity dataset. Linear correlation coefficients $(r)$ included $(\mathrm{p}<0.001)$.

\subsection{From export production to exposure factor}

A power regression model was fitted to the $\mathrm{XF}_{\mathrm{LME}}$ results as a function of $\mathrm{PP}_{\mathrm{LME}}$ for the five $\mathrm{CZs}$ and a global default (Figure 7). The XF-PP results show a decrease of linearity of the algorithm curves when compared to those of $P_{\mathrm{E}} \mathrm{PP}$ (Figure 5). This fact reflects the increasing losses by consumption of sinking POC (proportional to PP rates) towards highly productive LMEs. Independent of the uncertainty of the PP dataset used (discussed earlier) the XF is mostly dependent on the PP rate input to the model, as shown in the sensitivity analysis (Figure 4). The spatial aggregation from LME- to CZ-specific XFs clearly does not involve a significant increase in uncertainty caused by variability. However, the adoption of a global XF algorithm is not recommended as only $56 \%$ of the XF variance is explained by the variance of PP (see also Figure S.4), which corresponds to ca. 34\% of SD explained (SD of errors less than the XF's SD). Spatially aggregated XFs are useful when information about the spatial variability of the emission(s) or the receiving ecosystem(s) is not relevant or is unknown. Ideally, the $\mathrm{XF}_{\mathrm{LME}}$ should be used to take full advantage of the discriminatory power of the model. The acceptance of any additional uncertainty introduced by spatial aggregation may be determined by the purpose of the study, i.e. scope and application, as it influences the confidence on the results.

As for the $P_{\mathrm{E}}$ model results, the aggregated $\mathrm{XF}_{\mathrm{CZ}}$ curves show good fit $\left(R^{2}\right.$ close to 1.00) for application when spatial information is not available, while $\mathrm{XF}_{\mathrm{LME}}$ is recommend when it is. Caution is however advised when applying $\mathrm{XF}_{\text {Subpolar }}$ as it may underestimate the ecosystem responses due to the contribution of the highly productive LME \#23 (Baltic Sea) (the rightmost data point in Figure 7). As discussed, the adoption of a global XF algorithm is not recommended. 


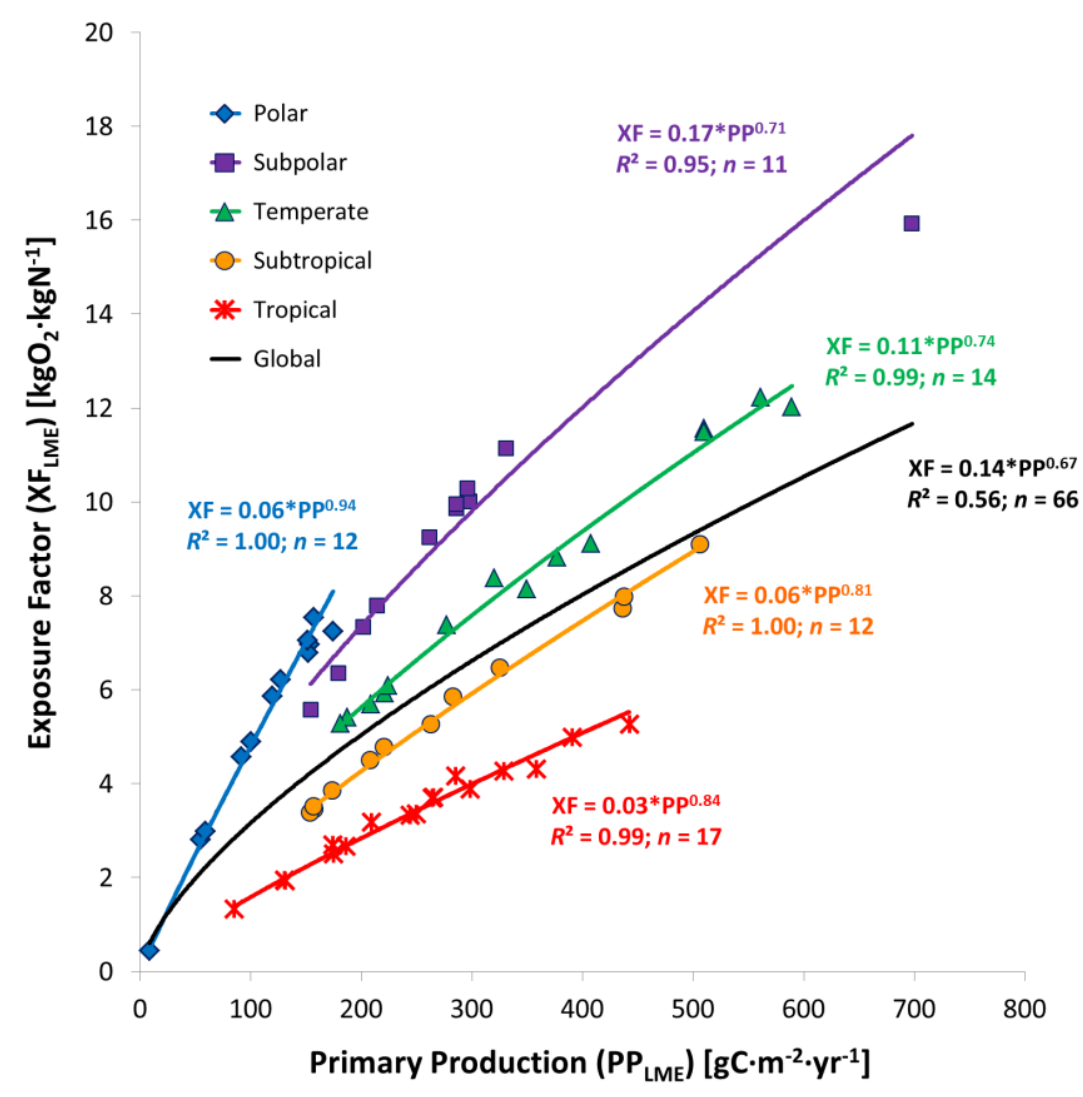

Figure 7 Exposure factor $\left(\mathrm{XF},\left[\mathrm{kgO}_{2} \cdot \mathrm{kgN}^{-1}\right]\right)$ as a function of primary production $\left(\mathrm{PP},\left[\mathrm{gC} \cdot \mathrm{m}^{-2} \cdot \mathrm{yr}^{-1}\right]\right)$. Aggregation of XFs from 66 large marine ecosystems (LME) into five climate zones (polar, subpolar, temperate, subtropical, tropical) and global default. Power regression equations and coefficients of determination $\left(R^{2}\right)$ included.

\subsection{Limitations and future research}

The limitations faced in quantifying the various model parameters at the respective resolutions and the necessary assumptions done, as discussed earlier, and even after an exhaustive literature research leave room for model refinement. The model has limited application to characterise local carbon vertical fluxes at spatial resolutions finer than LME and, currently, only considers temporal resolution of one year. The estimated carbon export and oxygen depletion in bottom waters does not consider external forcing that might distort the results, e.g. coastal hydrodynamics intensifying either mixing or stratification, and factors determining nutrient limitation and variable N:P ratios of the anthropogenic loadings. Furthermore, seasonal or daily variability of species succession or dominance is not reflected in this time-integrated approach.

Adding a temporal dimension to the variability of the natural processes involving the mismatch of phytoand zooplankton, the $\mathrm{C}: \mathrm{N}$ ratio over different moments in a year, and limitation by different nutrients may thus contribute to the model refinement and possibly its robustness. However, increasing the spatial resolution per se, to e.g. grid cells, without modelling further parameters relevant at such scale (like mixing, stratification, ventilation, biogeochemistry of sediments, etc.) does not seem a valuable addition. For that, the spatial units should still be distinct from one another based on those additional parameters. The global coverage, essential for the comparative purpose, would then need an immensity of data.

The carbon export component of the model is not including regeneration or remineralisation processes and their contributions. The focus is on the quantification of $P_{\text {new }}$ supported by allochthonous and anthropogenic $\mathrm{N}$, as intended, but this limits the use of the model in other applications that also address $\mathrm{N}$ and $\mathrm{C}$ cycles in e.g. ecological studies aimed at characterising pelagic food webs efficiency. 


\section{Conclusions}

We developed a method to quantify the response of coastal marine ecosystems to $\mathrm{N}$ inputs from anthropogenic sources. The pathway from $\mathrm{N}$ assimilation to organic carbon sink and subsequent oxygen depletion (exposure pathway) was modelled mechanistically. Exposure Factors (XF) for 66 coastal marine spatial units were estimated. These may be further combined with environmental fate and effect modelling to compose CFs applicable in LCIA for the marine eutrophication impact category.

The model results support the notion that distinct coastal marine ecosystems show distinct responses to equal $\mathrm{N}$ loadings. The sensitivity of the receiving ecosystems depends on the interaction of various biological processes occurring there. In the proposed model, the main modulators of this interaction are the primary production rate and latitude. These determine the spatial differentiation of the results and the resolution of the parameters modelled - some are site-dependent for LMEs or climate zones and others sitegeneric. Eighteen primary and 12 derived parameters were combined in a conceptual pathway that includes production, carbon export, consumption/degradation, and respiration. The result is a mechanistic model that delivers XFs with a spatial variation of a factor 35 among LMEs.

$\mathrm{N}$-limited systems are characterised by a positive covariation between production and export, implying that a higher productivity leads to a higher sinking flux (Harrison et al., 1987; Platt and Sathyendranath, 1988). Therefore, an input of anthropogenic $\mathrm{N}$ makes more limiting nutrient available to PP resulting in higher downward carbon export and potential benthic oxygen depletion. An indicator that is capable of quantifying the oxygen consumption as a function of $\mathrm{N}$ input may be of useful application to assess the ecosystem condition or the impacts of $\mathrm{N}$ emissions from human activities. The latter constitutes the main objective of LCIA methods in support of e.g. sustainability assessment of such activities. The presented approach shows ecological relevance by describing every relevant parameter and process in the exposure pathway based on state of the art science. It is built on a transparent, documented, and robust model whose results are significant and useful contributions to characterisation modelling in LCIA for the marine eutrophication impact category.

\section{Acknowledgements}

The present research was partially funded by the European Commission under the 7th Framework Programme on Environment; ENV.2009.3.3.2.1: LC-IMPACT - Improved Life Cycle Impact Assessment methods (LCIA) for better sustainability assessment of technologies, grant agreement number 243827 . We further thank the two anonymous reviewers whose comments/suggestions helped improve and clarify this manuscript.

\section{References}

Alldredge, A.L., King, J.M., 1980. Effects of moonlight on the vertical migration patterns of demersal zooplankton. J. Exp. Mar. Bio. Ecol. 44, 133-156.

Alldredge, A.L., Silver, M.W., 1988. Characteristics, Dynamics and Significance of Marine Snow. Prog. Oceanogr. 20, 41-82.

Arrigo, K.R., 2005. Marine microorganisms and global nutrient cycles. Nature 437, 349-356.

Atkinson, A., Ward, P., Williams, R., Poulet, S.A., 1992. Feeding rates and diel vertical migration of copepods near South Georgia: comparison of shelf and oceanic sites. Mar. Biol. 114, 49-56.

Behrenfeld, M.J., Boss, E.S., 2014. Resurrecting the ecological underpinnings of ocean plankton blooms. Ann. Rev. Mar. Sci. 6, 167-94.

Behrenfeld, M.J., Falkowski, P.G., 1997. Photosynthetic rates derived from satellite-based chlorophyll concentration. Limnol. Oceanogr. 42, 1-20. 
Besiktepe, S., Dam, H.G., 2002. Coupling of ingestion and defecation as a function of diet in the calanoid copepod Acartia tonsa. Mar. Ecol. Prog. Ser. 229, 151-164.

Besiktepe, S., Kideys, A.E., Unsal, M., 1998. In situ grazing pressure and diel vertical migration of female Calanus euxinus in the Black Sea. Hydrobiologia 363, 323-332.

Betzer, P.R., Showers, W.J., Laws, E.A., Winn, C.D., DiTullio, G.R., Kroopnick, P.M., 1984. Primary productivity and particle fluxes on a transect of the equator at $153^{\circ} \mathrm{W}$ in the Pacific Ocean. Deep Sea Res. Part A. Oceanogr. Res. Pap. 31, 1-11.

Bouvet, M., Hoepffner, N., Dowell, M.D., 2002. Parameterization of a spectral solar irradiance model for the global ocean using multiple satellite sensors. J. Geophys. Res. 107, 3215.

Calbet, A., 2001. Mesozooplankton grazing effect on primary production: A global comparative analysis in marine ecosystems. Limnol. Oceanogr. 46, 1824-1830.

Calbet, A., Landry, M.R., 2004. Phytoplankton growth, microzooplankton grazing, and carbon cycling in marine systems. Limnol. Oceanogr. 49, 51-57.

Chassot, E., Bonhommeau, S., Dulvy, N.K., Mélin, F., Watson, R., Gascuel, D., Le Pape, O., 2010. Global marine primary production constrains fisheries catches. Ecol. Lett. 13, 495-505.

Cole, J.J., Findlay, S., Pace, M.L., 1988. Bacterial production in fresh and saltwater ecosystems: a crosssystem overview. Mar. Ecol. Prog. Ser. 43, 1-10.

Conover, R.J., 1966. Factors affecting the assimilation of organic matter by zooplankton and the question of superfluous feeding. Limnol. Oceanogr. 11, 346-354.

Cushing, D.H., 1975. Marine Ecology and Fisheries. Cambridge University Press, Cambridge.

Cushing, D.H., 1990. Plankton Production and Year-class Strength in Fish Populations: an Update of the Match/Mismatch Hypothesis. Adv. Mar. Biol. 26, 249-293.

Del Giorgio, P.A., Cole, J.J., 1998. Bacterial Growth Efficiency in Natural Aquatic Systems. Annu. Rev. Ecol. Syst. 29, 503-541.

Diaz, R.J., Rosenberg, R., 2008. Spreading dead zones and consequences for marine ecosystems. Science $321,926-9$.

Duarte, B., Saraiva, P.M., Pantelides, C.C., 2004. Combined Mechanistic and Empirical Modelling. Int. J. Chem. React. Eng. 2, A3.

Ducklow, H., Steinberg, D., Buesseler, K., 2001. Upper Ocean Carbon Export and the Biological Pump. Oceanography $14,50-58$.

Ducklow, H.W., Carlson, C.A., 1992. Oceanic bacterial production. Adv. Microb. Ecol. 12, 113-181.

Dugdale, R.C., Goering, J.J., 1967. Uptake of new and regenerated forms of nitrogen in primary productivity. Limnol. Oceanogr. 12, 196-206.

Durant, J.M., Hjermann, D.Ø., Ottersen, G., Stenseth, N.C., 2007. Climate and the match or mismatch between predator requirements and resource availability. Clim. Res. 33, 271-283.

Elmgren, R., 2001. Understanding Ecosystem : Changing Impact Views on in the Recent Baltic Decades. Ambio 30, 222-231.

Elser, J.J., Bracken, M.E.S., Cleland, E.E., Gruner, D.S., Harpole, W.S., Hillebrand, H., Ngai, J.T., Seabloom, E.W., Shurin, J.B., Smith, J.E., 2007. Global analysis of nitrogen and phosphorus limitation of primary producers in freshwater, marine and terrestrial ecosystems. Ecol. Lett. 10, 1135-42.

Eppley, R.W., Peterson, B.J., 1979. Particulate organic matter flux and planktonic new production in the deep ocean. Nature. 
Eppley, R.W., Renger, E.H., Betzer, P.R., 1983. The residence time of particulate organic carbon in the surface layer of the ocean. Deep Sea Res. 30, 311-323.

Fowler, S.W., Knauer, G.A., 1986. Role of large particles in the transport of elements and organic compounds through the oceanic water column. Prog. Oceanogr. 16, 147-194.

Galloway, J.N., Cowling, E.B., Seitzinger, S.P., Socolow, R.H., 2002. Reactive nitrogen: too much of a good thing? Ambio 31, 60-3.

Galloway, J.N., Townsend, A.R., Erisman, J.W., Bekunda, M., Cai, Z., Freney, J.R., Martinelli, L.A., Seitzinger, S.P., Sutton, M.A., 2008. Transformation of the Nitrogen Cycle: Recent Trends, Questions, and Potential Solutions. Science (80-. ). 320, 889-892.

Gray, J.S., Wu, R.S., Or, Y.Y., 2002. Effects of hypoxia and organic enrichment on the coastal marine environment. Mar. Ecol. Prog. Ser. 238, 249-279.

Harrison, W.G., Platt, T., Lewis, M.R., 1987. f-Ratio and its relationship to ambient nitrate concentration in coastal waters. J. Plankton Res. 9, 235-248.

Hauschild, M.Z., 2005. Assessing Environmental Impacts in a Life-Cycle Perspective. Environ. Sci. Technol. 39, 81-88.

Henderson, A.D., 2015. Eutrophication, in: Hauschild, M.Z., Huijbregts, M.A.J. (Eds.), Life Cycle Impact Assessment, LCA Compendium - The Complete World of Life Cycle Assessment. Springer Science+Business Media Dordrecht, pp. 177-196.

Hirst, A.G., Kiørboe, T., 2002. Mortality of marine planktonic copepods: global rates and patterns. Mar. Ecol. Prog. Ser. 230, 195-209.

Ho, T., Quigg, A., Zoe, V., Milligan, A.J., Falkowski, P.G., Morel, M.M., 2003. The elemental composition of some phytoplankton. J. Phycol. 39, 1145-1159.

Howarth, R.W., Marino, R., 2006. Nitrogen as the limiting nutrient for eutrophication in coastal marine ecosystems: Evolving views over three decades. Limnol. Oceanogr. 51, 364-376.

Huisman, J., van Oostveen, P., Weissing, F.J., 1999. Critical depth and critical turbulence: Two different mechanisms for the development of phytoplankton blooms. Limnol. Oceanogr. 44, 1781-1787.

Iversen, M.H., Ploug, H., 2010. Ballast minerals and the sinking carbon flux in the ocean: carbonspecific respiration rates and sinking velocity of marine snow aggregates. Biogeosciences 7 , 2613-2624.

Keeling, R.F., Körtzinger, A., Gruber, N., 2010. Ocean Deoxygenation in a Warming World. Ann. Rev. Mar. Sci. 2, 199-229.

Kelly, J.R., 2008. Nitrogen Effects on Coastal Marine Ecosystems, in: Hatfield, J.L., Follet, R.F. (Eds.), Nitrogen in the Environment: Sources, Problems, and Management. U.S. Environmental Protection Agency, pp. 271-332.

Kiørboe, T., 1996. Material Flux in the Water Column, in: Jorgensen, B.B., Richardson, K. (Eds.), Eutrophication in Coastal Marine Ecosystems Coastal and Estuarine Studies. American Geophysical Union, pp. 67-94.

Kiørboe, T., 2001. Formation and fate of marine snow: small-scale processes with large-scale implications. Sci. Mar. 65, 57-71.

Kiørboe, T., Hansen, J.L.S., Alldredge, A.L., Jackson, G.A., Passow, U., Dam, H.G., Drapeau, D.T., Waite, A., Garcia, C.M., 1996. Sedimentation of phytoplankton during a diatom bloom: Rates and mechanisms. J. Mar. Res. 54, 1123-1148. 
Koski, M., Jónasdóttir, S.H., Bagøien, E., 2011. Biological processes in the North Sea: vertical distribution and reproduction of neritic copepods in relation to environmental factors. J. Plankton Res. 33, 63-84.

Lai, S., 2004. Primary Production [WWW Document]. Sea Around Us Proj. Fish. Centre, UBC. URL http://www.seaaroundus.org/doc/saup_manual.htm\#3 (accessed 6.18.14).

Lampert, W., 1978. Release of dissolved organic carbon by grazing zooplankton. Limnol. Ocean. 23, 831-834.

Lampert, W., 1989. The Adaptive Significance of Diel Vertical Migration of Zooplankton. Funct. Ecol. 3, 21-27.

Laws, E.A., Falkowski, P.G., Smith Jr., W.O., Ducklow, H., McCarthy, J.J., 2000. Temperature effects on export production in the open ocean. Global Biogeochem. Cycles 14, 1231-1246.

Lehman, J.T., 1991. Interacting growth and loss rates: The balance of top-down and bottom-up controls in plankton communities. Limnol. Oceanogr. 36, 1546-1554.

Levin, L.A., Ekau, W., Gooday, A.J., Jorissen, F., Middelburg, J.J., Naqvi, S.W.A., Neira, C., Rabalais, N.N., Zhang, J., 2009. Effects of natural and human-induced hypoxia on coastal benthos. Biogeosciences 6, 2063-2098.

Longhurst, A.R., 1998. Ecological Geography of the Sea. Academic Press Limited, London, UK.

Longhurst, A.R., Harrison, W.G., 1988. Vertical nitrogen flux from the oceanic photic zone by diel migrant zooplankton and nekton. Deep. Res. 35, 881-889.

Møller, E.F., 2007. Production of dissolved organic carbon by sloppy feeding in the copepods Acartia tonsa, Centropages typicus, and Temora longicornis. Limnol. Oceanogr. 52, 79-84.

Møller, E.F., Nielsen, T.G., 2001. Production of bacterial substrate by marine copepods: Effect of phytoplankton biomass and cell size. J. Plankton Res. 23, 527-536.

Møller, E.F., Thor, P., Nielsen, T.G., 2003. Production of DOC by Calanus finmarchicus, C. glacialis and C. hyperboreus through sloppy feeding and leakage from fecal pellets. Mar. Ecol. Prog. Ser. 262, 185-191.

Morales, C.E., Harris, R.P., Head, R.N., Tranter, P.R.G., 1993. Copepod grazing in the oceanic northeast Atlantic during a 6 week drifting station: The contribution of size classes and vertical migrants. J. Plankton Res. 15, 185-212.

Niemi, G., Wardrop, D., Brooks, R., Anderson, S., Brady, V., Paerl, H.W., Rakocinski, C.F., Brouwer, M., Levinson, B., McDonald, M., 2004. Rationale for a New Generation of Indicators for Coastal Waters. Environ. Health Perspect. 112, 979-986.

Nixon, S.W., 1995. Coastal marine eutrophication: A definition, social causes, and future concerns. Ophelia 41, 199-219.

NRC, 2000. Clean Coastal Waters: Understanding and Reducing the Effects of Nutrient Pollution. National Academy press, Washington, DC.

Odum, E.P., 1971. Fundamentals of Ecology, 3rd ed. W.B. Saunders Co., Philadelphia.

Pace, M.L., Knauer, G.A., Karl, D.M., Martin, J.H., 1987. Primary production, new production and vertical flux in the eastern Pacific Ocean. Nature 325, 803-804.

Pauly, D., Christensen, V., 1995. Primary production required to sustain global fisheries. Nature.

Platt, T., Harrison, W.G., Lewis, M.R., Li, W.K.W., Sathyendranath, S., Smith, R.E., Vezina, A.F., 1989. Biological production of the oceans: the case for a consensus. Mar. Ecol. Prog. Ser. 52, 77-88. 
Platt, T., Sathyendranath, S., 1988. Oceanic Primary Production: Estimation by Remote Sensing at Local and Regional Scales. Science (80-. ). 241, 1613-1620.

Puelles, M.L.F. de, Valdés, L., Varela, M., Halliday, N., 1996. Diel variations in the vertical distribution of copepods off the north coast of Spain. ICES J. Mar. Sci. 53, 97-106.

Redfield, A.C., 1958. The Biological Control of Chemical Factors in the Environment. Am. Sci. 46, 205221.

Roman, M.R., Adolf, H.A., Landry, M.R., Madin, L.P., Steinberg, D.K., Zhang, X., 2002. Estimates of oceanic mesozooplankton production: a comparison using the Bermuda and Hawaii time-series data. Deep. Res. Part II 49, 175-192.

Roman, M.R., Furnas, M.J., Mullin, M.M., 1990. Zooplankton abundance and grazing at Davies Reef, Great Barrier Reef, Australia. Mar. Biol. 105, 73-82.

Saba, G.K., Steinberg, D.K., Bronk, D. a., 2011. The relative importance of sloppy feeding, excretion, and fecal pellet leaching in the release of dissolved carbon and nitrogen by Acartia tonsa copepods. J. Exp. Mar. Bio. Ecol. 404, 47-56.

Saba, G.K., Steinberg, D.K., Bronk, D.A., 2009. Effects of diet on release of dissolved organic and inorganic nutrients by the copepod Acartia tonsa. Mar. Ecol. Prog. Ser. 386, 147-161.

Sherman, K., Alexander, L.M. (Eds.), 1986. Variability and Management of Large Marine Ecosystems. Westview Press Inc., Boulder, CO.

Sherman, K., Aquarone, M.C., Adams, S. (Eds.), 2009. Sustaining the World's Large Marine Ecosystems. IUCN, Gland, Switzerland.

Smith, V.H., 2007. Using primary productivity as an index of coastal eutrophication: the units of measurement matter. J. Plankton Res. 29, 1-6.

Smith, V.H., Tilman, G.D., Nekola, J.C., 1999. Eutrophication: impacts of excess nutrient inputs on freshwater, marine, and terrestrial ecosystems. Environ. Pollut. 100, 179-196.

Socolow, R.H., 1999. Nitrogen management and the future of food: Lessons from the management of energy and carbon. Proc. Natl. Acad. Sci. U. S. A. 96, 6001-6008.

Spalding, M.D., Fox, H.E., Allen, G.R., Davidson, N., Ferdaña, Z.A., Finlayson, M., Halpern, B.S., Jorge, M.A., Lourie, S.A., Martin, K.D., Mcmanus, E., Recchia, C.A., Robertson, J., 2007. Marine Ecoregions of the World: A Bioregionalization of Coastal and Shelf Areas. Bioscience 57, 573-583.

Strandesen, M., Birkved, M., Holm, P.E., Hauschild, M.Z., 2007. Fate and distribution modelling of metals in life cycle impact assessment. Ecol. Modell. 203, 327-338.

Suess, E., 1980. Particulate organic carbon flux in the oceans - surface productivity and oxygen utilization. Nature 288, 260-263.

Tang, K.W., Elliott, D.T., 2013. Copepod Carcasses: Occurrence, fate and Ecological Importance, in: Seuront, L. (Ed.), Copepods: Diversity, Habitat and Behaviour. Nova Science Publishers, Inc., p. 28.

Turner, J.T., 2002. Zooplankton fecal pellets, marine snow and sinking phytoplankton blooms. Aquat. Microb. Ecol. 27, 57-102.

Turner, R.E., Qureshi, N., Rabalais, N.N., Dortch, Q., Justić, D., Shaw, R.F., Cope, J., 1998. Fluctuating silicate: nitrate ratios and coastal plankton food webs. Proc. Natl. Acad. Sci. U. S. A. 95, 1304813051.

UBC, 1999. Sea Around Us Project: Fisheries, Ecosystems \& Biodiversity [WWW Document]. URL http://seaaroundus.org/ (accessed 6.18.14). 
UNEP, 2006. Marine and coastal ecosystems and human well-being: A synthesis report based on the findings of the Millennium Ecosystem Assessment.

UNESCO, 2009. Global Open Oceans and Deep Seabed (GOODS) - Biogeographic Classification.

Vézina, A.F., Platt, T., 1987. Small-Scale Variability of New Production and Particulate Fluxes in the Ocean. Can. J. Fish. Aquat. Sci. 44, 198-205.

Vitousek, P.M., Hättenschwiler, S., Olander, L., Allison, S., 2002. Nitrogen and nature. Ambio 31, 97-101.

Wassmann, P., 1990a. Relationship between primary and export production in the boreal coastal zone of the North Atlantic. Limnol. Ocean. 35, 464-471.

Wassmann, P., 1990b. Calculating the Load of Organic Carbon to the Aphotic Zone in Eutrophicated Coastal Waters. Mar. Pollut. Bull. 21, 183-187.

Wassmann, P., 1993. Regulation of vertical export of particulate organic matter from the euphotic zone by planktonic heterotrophs in eutrophicated aquatic environments. Mar. Pollut. Bull. 26, 636643.

Wassmann, P., 1998. Retention versus export food chains: processes controlling sinking loss from marine pelagic systems 29-57.

Watson, R., Zeller, D., Pauly, D., 2014. Primary productivity demands of global fishing fleets. Fish Fish. $15,231-241$. 


\section{Supporting Information}

\section{Manuscript Title:}

\section{Exposure factors for marine eutrophication impacts assessment based on a mechanistic biological model}

\section{Authors:}

Nuno Cosme ${ }^{\mathrm{a}, *}$, Marja Koski ${ }^{\mathrm{b}}$, Michael Z. Hauschild ${ }^{\mathrm{a}}$

${ }^{a}$ Division for the Quantitative Sustainability Assessment, Department of Management Engineering, Technical University of Denmark, Produktionstorvet 424, DK-2800 Kgs. Lyngby, Denmark

${ }^{\mathrm{b}}$ Section of Marine Ecology and Oceanography, Technical University of Denmark, Kavalergården 6, DK2920 Charlottenlund, Denmark

* Corresponding author. Tel.: +45 45254729.

E-mail address: nmcosme@dtu.dk

\section{S.1 On the modelling of the indicator of exposure to nitrogen}

The paper has the aim to estimate exposure factors (XF) for the assessment of marine eutrophication impacts caused by discharges of nitrogen $(\mathrm{N})$ from anthropogenic sources to coastal waters based on mechanistic modelling of the underlying biological processes. The relevant processes for this assessment are nutrient-limited primary production (PP), metazoan consumption, and bacterial degradation of this PP. The proposed model framework delivers an indicator of the exposure of marine coastal ecosystems to N-loadings, which expresses the amount of dissolved oxygen consumed as a function of N-loadings. Such indicator (XF, $\left[\mathrm{kgO}_{2} \cdot \mathrm{KgN}^{-1}\right]$ ) may be applicable in Life Cycle Impact Assessment (LCIA) as an essential component for characterisation modelling of N-emissions with eutrophying impacts, or be useful in ecosystems management.

In a broad sense, the environmental conditions govern nutrients' fate and assimilation. These can be affected by abiotic factors, e.g. irradiance, temperature, residence time, advection, and by biotic factors, e.g. species, their life cycles, and growth rates. Modelling environmental parameters, specific local conditions, and how they affect phytoplankton in what regards to energy budget, reproduction, distribution, species composition, productivity, etc., is complicated. Modelling all the factors simultaneously to mechanistically predict the ecosystem response to $\mathrm{N}$ fertilization is even more complicated, as well as time- and resourceconsuming. Indicators, such as the PP rate (Niemi et al., 2004; Smith, 2007) and the method introduced here, are useful approaches to quantify these responses and of special interest for application in ecological modelling of marine eutrophication and impact assessment. However, PP as an indicator is unable to explain how different coastal areas may have distinct responses because it misses the explanatory power for the impacts, e.g. different water masses may show distinct impacts while sharing similar PP rates. The indicator we propose here, the ecosystem eXposure Factor (XF), adds a mechanistic explanation for the potential impacts and addresses the reasons for its variability. This seems more relevant than a simple PP-impacts empirical correlation (e.g. PP to levels of hypoxia, or PP to extension of dead zones) and useful for predictive advice, ecosystems management, and modelling of eutrophication. 


\section{S.1.1 Primary production and vertical carbon flux}

The productivity of marine ecosystems depends on light-harvesting primary producers (phytoplankton). The photosynthetic production of organic matter by phytoplankton supports the food webs of the entire pelagic and demersal marine ecosystems (Baines et al., 1994; Mills, 1975; Reynolds, 2006). Despite being limited to the upper layer of the ocean (euphotic zone) the net primary production of the ocean is comparable to the terrestrial primary production at 48.3 and $56.4 \mathrm{GtC} \cdot \mathrm{yr}^{-1}$, respectively (Geider et al., 2001).

The main modulators of PP are the availability of light and nutrients, thus determining the efficiency and distribution of phytoplankton species in the euphotic zone (Field, 1998). Water mixing is also relevant for it determines how phytoplankton is exposed to light and how nutrients are made available. Stratification originated by the heating of the upper water layer or by freshwater input from river discharge and ice melting is important in the regulation of the timing, duration, and intensity of the productive periods (Lemke et al., 2007; Peterson et al., 2006; Tremblay et al., 2006). In general, the resulting density-driven stratification constitutes a simultaneous barrier for nutrients supply to the upper layer and to the ventilation of the deeper layers. A strong stratification poses a potential threat to benthic communities as it influences the availability of dissolved oxygen.

The concept of 'limiting nutrient' is essential for the modelling of productivity and it is based on Liebig's Law of the Minimum (reviewed by van der Ploeg et al. (1999)). It states that growth, abundance or distribution of individuals or populations is controlled not by the total amount of resources but by the scarcest resource, i.e. one nutrient has a limiting role and all other nutrients are available in excess. In practice, any additional amount of the limiting nutrient introduced to the system promotes an increase in response (growth), whereas the introduction of any other nutrient has no reflection on growth as they are already in excess (Finnveden and Potting, 1999).

Specific biotic (mainly limited grazing pressure) and abiotic (environmental) conditions determine when phytoplankton blooms initiate (Behrenfeld and Boss, 2014). The hypotheses supporting the phytoplankton bloom initiation have been widely discussed (Behrenfeld, 2010; Boss and Behrenfeld, 2010; Chiswell, 2011; Evans and Parslow, 1985; Gran and Braarud, 1935; Platt et al., 1991; Smetacek and Passow, 1990; Sverdrup, 1953; Taylor and Ferrari, 2011)). These have evolved from the critical depth hypothesis (Sverdrup, 1953) focused on the shoaling of the mixed-layer depth, to the critical turbulence hypothesis (Huisman et al., 2002, 1999) focused on the shoaling of a density-defined mixed layer, and more recently to the disturbancerecovery hypothesis (Behrenfeld et al., 2013) focused on the disruption of the balance between phytoplankton growth and consumptive mortality (grazing).

The match-mismatch hypothesis described by Cushing (1975) is further used in the present approach to define a critical fate process of primary producers' biomass by determining the grazed and sunken fractions per climate zone. The magnitude of the subsequent vertical carbon flux thus depends on the biological response of primary producers to the abiotic conditions (e.g. light, temperature, and nutrient availability) and on the activity of their consumers (mainly zooplankton) and degraders (microbial loop). In short, if the biomass resulting from the assimilation of nutrients exceeds consumption and degradation there is a net flux of organic carbon to bottom waters.

Considering the processes that regulate (i) the export production, (ii) the oxygen consumption near the bottom, and (iii) the potential impacts to marine eutrophication that may come from excessive $\mathrm{N}$ fertilization, it seems crucial to integrate all the relevant coastal biological processes into a common model framework if trying to quantify the ecosystem's response to N-loadings from anthropogenic sources. 


\section{S.1.2 Complementary information on modelling anthropogenic sources of nitrogen}

Several studies and reviews have focused on understanding and discussing the sources, fate, and general impacts of nitrogen in ecosystems. Examples of these include global, estuarine, and coastal marine nitrogen cycling (Galloway et al., 2008, 2004; Herbert, 1999; Pinckney et al., 2001; Rabalais, 2002; Ryther and Dunstan, 1971; Vitousek et al., 1997), fate modelling in soils, groundwater, and surface freshwater systems (Bouwman, 2005; Seitzinger et al., 2010, 2005; Van Drecht et al., 2003; Wollheim et al., 2008), atmospheric emissions and deposition (Lee et al., 1997; Roy et al., 2012; van Vuuren et al., 2011), emissions from agriculture (Beusen et al., 2008; Bouwman et al., 2009, 2002; Butterbach-Bahl and Dannenmann, 2011; Carpenter et al., 1998), emissions from wastewater (Van Drecht et al., 2009, 2003), loadings from rivers (Green et al., 2004; Kroeze et al., 2012; Seitzinger et al., 2010), or impacts from excess nitrogen inputs and eutrophication to marine ecosystems (Cloern, 2001; de Jonge et al., 2002; Kitsiou and Karydis, 2011; Nixon, 1995; Rabalais et al., 2009; Smith et al., 2006, 1999).

\section{S.1.3 Empirical vs. mechanistic models}

Characterisation models in LCIA can be single-level descriptive (or empirical) or hierarchical/multilevel explanatory (or mechanistic) (Duarte et al., 2004, 2003; Steen, 2002). Empirical models are based on statistically significant correlations between properties and responses, i.e. rely on statistical treatment of large amounts of empirical data to describe the 'natural' processes. These are 'black box' models that mine correlation-based knowledge out of the available data with the introduction of as few assumptions about the processes as possible (Duarte et al., 2004) to describe the observed behaviour, offering low explanatory depth (Mulligan and Wainwright, 2004). In practice, they fit the behaviour/responses to real available data by minimising the residuals (differences) between predicted estimates (results) and dependent variable observations (data) (Duarte et al., 2004). Although highly predictive, empirical approaches allow limited extrapolation beyond the scope of the data, as they do not offer a mechanistic understanding of the processes they try to describe.

Mechanistic models use existing scientific knowledge about the processes they try to represent by means of equations that express the systems' response or behaviour. Mechanistic approaches allow some extrapolation of the results beyond the intrinsic limitations of specificity of the experimental data and evidence available as well as estimation of unmeasured state variables (Duarte et al., 2004). A possible drawback of a mechanistic approach is the failure to forecast the 'natural' processes accurately (low predictive power) (Mulligan and Wainwright, 2004) by not including all the knowledge and data available, mainly because of the inevitable introduction of model simplifications and assumptions to offset the lack of understanding or integration of multiple interactions or simply the inability to handle the complexity of the modelling needs (Duarte et al., 2004).

The model framework proposed here fits a mechanistic approach. It explores the system hierarchy in an effort to predict and explain the integrated response by building on descriptive (empirical) studies and their results to ultimately become explanatory at the higher levels. In practice, we build a mechanistic cause-effect pathway of cascading biological processes to deliver an overall conversion of nitrogen into oxygen consumption. With this approach we aim at ensuring environmental relevance and significance by describing all the relevant parameters based on state of the art science. In doing so, we minimise the drawbacks. Finally, we deliver a transparent model with manageable complexity and good extrapolation potential by using adaptable parameterisation that can reflect e.g. different regional environmental settings or future climatic pressures. 
The present XF estimation method is equivalent to a modified and expanded export production $\left(P_{\mathrm{E}}\right)$ model in delivering spatially differentiated indicators of the ecosystem response (XF) to nitrogen. The method renders an indicator which is equivalent in concept to $P_{\mathrm{E}}$ fuelled by $\mathrm{N}$ from anthropogenic allochthonous sources plus subsequent degradation of the exported organic material. The applicability of such indicator seems greater than the $P_{\mathrm{E}}$ alone for the purpose of the LCIA method in which it is to be incorporated, i.e. a comparative assessment of the potential impacts to marine eutrophication from $\mathrm{N}$ emissions as it expresses not only the exported fraction but also the subsequent pathway that leads to the endpoint oxygen consumption. This final step is important to the impacts assessment framework as oxygen depletion is the stressor that leads to the ultimate effect on biota survival and its role in ecosystem structure and functioning.

\section{S.2 Additional information to methods description}

\section{S.2.1. Grouping spatial units into climate zones}

Spatial units of marine coastal waters (LMEs) were grouped into climate zones (tropical, subtropical, temperate, subpolar, and polar) (results in Figure S.1 and geographical distribution in Figure S.2) using with the following criteria:

- Latitudinal distribution: Tropical from Equator to $\approx 20^{\circ} \mathrm{N}$, Subtropical from $\approx 20^{\circ}-30^{\circ} \mathrm{N}$, Temperate from $\approx 30^{\circ}-50^{\circ} \mathrm{N}$, Subpolar from $\approx 50^{\circ}-70^{\circ} \mathrm{N}$, and Polar from $\approx 70^{\circ}-90^{\circ} \mathrm{N}$ (and the same for the Southern Hemisphere);

- Mean annual sea surface temperature (maSST): based on Sherman and Hempel (2009), which includes regression equations for maSST (from 1975-2005) per LME;

- To help on the classification of certain LMEs, complementary information was found on the MEOW classification system (Spalding et al., 2007) and on the Köppen-Geiger climate classification system (Peel et al., 2007). 


\begin{tabular}{|c|c|c|}
\hline LME [\#.name] & massT $2005\left[{ }^{\circ} \mathrm{C}\right]$ & Climate zone \\
\hline 64. Central Arctic Ocean & $-1.2]$ & \multirow{12}{*}{$\frac{\frac{1}{0}}{0}$} \\
\hline 55. Beaufort Sea & -1.2 & \\
\hline 61. Antarctic & -1.2 & \\
\hline 56. East Siberian Sea & -1.1 & \\
\hline 66. Canadian High Arctic - North Greenland & -1.0 & \\
\hline 57. Laptev Sea & -0.8 & \\
\hline 58. Kara Sea & -0.5 & \\
\hline 54. Northern Bering - Chukchi Seas & -0.1 & \\
\hline 63. Hudson Bay Complex & 1.01 & \\
\hline 18. Canadian Eastern Arctic - West Greenland & $1.0]$ & \\
\hline 19. Greenland Sea & 1.9 & \\
\hline 20. Barents Sea & 3.3 & \\
\hline 52. Sea of Okhotsk & 4.6 & \multirow{11}{*}{$\begin{array}{l}\frac{2}{0} \\
\frac{0}{0} \\
\text { ज }\end{array}$} \\
\hline 01. East Bering Sea & 5.1 & \\
\hline 53. West Bering Sea & 5.2 & \\
\hline 09. Newfoundland-Labrador Shelf & 5.6 & \\
\hline 59. Iceland Shelf and Sea & 6.0 & \\
\hline 65. Aleutian Islands & 6.0 & \\
\hline 51. Oyashio Current & 7.0 & \\
\hline 23. Baltic Sea & 8.3 & \\
\hline 21. Norwegian Sea & 8.6 & \\
\hline 60. Faroe Plateau & 9.6 & \\
\hline 02. Gulf of Alaska & 9.6 & \\
\hline 08. Scotian Shelf & 8.4 & \multirow{14}{*}{ 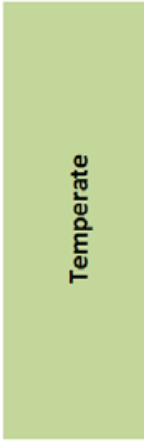 } \\
\hline 22. North Sea & 10.5 & \\
\hline 14. Patagonian Shelf & 10.8 & \\
\hline 07. Northeast U.S. Continental Shelf & 12.6 & \\
\hline 24. Celtic-Biscay Shelf & 13.1 & \\
\hline 50. Sea of Japan/East Sea & 13.4 & \\
\hline 62. Black Sea & 14.9 & \\
\hline 42. Southeast Australian Shelf & 14.9 & \\
\hline 46. New Zealand Shelf & 15.4 & \\
\hline 48. Yellow Sea & 15.4 & \\
\hline 13. Humboldt Current & 16.5 & \\
\hline 25. Iberian Coastal & 17.0 & \\
\hline 43. Southwest Australian Shelf & 17.2 & \\
\hline 03. California Current & 17.4 & \\
\hline 26. Mediterranean & 20.0 & \multirow{12}{*}{ 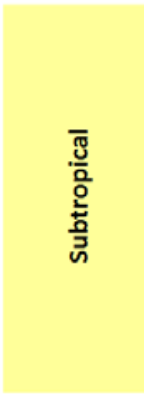 } \\
\hline 29. Benguela Current & 20.7 & \\
\hline 27. Canary Current & 22.0 & \\
\hline 47. East China Sea & 22.2 & \\
\hline 44. West-Central Australian Shelf & 22.4 & \\
\hline 15. South Brazil Shelf & 22.9 & \\
\hline 49. Kuroshio Current & 23.0 & \\
\hline 41. East-Central Australian Shelf & 23.0 & \\
\hline 04. Gulf of California & 24.5 & \\
\hline 06. Southeast U.S. Continental Shelf & 24.8 & \\
\hline 30. Agulhas Current & 25.5 & \\
\hline 05. Gulf of Mexico & 26.1 & \\
\hline 10. Insular Pacific-Hawaiian & 25.0 & \multirow{17}{*}{$\begin{array}{l}\overline{3} \\
\frac{3}{2} \\
\frac{2}{2}\end{array}$} \\
\hline 40. Northeast Australian Shelf & 26.7 & \\
\hline 16. East Brazil Shelf & 27.2 & \\
\hline 31. Somali Coastal Current & 27.3 & \\
\hline 11. Pacific Central-American & 27.5 & \\
\hline 28. Guinea Current & 27.6 & \\
\hline 32. Arabian Sea & 27.7 & \\
\hline 12. Caribbean Sea & 27.8 & \\
\hline 45. Northwest Australian Shelf & 27.8 & \\
\hline 17. North Brazil Shelf & 27.9 & \\
\hline 36. South China Sea & 28.0 & \\
\hline 33. Red Sea & 28.1 & \\
\hline 39. North Australian Shelf & 28.2 & \\
\hline 34. Bay of Bengal & 28.7 & \\
\hline 38. Indonesian Sea & 28.7 & \\
\hline 35. Gulf of Thailand & 28.9 & \\
\hline 37. Sulu-Celebes Sea & 29.0 & \\
\hline
\end{tabular}

Figure S.1 Classification and grouping of Large Marine Ecosystems (LME) into climate zones (polar, subpolar, temperate, subtropical, and tropical) based on mean annual sea surface temperature (maSST), latitude, and consistency with the Köppen-Geiger climate classification system (data from Sherman and Hempel (2009)). 


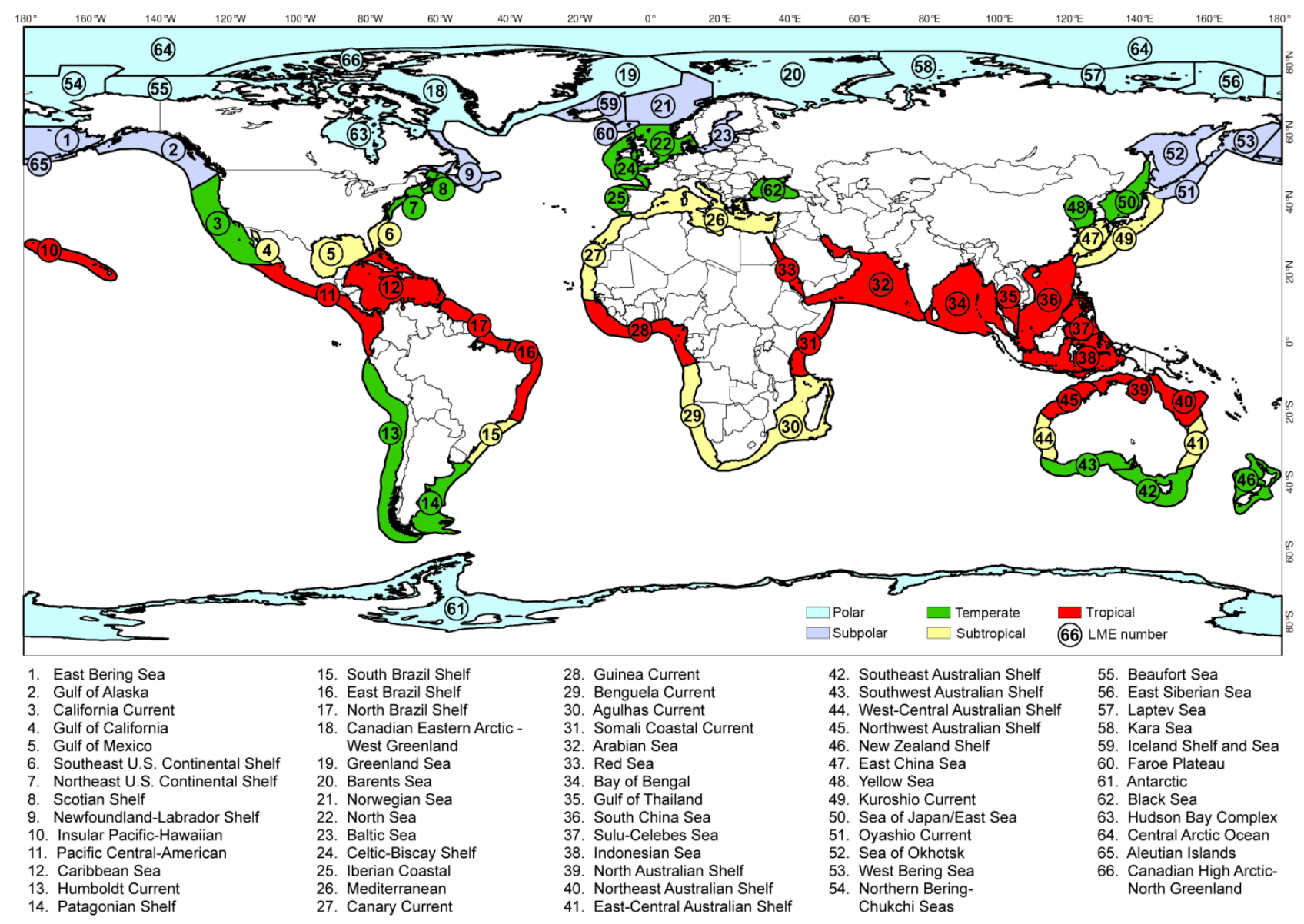

Figure S.2 Geographical distribution of the 66 Large Marine Ecosystems (LMEs) grouped into the five proposed climate zones (polar, subpolar, temperate, subtropical, tropical) (spatial units coloured from the original digital map available at http://lme.edc.uri.edu/).

\section{S.2.2. Model input parameters}

The 18 primary input parameters and others derived from these are included in Table S.1, that complement Table 1 included in the main text. Details on the specific calculations and description are included as well as the estimated coefficients per relevant resolution used in the model work. 
Table S.1 Parameters used in the model, their quantification and characteristics.

\begin{tabular}{|c|c|c|c|c|c|}
\hline $\begin{array}{l}\text { Input } \\
\text { parameter }\end{array}$ & $\begin{array}{l}\text { Spatial } \\
\text { resolution }\end{array}$ & Value & Unit & $\begin{array}{l}\text { Source } \\
\text { (reference or calculation) }\end{array}$ & Description \\
\hline $\mathrm{C}: \mathrm{N}$ & GLO & 5.681 & {$\left[\mathrm{kgC} \cdot \mathrm{kgN}^{-1}\right]$} & Stoichiometry of the photosynthesis equation & Molar mass ratio: $106 * \mathrm{M}(\mathrm{C}) / 16 * \mathrm{M}(\mathrm{N})$ \\
\hline $\mathrm{O}_{2}: \mathrm{C}$ & GLO & 3.468 & {$\left[\mathrm{kgO}_{2} \cdot \mathrm{kgC}^{-1}\right]$} & Stoichiometry of the respiration equation & Molar mass ratio: $138 * \mathrm{M}\left(\mathrm{O}_{2}\right) / 106 * \mathrm{M}(\mathrm{C})$ \\
\hline $\mathrm{O}_{2}: \mathrm{N}$ & GLO & 19.704 & {$\left[\mathrm{kgO}_{2} \cdot \mathrm{kgN}^{-1}\right]$} & $\left(\mathrm{O}_{2}: \mathrm{N}\right)=(\mathrm{C}: \mathrm{N}) *\left(\mathrm{O}_{2}: \mathrm{N}\right)$ & Molar mass ratio: $138 * \mathrm{M}\left(\mathrm{O}_{2}\right) / 16 * \mathrm{M}(\mathrm{N})$ \\
\hline$P P_{\text {Pot }}$ & $\mathrm{LME}$ & $0.033 \leftrightarrow 2.707$ & {$[-]$} & $\mathrm{PP}_{\mathrm{Pot}}=\mathrm{PP}_{\mathrm{LME}} / \mathrm{PP}_{\mathrm{Avg} 66 \mathrm{LME}}$ & $\mathrm{PP}_{\mathrm{LME}}$ normalised by $\mathrm{PP}_{\mathrm{Avg}} 66 \mathrm{LME}$ \\
\hline \multirow{5}{*}{$f_{\text {PPsink }}$} & CZ POL & 0.670 & {$[-]$} & Cushing (1975); Laws et al. (2000) & \multirow{5}{*}{ Sinking fraction of mismatched PP biomass } \\
\hline & CZ SPO & 0.485 & {$[-]$} & Average $\left(f_{\text {PPsink_Polar }}, f_{\text {PPsink_Temperate }}\right)$ & \\
\hline & CZ TEP & 0.300 & {$[-]$} & Cushing (1975); Laws et al. (2000) & \\
\hline & CZ STR & 0.225 & {$[-]$} & Average $\left(f_{\mathrm{PPsink}}\right.$ Temperate,,$f_{\mathrm{PPsink}}$ Tropical $)$ & \\
\hline & CZ TRO & 0.150 & {$[-]$} & Cushing (1975); Laws et al. (2000) & \\
\hline \multirow{5}{*}{$f_{\mathrm{PPgrz}}$} & CZ POL & 0.330 & {$[-]$} & $f_{\text {PPgrz_Polar }}=1-f_{\text {PPsink_Polar }}$ & \multirow{5}{*}{$\begin{array}{l}\text { Fraction of PP biomass grazed by zooplankton in the } \\
\text { photic zone }\end{array}$} \\
\hline & CZ SPO & 0.515 & {$[-]$} & $f_{\text {PPgrz_Subpolar }}=1-f_{\text {PPsink_Subpolar }}$ & \\
\hline & CZ TEP & 0.700 & {$[-]$} & $f_{\text {PPgrz Temperate }}=1-f_{\text {PPsink }}$ Temperate & \\
\hline & CZ STR & 0.775 & {$[-]$} & $f_{\mathrm{PPgrz}}$ Subtropical $=1-f_{\mathrm{PP} \text { sink }}$ Subtropical & \\
\hline & CZ TRO & 0.850 & {$[-]$} & $f_{\mathrm{PPgz} \text { Tropical }}=1-f_{\mathrm{PPsink} \text { Tropical }}$ & \\
\hline$f_{\text {SPingest }}$ & GLO & 0.643 & {$[-]$} & $\begin{array}{l}\text { Møller and Nielsen (2001); Møller (2007); Saba } \\
\text { et al. (2011) }\end{array}$ & $\begin{array}{l}\text { Averaged fraction of grazed biomass ingested and } \\
\text { not lost by sloppy feeding }\end{array}$ \\
\hline \multirow{5}{*}{$f_{\text {SPassimil }}$} & CZ POL & 0.300 & {$[-]$} & Besiktepe and Dam (2002) & Assimilation efficiency: diet mainly diatoms \\
\hline & CZ SPO & 0.500 & {$[-]$} & Average $\left(f_{\text {SPassimil Polar }}, f_{\text {SPassimil Temperate }}\right)$ & Assimilation efficiency: average $\uparrow$ \\
\hline & CZ TEP & 0.700 & {$[-]$} & Besiktepe and Dam (2002) & Assimilation efficiency: diet mainly flagellates \\
\hline & CZ STR & 0.800 & {$[-]$} & Average $\left(f_{\text {sPassimil_Temperate }}, f_{\text {SPassimil_Tropical }}\right)$ & Assimilation efficiency: average $\uparrow$ \\
\hline & CZ TRO & 0.900 & {$[-]$} & Besiktepe and Dam (2002) & Assimilation efficiency: diet mainly cilliates \\
\hline \multirow{5}{*}{$f_{\text {SPegest }}$} & CZ POL & 0.700 & {$[-]$} & \multirow{5}{*}{$\begin{array}{l}f_{\text {SPegest Polar }}=1-f_{\text {SPassimil Polar }} \\
f_{\text {SPegest Subpolar }}=1-f_{\text {SPassimil Subpolar }} \\
f_{\text {SPegest Temperate }}=1-f_{\text {SPassimil Temperate }} \\
f_{\text {SPegest_Subtropical }}=1-f_{\text {SPassimil_Subtropical }} \\
f_{\text {SPegest Tropical }}=1-f_{\text {SPassimil Tropical }}\end{array}$} & \multirow{5}{*}{ Fraction of organic carbon egested by SP } \\
\hline & CZ SPO & 0.500 & {$[-]$} & & \\
\hline & CZ TEP & 0.300 & {$[-]$} & & \\
\hline & CZ STR & 0.200 & {$[-]$} & & \\
\hline & CZ TRO & 0.100 & {$[-]$} & & \\
\hline \multirow{5}{*}{$f_{\mathrm{AVTgrz}}$} & CZ POL & 0.033 & {$[-]$} & $f_{\text {AVTgrz_Polar }}=0.10 * f_{\text {PPgrz_Polar }}$ & \multirow{5}{*}{$\begin{array}{l}\text { Fraction of organic carbon transported by AVT } \\
\text { Assumed } 10 \% \text { of the euphotic zone grazing pressure } \\
\text { is made by emergent zooplankton }\end{array}$} \\
\hline & CZ SPO & 0.052 & {$[-]$} & $f_{\text {AVTgrz Subpolar }}=0.10 * f_{\text {PPgrz_Subpolar }}$ & \\
\hline & CZ TEP & 0.070 & {$[-]$} & $f_{\text {AVTgrz_Temperate }}=0.10 * f_{\text {PPgrz_Temperate }}$ & \\
\hline & CZ STR & 0.078 & {$[-]$} & $f_{\text {AVTgrz Subtropical }}=0.10 * f_{\text {PPgrz Subtropical }}$ & \\
\hline & CZ TRO & 0.085 & {$[-]$} & $f_{\mathrm{AVTgrz}}$ Tropical $=0.10 * f_{\mathrm{pPgrz} \text { Tropical }}$ & \\
\hline \multirow{5}{*}{$f_{\text {PPsinkGZ }}$} & CZ POL & 0.101 & {$[-]$} & $f_{\text {PPsinkGZ Polar }}=0.15 * f_{\text {PPsink_Polar }}$ & \multirow{5}{*}{$\begin{array}{l}\text { Fraction of the PP biomass that is consumed during } \\
\text { sink }\end{array}$} \\
\hline & CZ SPO & 0.073 & {$[-]$} & \multirow{4}{*}{$\begin{array}{l}f_{\text {PPsinkGZ_Subpolar }}=0.15 * f_{\text {PPsink_Subpolar }} \\
f_{\text {PPsinkGZ Temperate }}=0.15 * f_{\text {PPsink Temperate }} \\
f_{\text {PPsinkGZ Subtropical }}=0.15 * f_{\text {PPsink_Subtropical }} \\
f_{\text {PPsinkGZ Tropical }}=0.15 * f_{\text {PPsink Tropical }}\end{array}$} & \\
\hline & CZ TEP & 0.045 & {$[-]$} & & \\
\hline & CZ STR & 0.034 & {$[-]$} & & \\
\hline & CZ TRO & 0.023 & {$[-]$} & & \\
\hline & CZ POL & 0.900 & {$[-]$} & $f_{\text {PPsinkNG_Polar }}=1-f_{\text {PPsinkGZ_Polar }}$ & \multirow{5}{*}{ Fraction of the sinking PP biomass that is not grazed } \\
\hline & CZ SPO & 0.927 & {$[-]$} & $f_{\text {PPsinkNG Subpolar }}=1-f_{\text {PPsinkGZ Subpolar }}$ & \\
\hline$f_{\text {PPsinkNG }}$ & CZ TEP & 0.955 & {$[-]$} & $f_{\text {PPsinkNG_Temperate }}=1-f_{\text {PPsinkGZ_Temperate }}$ & \\
\hline & CZ STR & 0.966 & {$[-]$} & $f_{\text {PPsinkNG_Subtropical }}=1-f_{\text {PPsinkGZ_Subtropical }}$ & \\
\hline & CZ TRO & 0.978 & {$[-]$} & $f_{\mathrm{PPSinkNG} \text { Tropical }}=1-f_{\mathrm{PPsinkGZ} \text { Tropical }}$ & \\
\hline$f_{\text {FPleach }}$ & GLO & 0.280 & {$[-]$} & Møller et al. (2003) & Fraction of organic carbon leached from SP f.p. \\
\hline & $\mathrm{CZ}$ POL & 0.007 & {$[-]$} & $f_{\text {FPSinkGZ Polar }}=0.20 * f_{\text {PPsinkGZ_Polar }}$ & \\
\hline & CZ SPO & 0.010 & {$[-]$} & $f_{\text {FPsinkG__Subpolar }}=0.20 * f_{\text {PPsinkGZ_Subpolar }}$ & \\
\hline$f_{\mathrm{FPsinkGZ}}$ & CZ TEP & 0.014 & {$[-]$} & $f_{\text {FPsinkGZ_Temperate }}=0.20 * f_{\text {PPsinkGZ_Temperate }}$ & Grazing pressure on faecal pellets is $20 \%$ of that of \\
\hline & CZ STR & 0.016 & {$[-]$} & $f_{\text {FPsinkGZ Subtropical }}=0.20 * f_{\text {PPsinkGZ Subtropical }}$ & \\
\hline & CZ TRO & 0.017 & {$[-]$} & $f_{\text {EPSinkGZ_Tropical }}=0.20 * f_{\text {PPsinkGZ_Tropical }}$ & \\
\hline & CZ POL & 0.715 & {$[-]$} & $f_{\text {FPsinkNG_Polar }}=\left(1-f_{\text {FPleach }}\right) *\left(1-f_{\text {FPsinkGZ_Polar }}\right)$ & \\
\hline & CZ SPO & 0.713 & {$[-]$} & $f_{\text {FPsinkNG_Subpolar }}=\left(1-f_{\text {FPleach }}\right) *\left(1-f_{\text {FPsinkG__Subpolar }}\right)$ & \\
\hline$f_{\text {FPsinkNG }}$ & CZ TEP & 0.710 & {$[-]$} & $f_{\text {FPsinkNG Temperate }}=\left(1-f_{\text {FPleach }}\right) *\left(1-f_{\text {FPsinkGZ Temperate }}\right)$ & Fraction of organic carbon sinking as faecal pellets \\
\hline & CZ STR & 0.709 & {$[-]$} & $f_{\text {FPsinkNG_Subtropical }}=\left(1-f_{\text {FPleach }}\right) *\left(1-f_{\text {FPsinkG__Subtropical }}\right)$ & \\
\hline & CZ TRO & 0.708 & {$[-]$} & $f_{\text {FPsinkNG Tropical }}=\left(1-f_{\text {FPleach }}\right) *\left(1-f_{\text {FPsinkGZ Tropical }}\right)$ & \\
\hline$f_{\text {sPmort }}$ & GLO & 0.290 & {$[-]$} & Hirst and Kiørboe (2002) & Fraction of predation mortality defining SP carcasses \\
\hline$Z_{\text {mean }}$ & GLO & 100 & [m] & Mean depth of continental shelf & Continental shelf depth assumed as $200 \mathrm{~m}$ \\
\hline$Z_{\mathrm{AVT}}$ & GLO & 20 & {$[\mathrm{~m}]$} & Atkinson et al. (1992); Puelles et al. (1996) & Vertical distance covered by diel migrant copepods \\
\hline$Z_{\text {photic }}$ & LME & $12 \leftrightarrow 68$ & {$[\mathrm{~m}]$} & Longhurst (1998) & LME photic depth adapted from Longhurst provinces \\
\hline$Z_{\text {aphotic }}$ & LME & $32 \leftrightarrow 88$ & {$[\mathrm{~m}]$} & $Z_{\text {aphotic LME }}=Z_{\text {mean }}-Z_{\text {photic LLME }}$ & Height of aphotic zone \\
\hline$U_{\mathrm{PP}}$ & GLO & 150 & {$\left[\mathrm{~m} \cdot \mathrm{d}^{-1}\right]$} & Turner $(2002)$ & Sinking velocity of phytodetritus + PP marine snow \\
\hline$U_{\mathrm{SP}}$ & GLO & 200 & {$\left[\mathrm{~m} \cdot \mathrm{d}^{-1}\right]$} & Turner (2002) & Sinking velocity of marine snow + SP f.p. \\
\hline$f_{\text {BRmarsnow }}$ & GLO & 0.130 & {$\left[\mathrm{~d}^{-1}\right]$} & Iversen and Ploug (2010) & Bacterial respiration rate on sinking marine snow \\
\hline$f_{\text {BRsinkSPaphotic. }}$ & LME & $0.021 \leftrightarrow 0.051$ & {$[-]$} & $f_{\mathrm{BRs} \text { sinkSPaphotic LMME }}=f_{\mathrm{BR} \text { marsnow }} U_{\mathrm{SP}} *\left(Z_{\text {mean }} Z_{\text {photic LLME }}\right)$ & BR rate on sinking f.p. egested in the aphotic zone \\
\hline$f_{\text {BRsinkPP }}$ & GLO & 0.087 & {$[-]$} & $f_{\mathrm{BRSinkPP}}=f_{\mathrm{BRmarsnow}} / \mathrm{U}_{\mathrm{PP}} * \mathrm{Z}_{\mathrm{meanLME}}$ & Respiration of sinking organic carbon from PP \\
\hline$f_{\mathrm{BRSinkSP}}$ & GLO & 0.065 & {$[-]$} & $f_{\mathrm{BRS} \text { sinkSP}}=f_{\mathrm{BRm}}$ & Respiration of sinking organic carbon from SP \\
\hline$B G E$ & LME & $0.039 \leftrightarrow 0.464$ & {$[-]$} & Cole et al.(1988); del Giorgio and Cole (1998) & Bacterial Growth Efficiency \\
\hline$f_{\text {BRbott }}$ & LME & $0.536 \leftrightarrow 0.961$ & {$[-]$} & $f_{\text {BRbott_LME }}=1-B G E_{\text {LME }}$ & Fraction of organic carbon respired at the bottom \\
\hline
\end{tabular}

Legend (GLO) Global, (CZ) Climate Zone, (POL (Polar), (SPO) Subpolar, (TEP) Temperate, (STR) Subtropical, (TRO) Tropical, (PP) Primary Producers, (SP) Secondary Producers, (M) Molar Mass, (C) Carbon, (O) Oxygen, (N) Nitrogen, (LME) Large Marine Ecosystem, (AVT) Active Vertical Transport, (f.p.) faecal pellets, (BR) Bacterial Respiration. 


\section{S.2.3. Estimation of zooplankton ingestion fractions}

The parameter $f_{\text {SPingest }}$ was estimated as to be $64.25 \%$ (Table S.2) of the phytoplankton grazed biomass. This value is the mean ingestion fraction of different diets and estimation methods compiled for the coastal planktonic copepod by Møller and Nielsen (2001), Møller (2007), and Saba et al. (2011, 2009).

Table S.2 Estimation of mean ingestion rate (dimensionless) from different data sources.

\begin{tabular}{|c|c|c|c|c|}
\hline Specific experimental conditions & $\begin{array}{c}\text { Ingestion rate } \\
{[-]}\end{array}$ & \multicolumn{2}{|c|}{$\begin{array}{l}\text { Average ingestion rate } \\
{[-]}\end{array}$} & Source \\
\hline Acartia tonsa feeding on Heterocapsa rotundata & 0.85 & \multirow{2}{*}{0.77} & \multirow{6}{*}{0.64} & Møller (2007) \\
\hline Acartia tonsa feeding on Ditylum brightwelli & 0.69 & & & Møller (2007) \\
\hline Acartia tonsa feeding on Ditylum brightwelli (RFS method) & 0.46 & \multirow{4}{*}{0.40} & & Møller and Nielsen (2001) \\
\hline Acartia tonsa feeding on Ditylum brightwelli (egg production method) & 0.31 & & & Møller and Nielsen (2001) \\
\hline Acartia tonsa feeding on Ceratium lineatum (RFS method) & 0.41 & & & Møller and Nielsen (2001) \\
\hline Acartia tonsa feeding on Ceratium lineatum (egg production method) & 0.41 & & & Møller and Nielsen (2001) \\
\hline Acartia tonsa feeding on Thalassiosira weissflogii & 0.97 & \multirow{4}{*}{0.76} & & Saba et al. (2011) \\
\hline Acartia tonsa feeding on Thalassiosira weissflogii (ESD-ratios method) & 0.69 & & & Saba et al. (2009) \\
\hline Acartia tonsa feeding on Oxyrrhis marina (ESD-ratios method) & 0.66 & & & Saba et al. (2009) \\
\hline Acartia tonsa feeding on Gyrodinium dominans (ESD-ratios method) & 0.72 & & & Saba et al. (2009) \\
\hline
\end{tabular}

Legend (RFS) Removed From Suspension, (ESD) Equivalent Spherical Diameter. 


\section{S.3 Extended and additional results}

\section{S.3.1 Contributions from sinking routes}

Table S.3 shows the relative contributions of each sinking route to the export production $\left(P_{\mathrm{E}}\right)$ and XF grouped into climate zones and Table S.4 the full results per LME.

The relative contributions (in percentage) of organic carbon to the total $P_{\mathrm{E}}$ and to $\mathrm{XF}$ are consistently higher in route 1 and increase towards higher latitudes, as do the PP-SP mismatch and biomass sinking $\left(f_{P \text { Psink_CZ }}\right)$. Route 2 increases its contribution to $P_{\mathrm{E}}$ and XF towards mid-low-latitudes due to the combination of $f_{P P g r z} C Z$ (increasing towards low latitudes) and $f_{\text {SPegest_CZ }}$ (increasing towards high latitudes). Contributions from route 3 decrease towards high latitudes as less PP biomass is grazed $\left(f_{P P g r z} C z\right)$. The contribution to $P_{\mathrm{E}}$ by route 4 is also correlated to the mismatch fraction but not the contribution to XF as a result of the mixed grazing on all types of sinking organic material (aggregates, faecal pellets, and carcasses) after export. Other minor discrepancies originate from site-dependent grazing pressures on sinking POC, as the XF modelling extends to include the loss processes below the photic depth that act on $P_{\mathrm{E}}$ (consumption, leaching, and respiration).

Table S.3 Extended contributions (in \%) of the four carbon export routes to total export production $\left(P_{\mathrm{E}}\right)$ and exposure factor (XF), per climate zone. The linear correlation coefficient $(r)$ and significance level $(p)$ between the relative contribution of each route per climate zone and the PP-SP mismatch fraction $\left(f_{P P s i n k_{-} C Z}\right)$ are also included. Route 1: sinking from primary production (PP) biomass; route 2: sinking as faecal pellets (f.p.) from secondary producers (SP); route 3: sinking carcasses (carc.) of SP; route 4: active vertical transport (AVT) via diel vertical migration of SP.

\begin{tabular}{|c|c|c|c|c|c|c|c|c|c|}
\hline \multirow{3}{*}{$\begin{array}{l}\text { Climate zone } \\
\text { [name (nr. of LMEs)] } \\
\text { Polar (12) }\end{array}$} & \multicolumn{8}{|c|}{ Source of contribution to $P_{\mathrm{E}}$ and to XF (mean \%) } & \multirow{3}{*}{$\begin{array}{r}\text { PP-SP mismatch } \\
f_{\text {PPsink_CZ }} \\
0.67\end{array}$} \\
\hline & \multicolumn{2}{|c|}{ Route 1 (PP) } & \multicolumn{2}{|c|}{ Route 2 (SP f.p.) } & \multicolumn{2}{|c|}{ Route 3 (SP carc.) } & \multicolumn{2}{|c|}{ Route 4 (AVT) } & \\
\hline & 81.3 & 81.9 & 15.1 & 11.9 & 1.0 & 3.9 & 2.6 & 5.2 & \\
\hline Subpolar (11) & 71.7 & 69.0 & 19.6 & 16.4 & 3.8 & 5.3 & 4.9 & 10.4 & 0.49 \\
\hline Temperate (14) & 56.4 & 55.8 & 30.1 & 26.7 & 5.0 & 6.1 & 8.5 & 11.5 & 0.30 \\
\hline Subtropical (12) & 51.9 & 56.0 & 32.3 & 29.9 & 4.3 & 4.6 & 11.5 & 8.8 & 0.23 \\
\hline Tropical (17) & 48.2 & 56.7 & 28.3 & 28.0 & 5.9 & 1.9 & 17.6 & 7.5 & 0.15 \\
\hline Global (66) & 60.6 & 63.0 & 25.6 & 23.2 & 4.2 & 5.2 & 9.7 & 8.6 & (wt) 0.35 \\
\hline Correlation $(r)$ with $f_{\text {PPsink_CZ }}$ & 1.00 & 0.96 & -0.92 & -0.97 & -0.93 & 0.26 & -0.93 & -0.39 & \\
\hline Significance $(p) ; n=5$ & 0.0006 & 0.0002 & 0.002 & 0.004 & 0.02 & 0.005 & 0.03 & 0.002 & \\
\hline
\end{tabular}


Table S.4 Extended results table of the estimation of export production $\left(P_{\mathrm{E}}\right)$ and exposure factor (XF), including specific datasets used for the model parameterisation: primary production (PP) dataset from http://www.seaaroundus.org, photic depth data from Longhurst (1998), and Primary Production Required (PPR) to sustain reported fisheries per LME (used to estimate the fraction of biomass of secondary producers consumed by planktivorous fish, $f_{\text {plfish_LME }}$ ) from Pauly and Christensen (1995) and UBC (1999). Contributions to $P_{\mathrm{E}}$ and XF per LME are also included.

\begin{tabular}{|c|c|c|c|c|c|c|c|c|c|c|c|c|c|c|c|c|c|}
\hline \multirow{2}{*}{$\begin{array}{l}\text { Large Marine Ecosystem } \\
\text { [\#. name] }\end{array}$} & \multirow{2}{*}{$\begin{array}{l}\text { Climate zone } \\
\text { [name] }\end{array}$} & \multicolumn{3}{|c|}{ PP PP $P_{\text {Pot_LME }} Z_{\text {photic_LME }}$} & \multirow{2}{*}{$f$ of $Z_{\text {aphotic }}$} & \multicolumn{2}{|c|}{$\mathrm{BR}_{\text {sinkaphotic }} \mathrm{PPR}_{\text {LME }}(2006)$} & $P_{\mathrm{E}}$ & & ontributi & tion to $P_{t}$ & & $\mathrm{XF}_{\text {LME }}$ & Cont & tribution & on to $\mathrm{XF}_{\mathrm{LN}}$ & \\
\hline & & {$\left[\mathrm{gC} \cdot \mathrm{m}^{-2} \cdot \mathrm{yr}^{-1}\right]$} & {$[-]$} & {$[\mathrm{m}]$} & & {$[-]$} & & {$\left[\mathrm{gC} \cdot \mathrm{m}^{-2} \cdot \mathrm{yr}^{-1}\right]$} & $\begin{array}{ll}\text { R1 [\%] } \\
\end{array}$ & R2 [\%] & R3 [\%] & $\mathrm{R} 4[\%]$ & {$\left[\mathrm{kgO}_{2} \cdot \mathrm{kgN}^{-1}\right]$} & R1 [\%] & R2 [\%] & R3 [\%] & $\mathrm{R} 4[\%]$ \\
\hline 18. Canadian Eastern Arctic - West Greenland & Polar & 151.9 & 0.59 & 16.3 & 0.239 & 0.054 & 0.093 & 125.4 & 81.2 & 15.5 & 0.7 & 2.6 & 6.80 & 80.7 & 12.3 & 0.7 & 6.3 \\
\hline 19. Greenland Sea & Polar & 174.2 & 0.68 & 16.3 & 0.239 & 0.054 & 1.000 & 130.9 & 89.2 & 0.0 & 8.0 & 2.8 & 7.25 & 84.3 & 0.0 & 8.5 & 7.3 \\
\hline 20. Barents Sea & Polar & 151.2 & 0.59 & 33.8 & 0.302 & 0.043 & 0.384 & 120.0 & 84.4 & 10.0 & 2.9 & 2.7 & 7.05 & 82.5 & 7.8 & 3.1 & 6.6 \\
\hline 54. Northern Bering - Chukchi Seas & Polar & 90.9 & 0.35 & 34.8 & 0.307 & 0.042 & 0.001 & 76.1 & 80.1 & 17.3 & 0.0 & 2.5 & 4.57 & 81.8 & 13.6 & 0.0 & 4.5 \\
\hline 55. Beaufort Sea & Polar & 119.1 & 0.46 & 34.8 & 0.307 & 0.042 & 0.000 & 99.6 & 80.1 & 17.4 & 0.0 & 2.5 & 5.87 & 80.9 & 13.7 & 0.0 & 5.4 \\
\hline 56. East Siberian Sea & Polar & 54.4 & 0.21 & 34.8 & 0.307 & 0.042 & 0.002 & 45.5 & 80.1 & 17.3 & 0.0 & 2.5 & 2.81 & 83.1 & 13.6 & 0.0 & 3.3 \\
\hline 57. Laptev Sea & Polar & 156.7 & 0.61 & 34.8 & 0.307 & 0.042 & 0.001 & 131.0 & 80.1 & 17.3 & 0.0 & 2.5 & 7.54 & 79.7 & 13.7 & 0.0 & 6.6 \\
\hline 58. Kara Sea & Polar & 126.7 & 0.49 & 34.8 & 0.307 & 0.042 & 0.000 & 106.0 & 80.1 & 17.4 & 0.0 & 2.5 & 6.22 & 80.7 & 13.7 & 0.0 & 5.6 \\
\hline 61. Antarctic & Polar & 99.7 & 0.39 & 26.5 & 0.272 & 0.048 & 0.000 & 83.4 & 80.1 & 17.4 & 0.0 & 2.5 & 4.91 & 81.6 & 13.7 & 0.0 & 4.7 \\
\hline 63. Hudson Bay Complex & Polar & 152.7 & 0.59 & 18.0 & 0.244 & 0.053 & 0.001 & 127.7 & 80.1 & 17.3 & 0.0 & 2.5 & 6.96 & 80.0 & 13.8 & 0.0 & 6.2 \\
\hline 64. Central Arctic Ocean & Polar & 8.4 & 0.03 & 34.8 & 0.307 & 0.042 & 0.001 & 7.0 & 80.1 & 17.4 & 0.0 & 2.5 & 0.45 & 84.5 & 13.6 & 0.0 & 1.9 \\
\hline 66. Canadian High Arctic - North Greenland & Polar & 58.8 & 0.23 & 34.8 & 0.307 & 0.042 & 0.029 & 49.0 & 80.4 & 16.8 & 0.2 & 2.5 & 2.99 & 83.1 & 13.2 & 0.2 & 3.5 \\
\hline 01. East Bering Sea & Subpolar & 285.6 & 1.11 & 28.1 & 0.278 & 0.047 & 0.153 & 196.4 & 70.5 & 22.6 & 2.1 & 4.8 & 9.86 & 68.7 & 18.8 & 2.4 & 10.1 \\
\hline 02. Gulf of Alaska & Subpolar & 330.9 & 1.28 & 28.8 & 0.281 & 0.046 & 0.142 & 228.1 & 70.4 & 22.9 & 1.9 & 4.8 & 11.15 & 67.2 & 19.2 & 2.2 & 11.4 \\
\hline 09. Newfoundland-Labrador Shelf & Subpolar & 295.5 & 1.15 & 29.1 & 0.282 & 0.046 & 0.072 & 206.6 & 69.4 & 24.9 & 1.0 & 4.7 & 10.28 & 67.7 & 20.9 & 1.1 & 10.3 \\
\hline 21. Norwegian Sea & Subpolar & 179.3 & 0.70 & 28.3 & 0.279 & 0.047 & 0.682 & 113.0 & 76.9 & 7.8 & 10.0 & 5.2 & 6.35 & 75.3 & 6.1 & 11.0 & 7.6 \\
\hline 23. Baltic Sea & Subpolar & 697.6 & 2.71 & 12.0 & 0.227 & 0.057 & 0.102 & 484.8 & 69.8 & 24.1 & 1.4 & 4.8 & 15.94 & 55.1 & 21.7 & 1.7 & 21.5 \\
\hline 51. Oyashio Current & Subpolar & 261.5 & 1.01 & 31.9 & 0.294 & 0.044 & 0.192 & 178.5 & 71.1 & 21.5 & 2.6 & 4.8 & 9.25 & 69.7 & 17.7 & 3.0 & 9.6 \\
\hline 52. Sea of Okhotsk & Subpolar & 297.7 & 1.16 & 28.1 & 0.278 & 0.047 & 0.309 & 198.7 & 72.7 & 18.1 & 4.3 & 5.0 & 10.01 & 69.6 & 14.9 & 4.9 & 10.6 \\
\hline 53. West Bering Sea & Subpolar & 214.0 & 0.83 & 28.1 & 0.278 & 0.047 & 0.103 & 148.7 & 69.8 & 24.1 & 1.4 & 4.8 & 7.80 & 70.4 & 19.9 & 1.6 & 8.2 \\
\hline 59. Iceland Shelf and Sea & Subpolar & 201.3 & 0.78 & 25.0 & 0.267 & 0.049 & 0.074 & 140.7 & 69.4 & 24.9 & 1.0 & 4.7 & 7.34 & 70.5 & 20.6 & 1.1 & 7.7 \\
\hline 60. Faroe Plateau & Subpolar & 154.1 & 0.60 & 33.8 & 0.302 & 0.043 & 1.000 & 94.2 & 79.4 & 0.0 & 15.2 & 5.4 & 5.58 & 76.7 & 0.0 & 16.2 & 7.1 \\
\hline 65. Aleutian Islands & Subpolar & 285.6 & 1.11 & 28.1 & 0.278 & 0.047 & 0.076 & 199.5 & 69.4 & 24.8 & 1.0 & 4.7 & 9.96 & 68.0 & 20.8 & 1.2 & 10.0 \\
\hline 03. California Current & Temperate & 223.9 & 0.87 & 34.3 & 0.305 & 0.043 & 0.141 & 120.8 & 55.6 & 32.8 & 3.3 & 8.3 & 6.09 & 58.8 & 28.6 & 3.9 & 8.7 \\
\hline 07. Northeast U.S. Continental Shelf & Temperate & 561.0 & 2.18 & 29.1 & 0.282 & 0.046 & 0.136 & 303.0 & 55.5 & 33.0 & 3.1 & 8.3 & 12.22 & 49.9 & 30.3 & 4.0 & 15.7 \\
\hline 08. Scotian Shelf & Temperate & 509.5 & 1.98 & 29.1 & 0.282 & 0.046 & 0.060 & 280.6 & 54.5 & 36.0 & 1.4 & 8.2 & 11.57 & 50.8 & 33.1 & 1.7 & 14.4 \\
\hline 13. Humboldt Current & Temperate & 320.0 & 1.24 & 43.6 & 0.355 & 0.037 & 0.180 & 170.9 & 56.2 & 31.2 & 4.2 & 8.4 & 8.38 & 56.5 & 27.4 & 5.1 & 11.0 \\
\hline 14. Patagonian Shelf & Temperate & 509.5 & 1.98 & 31.4 & 0.292 & 0.045 & 0.182 & 272.1 & 56.2 & 31.2 & 4.2 & 8.4 & 11.50 & 51.7 & 28.3 & 5.3 & 14.7 \\
\hline 22. North Sea & Temperate & 407.3 & 1.58 & 22.8 & 0.259 & 0.050 & 0.340 & 209.8 & 58.2 & 24.8 & 8.2 & 8.7 & 9.11 & 55.7 & 21.8 & 10.1 & 12.4 \\
\hline 24. Celtic-Biscay Shelf & Temperate & 349.2 & 1.35 & 22.8 & 0.259 & 0.050 & 0.314 & 180.9 & 57.9 & 25.9 & 7.5 & 8.7 & 8.15 & 57.1 & 22.6 & 9.2 & 11.2 \\
\hline 25. Iberian Coastal & Temperate & 276.9 & 1.07 & 45.0 & 0.364 & 0.036 & 0.248 & 145.6 & 57.1 & 28.5 & 5.9 & 8.6 & 7.38 & 58.0 & 24.7 & 7.1 & 10.2 \\
\hline 42. Southeast Australian Shelf & Temperate & 187.0 & 0.73 & 44.1 & 0.358 & 0.036 & 0.012 & 104.3 & 53.8 & 37.9 & 0.3 & 8.1 & 5.41 & 58.3 & 33.3 & 0.3 & 8.1 \\
\hline 43. Southwest Australian Shelf & Temperate & 180.8 & 0.70 & 47.2 & 0.379 & 0.034 & 0.011 & 100.9 & 53.8 & 38.0 & 0.2 & 8.1 & 5.28 & 58.4 & 33.3 & 0.3 & 8.0 \\
\hline 46. New Zealand Shelf & Temperate & 208.2 & 0.81 & 36.3 & 0.314 & 0.041 & 0.211 & 110.4 & 56.6 & 30.0 & 5.0 & 8.5 & 5.69 & 59.7 & 25.9 & 5.9 & 8.5 \\
\hline 48. Yellow Sea & Temperate & 589.1 & 2.29 & 29.8 & 0.285 & 0.046 & 0.714 & 284.4 & 62.2 & 10.1 & 18.4 & 9.3 & 12.02 & 51.8 & 8.8 & 22.3 & 17.1 \\
\hline 50. Sea of Japan/East Sea & Temperate & 220.6 & 0.86 & 36.3 & 0.314 & 0.041 & 0.293 & 114.8 & 57.6 & 26.7 & 7.0 & 8.6 & 5.92 & 60.0 & 22.9 & 8.3 & 8.8 \\
\hline 62. Black Sea & Temperate & 376.6 & 1.46 & 21.3 & 0.254 & 0.051 & 0.067 & 207.1 & 54.6 & 35.7 & 1.5 & 8.2 & 8.83 & 54.5 & 32.2 & 1.9 & 11.4 \\
\hline 04. Gulf of California & Subtropical & 437.9 & 1.70 & 34.3 & 0.305 & 0.043 & 0.032 & 191.8 & 51.4 & 36.3 & 1.0 & 11.4 & 7.97 & 52.6 & 34.9 & 1.3 & 11.2 \\
\hline 05. Gulf of Mexico & Subtropical & 208.2 & 0.81 & 44.8 & 0.362 & 0.036 & 0.048 & 90.9 & 51.5 & 35.6 & 1.5 & 11.4 & 4.49 & 57.6 & 32.6 & 1.9 & 7.9 \\
\hline 06. Southeast U.S. Continental Shelf & Subtropical & 263.3 & 1.02 & 29.1 & 0.282 & 0.046 & 0.020 & 115.6 & 51.3 & 36.8 & 0.6 & 11.3 & 5.26 & 56.7 & 34.3 & 0.8 & 8.2 \\
\hline 15. South Brazil Shelf & Subtropical & 283.1 & 1.10 & 44.9 & 0.363 & 0.036 & 0.036 & 123.9 & 51.4 & 36.1 & 1.1 & 11.4 & 5.84 & 56.0 & 33.5 & 1.5 & 9.1 \\
\hline 26. Mediterranean & Subtropical & 157.8 & 0.61 & 37.2 & 0.318 & 0.041 & 0.157 & 67.8 & 52.4 & 31.0 & 5.0 & 11.6 & 3.45 & 59.0 & 27.8 & 6.3 & 6.9 \\
\hline 27. Canary Current & Subtropical & 436.8 & 1.70 & 28.7 & 0.281 & 0.046 & 0.116 & 188.8 & 52.1 & 32.8 & 3.7 & 11.5 & 7.73 & 52.9 & 31.2 & 4.9 & 11.0 \\
\hline 29. Benguela Current & Subtropical & 506.6 & 1.97 & 41.9 & 0.344 & 0.038 & 0.088 & 219.9 & 51.8 & 33.9 & 2.8 & 11.5 & 9.09 & 50.8 & 32.7 & 3.7 & 12.8 \\
\hline 30. Agulhas Current & Subtropical & 221.0 & 0.86 & 49.1 & 0.393 & 0.033 & 0.049 & 96.5 & 51.5 & 35.5 & 1.5 & 11.4 & 4.76 & 57.3 & 32.6 & 2.0 & 8.2 \\
\hline 41. East-Central Australian Shelf & Subtropical & 157.4 & 0.61 & 44.8 & 0.362 & 0.036 & 0.009 & 69.2 & 51.2 & 37.2 & 0.3 & 11.3 & 3.51 & 58.6 & 34.0 & 0.4 & 7.1 \\
\hline 44. West-Central Australian Shelf & Subtropical & 173.9 & 0.67 & 47.2 & 0.379 & 0.034 & 0.010 & 76.4 & 51.2 & 37.2 & 0.3 & 11.3 & 3.85 & 58.2 & 34.0 & 0.4 & 7.4 \\
\hline 47. East China Sea & Subtropical & 325.4 & 1.26 & 29.8 & 0.285 & 0.046 & 0.844 & 133.5 & 54.9 & 4.8 & 28.2 & 12.1 & 6.45 & 53.5 & 4.1 & 33.5 & 9.0 \\
\hline 49. Kuroshio Current & Subtropical & 154.1 & 0.60 & 36.3 & 0.314 & 0.041 & 0.169 & 66.1 & 52.5 & 30.5 & 5.4 & 11.6 & 3.37 & 59.1 & 27.3 & 6.7 & 6.8 \\
\hline 10. Insular Pacific-Hawaiian & Tropical & 84.7 & 0.33 & 68.0 & 0.625 & 0.021 & 0.006 & 26.1 & 48.7 & 33.3 & 0.3 & 17.7 & 1.33 & 60.6 & 31.7 & 0.4 & 7.3 \\
\hline 11. Pacific Central-American & Tropical & 244.0 & 0.95 & 39.6 & 0.331 & 0.039 & 0.049 & 75.3 & 48.6 & 31.3 & 2.4 & 17.7 & 3.33 & 58.0 & 31.2 & 3.3 & 7.4 \\
\hline 12. Caribbean Sea & Tropical & 174.6 & 0.68 & 44.8 & 0.362 & 0.036 & 0.026 & 53.8 & 48.7 & 32.4 & 1.3 & 17.7 & 2.51 & 59.5 & 31.8 & 1.7 & 6.9 \\
\hline 16. East Brazil Shelf & Tropical & 130.4 & 0.51 & 44.9 & 0.363 & 0.036 & 0.049 & 40.3 & 48.6 & 31.4 & 2.4 & 17.7 & 1.94 & 60.0 & 30.4 & 3.2 & 6.4 \\
\hline 17. North Brazil Shelf & Tropical & 442.3 & 1.72 & 38.7 & 0.326 & 0.040 & 0.038 & 136.5 & 48.6 & 31.9 & 1.8 & 17.7 & 5.26 & 54.2 & 33.4 & 2.7 & 9.8 \\
\hline 28. Guinea Current & Tropical & 357.9 & 1.39 & 27.0 & 0.274 & 0.047 & 0.051 & 110.5 & 48.6 & 31.3 & 2.5 & 17.7 & 4.31 & 56.0 & 32.2 & 3.5 & 8.3 \\
\hline 31. Somali Coastal Current & Tropical & 249.5 & 0.97 & 39.5 & 0.330 & 0.039 & 0.012 & 76.9 & 48.7 & 33.0 & 0.6 & 17.7 & 3.36 & 58.5 & 33.2 & 0.8 & 7.5 \\
\hline 32. Arabian Sea & Tropical & 390.5 & 1.52 & 39.3 & 0.329 & 0.039 & 0.173 & 121.7 & 48.1 & 26.0 & 8.3 & 17.5 & 4.99 & 53.3 & 26.2 & 11.6 & 8.8 \\
\hline 33. Red Sea & Tropical & 298.4 & 1.16 & 33.7 & 0.302 & 0.043 & 0.082 & 92.3 & 48.5 & 29.9 & 4.0 & 17.6 & 3.89 & 56.6 & 30.1 & 5.6 & 7.8 \\
\hline 34. Bay of Bengal & Tropical & 265.2 & 1.03 & 40.0 & 0.334 & 0.039 & 0.199 & 82.8 & 48.0 & 25.0 & 9.5 & 17.5 & 3.71 & 55.4 & 24.3 & 12.9 & 7.4 \\
\hline 35. Gulf of Thailand & Tropical & 284.9 & 1.11 & 38.6 & 0.326 & 0.040 & 0.412 & 91.1 & 46.9 & 16.7 & 19.3 & 17.1 & 4.17 & 51.8 & 15.8 & 25.3 & 7.2 \\
\hline 36. South China Sea & Tropical & 174.2 & 0.68 & 34.2 & 0.304 & 0.043 & 0.389 & 55.6 & 47.0 & 17.5 & 18.3 & 17.1 & 2.70 & 54.2 & 16.3 & 23.5 & 6.0 \\
\hline 37. Sulu-Celebes Sea & Tropical & 209.3 & 0.81 & 38.6 & 0.326 & 0.040 & 0.368 & 66.6 & 47.2 & 18.3 & 17.3 & 17.2 & 3.18 & 53.9 & 17.1 & 22.5 & 6.5 \\
\hline 38. Indonesian Sea & Tropical & 263.7 & 1.02 & 38.6 & 0.326 & 0.040 & 0.206 & 82.4 & 48.0 & 24.7 & 9.8 & 17.5 & 3.69 & 55.3 & 24.0 & 13.3 & 7.3 \\
\hline 39. North Australian Shelf & Tropical & 328.7 & 1.28 & 44.8 & 0.362 & 0.036 & 0.018 & 101.3 & 48.7 & 32.7 & 0.9 & 17.7 & 4.26 & 56.7 & 33.4 & 1.2 & 8.7 \\
\hline 40. Northeast Australian Shelf & Tropical & 130.8 & 0.51 & 44.8 & 0.362 & 0.036 & 0.016 & 40.3 & 48.7 & 32.8 & 0.8 & 17.7 & 1.93 & 60.5 & 32.0 & 1.0 & 6.4 \\
\hline 45. Northwest Australian Shelf & Tropical & 185.9 & 0.72 & 47.2 & 0.379 & 0.034 & 0.023 & 57.3 & 48.7 & 32.5 & 1.1 & 17.7 & 2.66 & 59.3 & 32.0 & 1.5 & 7.1 \\
\hline
\end{tabular}




\section{S.3.2 Estimation of Bacterial Growth Efficiency (BGE)}

Table S.5 Calculation of Bacterial Growth Efficiency (BGE) from Bacterial Production (BP) and Primary Production (PP) per large marine ecosystem (LME). Equations used to estimate BP from PP and BGE from BP: ${ }^{a} B P_{L M E}=-0.249 * P P_{L M E}{ }^{0.86}$ (Cole et al., 1988); ${ }^{\mathrm{b}} B G E_{L M E}=\left(0.037+0.65 * B P_{L M E}\right) /\left(1.8+B P_{L M E}\right)$ (del Giorgio and Cole, 1998).

\begin{tabular}{|c|c|c|c|c|c|}
\hline \multirow{2}{*}{$\begin{array}{l}\text { Large Marine Ecosystem } \\
\text { [\#. name] }\end{array}$} & \multirow{2}{*}{$\begin{array}{r}Z_{\text {photic_LME }} \\
{[\mathrm{m}]}\end{array}$} & \multicolumn{2}{|c|}{$\mathrm{PP}_{\mathrm{LME}}$} & \multirow{2}{*}{$\begin{array}{r}\mathrm{BP}_{\mathrm{LME}^{\mathrm{a}}} \\
{\left[\mu \mathrm{gC} \cdot \mathrm{L}^{-1} \mathrm{~h}^{-1}\right]}\end{array}$} & \multirow{2}{*}{$\begin{array}{r}\text { BGE }_{\text {LME }}{ }^{b} \\
{[-]}\end{array}$} \\
\hline & & {$\left[\mathrm{gC} \cdot \mathrm{m}^{-2} \cdot \mathrm{yr}^{-1}\right]$} & {$\left[\mu \mathrm{gC} \cdot \mathrm{L} \cdot \mathrm{h}^{-1}\right]$} & & \\
\hline 01. East Bering Sea & 28.1 & 285.6 & 2.32 & 0.51 & 0.16 \\
\hline 02. Gulf of Alaska & 28.8 & 330.9 & 2.62 & 0.57 & 0.17 \\
\hline 03. California Current & 34.3 & 223.9 & 1.49 & 0.35 & 0.12 \\
\hline 04. Gulf of California & 34.3 & 437.9 & 2.91 & 0.63 & 0.18 \\
\hline 05. Gulf of Mexico & 44.8 & 208.2 & 1.06 & 0.26 & 0.10 \\
\hline 06. Southeast U.S. Continental Shelf & 29.1 & 263.3 & 2.07 & 0.47 & 0.15 \\
\hline 07. Northeast U.S. Continental Shelf & 29.1 & 561.0 & 4.40 & 0.89 & 0.23 \\
\hline 08. Scotian Shelf & 29.1 & 509.5 & 4.00 & 0.82 & 0.22 \\
\hline 09. Newfoundland-Labrador Shelf & 29.1 & 295.5 & 2.32 & 0.51 & 0.16 \\
\hline 10. Insular Pacific-Hawaiian & 68.0 & 84.7 & 0.28 & 0.08 & 0.05 \\
\hline 11. Pacific Central-American & 39.6 & 244.0 & 1.41 & 0.33 & 0.12 \\
\hline 12. Caribbean Sea & 44.8 & 174.6 & 0.89 & 0.23 & 0.09 \\
\hline 13. Humboldt Current & 43.6 & 320.0 & 1.68 & 0.39 & 0.13 \\
\hline 14. Patagonian Shelf & 31.4 & 509.5 & 3.70 & 0.77 & 0.21 \\
\hline 15. South Brazil Shelf & 44.9 & 283.1 & 1.44 & 0.34 & 0.12 \\
\hline 16. East Brazil Shelf & 44.9 & 130.4 & 0.66 & 0.18 & 0.08 \\
\hline 17. North Brazil Shelf & 38.7 & 442.3 & 2.61 & 0.57 & 0.17 \\
\hline 18. Canadian Eastern Arctic - West Greenland & 16.3 & 151.9 & 2.13 & 0.48 & 0.15 \\
\hline 19. Greenland Sea & 16.3 & 174.2 & 2.45 & 0.54 & 0.17 \\
\hline 20. Barents Sea & 33.8 & 151.2 & 1.02 & 0.25 & 0.10 \\
\hline 21. Norwegian Sea & 28.3 & 179.3 & 1.45 & 0.34 & 0.12 \\
\hline 22. North Sea & 22.8 & 407.3 & 4.09 & 0.84 & 0.22 \\
\hline 23. Baltic Sea & 12.0 & 697.6 & 13.27 & 2.30 & 0.37 \\
\hline 24. Celtic-Biscay Shelf & 22.8 & 349.2 & 3.50 & 0.73 & 0.20 \\
\hline 25. Iberian Coastal & 45.0 & 276.9 & 1.40 & 0.33 & 0.12 \\
\hline 26. Mediterranean & 37.2 & 157.8 & 0.97 & 0.24 & 0.10 \\
\hline 27. Canary Current & 28.7 & 436.8 & 3.47 & 0.73 & 0.20 \\
\hline 28. Guinea Current & 27.0 & 357.9 & 3.03 & 0.65 & 0.19 \\
\hline 29. Benguela Current & 41.9 & 506.6 & 2.76 & 0.60 & 0.18 \\
\hline 30. Agulhas Current & 49.1 & 221.0 & 1.03 & 0.26 & 0.10 \\
\hline 31. Somali Coastal Current & 39.5 & 249.5 & 1.44 & 0.34 & 0.12 \\
\hline 32. Arabian Sea & 39.3 & 390.5 & 2.27 & 0.50 & 0.16 \\
\hline 33. Red Sea & 33.7 & 298.4 & 2.02 & 0.46 & 0.15 \\
\hline 34. Bay of Bengal & 40.0 & 265.2 & 1.51 & 0.36 & 0.12 \\
\hline 35. Gulf of Thailand & 38.6 & 284.9 & 1.69 & 0.39 & 0.13 \\
\hline 36. South China Sea & 34.2 & 174.2 & 1.16 & 0.28 & 0.11 \\
\hline 37. Sulu-Celebes Sea & 38.6 & 209.3 & 1.24 & 0.30 & 0.11 \\
\hline 38. Indonesian Sea & 38.6 & 263.7 & 1.56 & 0.37 & 0.13 \\
\hline 39. North Australian Shelf & 44.8 & 328.7 & 1.68 & 0.39 & 0.13 \\
\hline 40. Northeast Australian Shelf & 44.8 & 130.8 & 0.67 & 0.18 & 0.08 \\
\hline 41. East-Central Australian Shelf & 44.8 & 157.4 & 0.80 & 0.21 & 0.09 \\
\hline 42. Southeast Australian Shelf & 44.1 & 187.0 & 0.97 & 0.24 & 0.10 \\
\hline 43. Southwest Australian Shelf & 47.2 & 180.8 & 0.88 & 0.22 & 0.09 \\
\hline 44. West-Central Australian Shelf & 47.2 & 173.9 & 0.84 & 0.21 & 0.09 \\
\hline 45. Northwest Australian Shelf & 47.2 & 185.9 & 0.90 & 0.23 & 0.09 \\
\hline 46. New Zealand Shelf & 36.3 & 208.2 & 1.31 & 0.31 & 0.11 \\
\hline 47. East China Sea & 29.8 & 325.4 & 2.50 & 0.55 & 0.17 \\
\hline 48. Yellow Sea & 29.8 & 589.1 & 4.52 & 0.91 & 0.23 \\
\hline 49. Kuroshio Current & 36.3 & 154.1 & 0.97 & 0.24 & 0.10 \\
\hline 50. Sea of Japan/East Sea & 36.3 & 220.6 & 1.39 & 0.33 & 0.12 \\
\hline 51. Oyashio Current & 31.9 & 261.5 & 1.87 & 0.43 & 0.14 \\
\hline 52. Sea of Okhotsk & 28.1 & 297.7 & 2.42 & 0.53 & 0.16 \\
\hline 53. West Bering Sea & 28.1 & 214.0 & 1.74 & 0.40 & 0.14 \\
\hline 54. Northern Bering - Chukchi Seas & 34.8 & 90.9 & 0.60 & 0.16 & 0.07 \\
\hline 55. Beaufort Sea & 34.8 & 119.1 & 0.78 & 0.20 & 0.08 \\
\hline 56. East Siberian Sea & 34.8 & 54.4 & 0.36 & 0.10 & 0.05 \\
\hline 57. Laptev Sea & 34.8 & 156.7 & 1.03 & 0.26 & 0.10 \\
\hline 58. Kara Sea & 34.8 & 126.7 & 0.83 & 0.21 & 0.09 \\
\hline 59. Iceland Shelf and Sea & 25.0 & 201.3 & 1.83 & 0.42 & 0.14 \\
\hline 60. Faroe Plateau & 33.8 & 154.1 & 1.04 & 0.26 & 0.10 \\
\hline 61. Antarctic & 26.5 & 99.7 & 0.86 & 0.22 & 0.09 \\
\hline 62. Black Sea & 21.3 & 376.6 & 4.05 & 0.83 & 0.22 \\
\hline 63. Hudson Bay Complex & 18.0 & 152.7 & 1.94 & 0.44 & 0.14 \\
\hline 64. Central Arctic Ocean & 34.8 & 8.4 & 0.06 & 0.02 & 0.03 \\
\hline 65. Aleutian Islands & 28.1 & 285.6 & 2.32 & 0.51 & 0.16 \\
\hline 66. Canadian High Arctic - North Greenland & 28.1 & 58.8 & 0.48 & 0.13 & 0.06 \\
\hline
\end{tabular}




\section{S.3.3 Sensitivity analysis table}

Table S.6 Results of the sensitivity analysis of the 18 primary input parameters modelled. Sensitivity ratios (SR, [dimensionless]) obtained after independent variation of $10 \%$ on the input values.

\begin{tabular}{lcr}
\hline Input parameter & Mean SR [-] & \multicolumn{1}{c}{ SR range [-] } \\
\hline$P P_{\text {Pot_LME }}$ & 0.92 & $(0.75,1.00)$ \\
$f_{\text {SPassimil_CZ }}$ & -0.59 & $(-1.64,-0.03)$ \\
$f_{\text {PPsink_CZ }}$ & 0.51 & $(0.43,0.69)$ \\
$f_{\text {SPingest }}$ & 0.31 & $(0.10,0.43)$ \\
$B G E_{\text {LME }}$ & -0.16 & $(-0.60,-0.03)$ \\
$f_{\text {FPleach }}$ & -0.11 & $(-0.16,-0.02)$ \\
$Z_{\text {mean }}$ & -0.08 & $(-0.09,-0.08)$ \\
$f_{\text {BRmarsnow }}$ & -0.08 & $(-0.09,-0.08)$ \\
$f_{\text {PPsinkGZ_LME }}$ & -0.08 & $(-0.23,0.00)$ \\
$U_{\text {PP }}$ & 0.05 & $(0.04,0.07)$ \\
$f_{\text {SPmort }}$ & 0.04 & $(0.00,0.33)$ \\
$f_{\text {AVTgr__CZ }}$ & 0.03 & $(0.01,0.04)$ \\
$U_{\text {SP }}$ & 0.02 & $(0.01,0.03)$ \\
$Z_{\text {AVT }}$ & 0.02 & $(0.00,0.03)$ \\
$Z_{\text {photic_LME }}$ & 0.01 & $(0.00,0.09)$ \\
$f_{\text {FPsinkGZ_CZ }}$ & -0.01 & $(-0.03,0.00)$ \\
$D O C_{\text {ExcrAVT }}$ & 0.01 & $(0.00,0.02)$ \\
$f_{\text {plisis__LME }}$ & 0.00 & $(-0.04,0.12)$ \\
\hline
\end{tabular}

\section{S.3.4 Export production $\left(P_{\mathrm{E}}\right)$ algorithms}

Table S.7 Summary of the regression analysis for PP vs. $P_{\mathrm{E}}$ with a power $\left(P_{\mathrm{E}}=\mathrm{a} * \mathrm{PP}\right)$, an exponential $\left(P_{\mathrm{E}}=\exp (\mathrm{a}+\mathrm{b} * \mathrm{PP})\right)$, and a linear $\left(P_{\mathrm{E}}=\mathrm{a}+\mathrm{b} * \mathrm{PP}\right)$ model. Additional notes: the regression line of the exponential model does not intersect the origin; $n$ is the number of spatial units; $R^{2}$ is the coefficient of determination; $p$ is the significance level.

\begin{tabular}{lrrrrr}
\hline Model & $n$ & $a$ & $b$ & $R^{2}$ & $p$ \\
\hline Power & 66 & 1.25 & 0.83 & 0.73 & 0.002 \\
Exponential & 66 & 42.67 & 0.004 & 0.61 & 0.006 \\
Linear & 66 & 4.34 & 0.49 & 0.73 & 0.101 \\
\hline
\end{tabular}




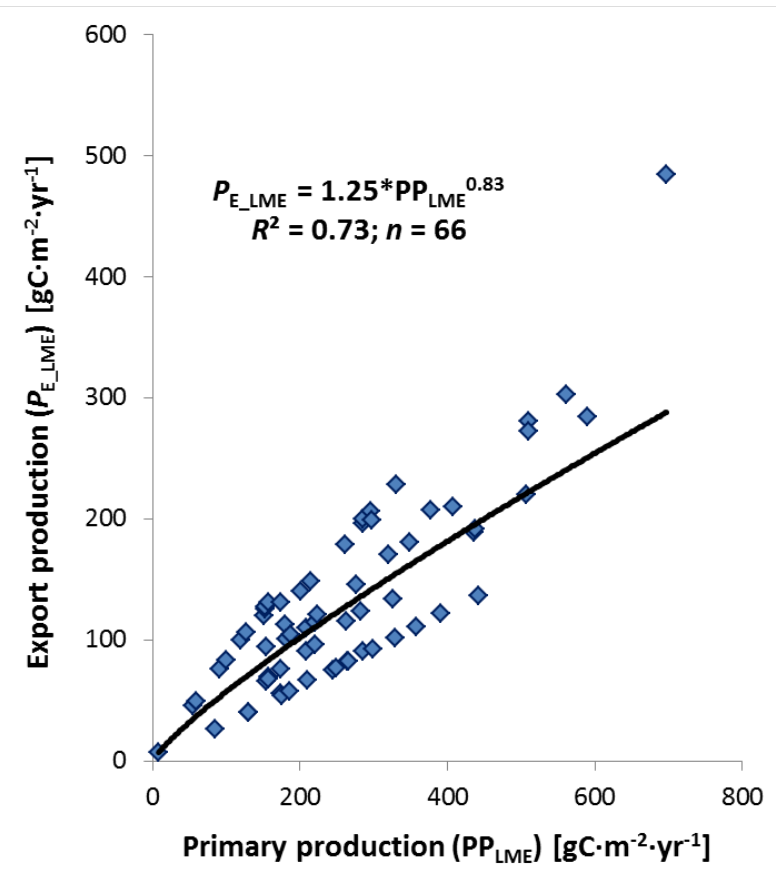

Figure S.3 Export production $\left(P_{\mathrm{E}},\left[\mathrm{gC} \cdot \mathrm{m}^{-2} \cdot \mathrm{yr}^{-1}\right]\right)$ as a function of primary production $\left(\mathrm{PP},\left[\mathrm{gC} \cdot \mathrm{m}^{-2} \cdot \mathrm{yr}^{-1}\right]\right)$. Power regression fitting of data for 66 Large Marine Ecosystems with resulting export algorithm equation $\left(P_{\mathrm{E}_{\perp} \mathrm{LME}}=1.25 * \mathrm{PP}_{\mathrm{LME}}{ }^{0.83}\right)$ and coefficient of determination $\left(R^{2}=0.73\right)$.

We used the same PP dataset to the export algorithms from others in order to validate the export component of the proposed exposure model. Analysing the correlation results (Table S.7) we obtained linear correlation coefficients ( $r$ ) values close to 0.90, except for Eppley and Peterson's algorithm (derived for the eastern Pacific Ocean).

Table S.8 Results for the correlation of $P_{\mathrm{E}}$-PP algorithms from this study to others.

\begin{tabular}{|c|c|c|}
\hline Correlation $(r)$ & Algorithm & Source \\
\hline 0.67 & $\begin{array}{l}P_{E_{-} L M E}=0.0025 * P P_{L M E}{ }^{2} \text { if } P P_{L M E}<200 \mathrm{gC} \cdot \mathrm{m}^{-2} \cdot y r^{-1} \\
P_{E_{-} L M E}=0.5 * P P_{L M E} \text { if } P P_{L M E}>200 \mathrm{gC} \cdot \mathrm{m}^{-2} \cdot y r^{-1}\end{array}$ & $\begin{array}{l}\text { (Eppley and Peterson, 1979) } \\
\text { (Eppley and Peterson, 1979) }\end{array}$ \\
\hline 0.92 & $P_{E_{-} L M E}=P P_{L M E} /\left(Z_{\text {aphotic }} c_{L M E}+0.212\right)$ & (Suess, 1980) \\
\hline 0.91 & $P_{E_{-} L M E}=0.409 * P P_{L M E}{ }^{1.41} /\left(Z_{\text {aphotic_LME }}{ }^{0.628}\right)$ & (Betzer et al., 1984) \\
\hline 0.91 & $P_{E_{-} L M E}=3.523 * Z_{\text {aphotic } L M E}{ }^{-0.734} * P P_{L M E}^{1.000}$ & (Pace et al., 1987) \\
\hline 0.87 & $P_{E_{-} L M E}=0.049 * P P_{L M E}^{1.41}$ & (Wassmann, 1990) \\
\hline-- & $P_{E_{-} L M E}=1.15 * P P_{L M E}^{0.86}$ & This study \\
\hline
\end{tabular}




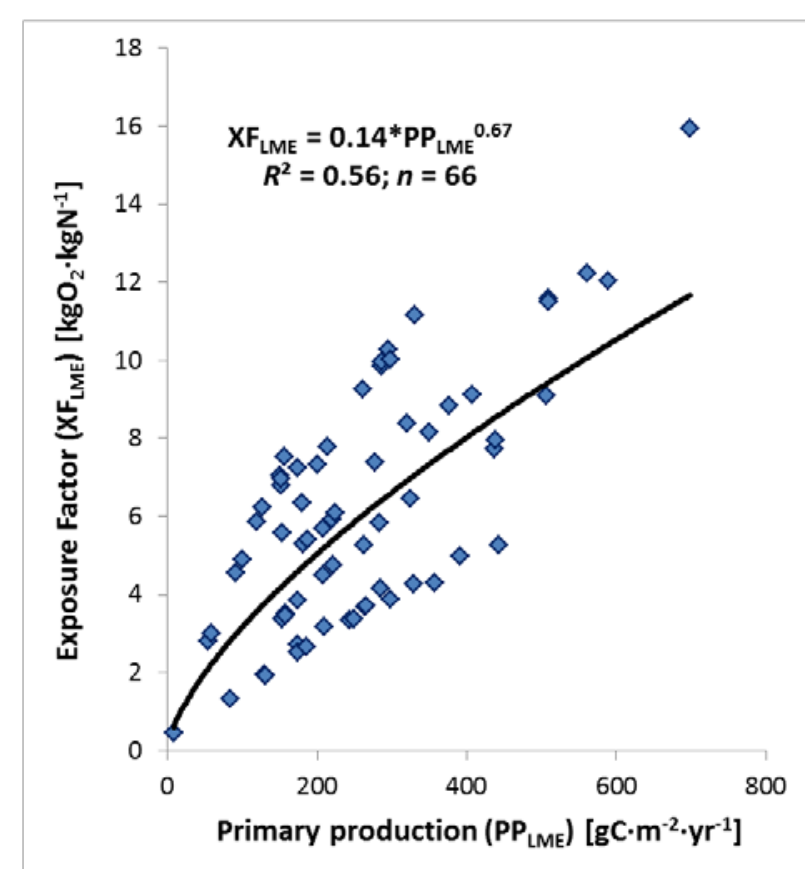

Figure S.4 Exposure factor (XF, $\left[\mathrm{kgO}_{2} \cdot \mathrm{kgN}^{-1}\right]$ ) as a function of primary production (PP, $\left.\left[\mathrm{gC} \cdot \mathrm{m}^{-2} \cdot \mathrm{yr}^{-1}\right]\right)$. Power regression fitting of data for 66 Large Marine Ecosystems with resulting export algorithm equation $\left(\mathrm{XF}_{\mathrm{LME}}\right.$ $\left.=0.14 * \mathrm{PP}_{\mathrm{LME}}{ }^{0.67}\right)$ and coefficient of determination $\left(R^{2}=0.56\right)$.

\section{S.4 References}

Baines, S.B., Pace, M.L., Karl, D.M., 1994. Why does the relationship between sinking flux and planktonic primary production differ between lakes and oceans? Limnol. Oceanogr. 39, 213-226.

Behrenfeld, M.J., 2010. Abandoning Sverdrup’s Critical Depth Hypothesis on phytoplankton blooms. Ecology 91, 977-89.

Behrenfeld, M.J., Boss, E.S., 2014. Resurrecting the ecological underpinnings of ocean plankton blooms. Ann. Rev. Mar. Sci. 6, 167-94.

Behrenfeld, M.J., Doney, S.C., Lima, I., Boss, E.S., Siegel, D.A., 2013. Annual cycles of ecological disturbance and recovery underlying the subarctic Atlantic spring plankton bloom. Global Biogeochem. Cycles 27, 526-540.

Betzer, P.R., Showers, W.J., Laws, E.A., Winn, C.D., DiTullio, G.R., Kroopnick, P.M., 1984. Primary productivity and particle fluxes on a transect of the equator at $153^{\circ} \mathrm{W}$ in the Pacific Ocean. Deep Sea Res. Part A. Oceanogr. Res. Pap. 31, 1-11.

Beusen, A.H.W., Bouwman, A.F., Heuberger, P.S.C., Van Drecht, G., Van der Hoek, K.W., 2008. Bottomup uncertainty estimates of global ammonia emissions from global agricultural production systems. Atmos. Environ. 42, 6067-6077.

Boss, E., Behrenfeld, M.J., 2010. In situ evaluation of the initiation of the North Atlantic phytoplankton bloom. Geophys. Res. Lett. 37, n/a-n/a.

Bouwman, A.F., 2005. Exploring changes in river nitrogen export to the world's oceans. Global Biogeochem. Cycles 19. 
Bouwman, A.F., Beusen, A.H.W., Billen, G., 2009. Human alteration of the global nitrogen and phosphorus soil balances for the period 1970-2050. Global Biogeochem. Cycles 23.

Bouwman, A.F., Boumans, L.J.M., Batjes, N.H., 2002. Estimation of global NH3 volatilization loss from synthetic fertilizers and animal manure applied to arable lands and grasslands. Global Biogeochem. Cycles 16.

Butterbach-Bahl, K., Dannenmann, M., 2011. Denitrification and associated soil N2O emissions due to agricultural activities in a changing climate. Curr. Opin. Environ. Sustain. 3, 389-395.

Carpenter, S.R., Caraco, N.F., Correll, D.L., Howarth, R.W., Sharpley, A.N., Smith, V.H., 1998. Nonpoint pollution of surface waters with phosphorus and nitrogen. Ecol. Appl. 8, 559-568.

Chiswell, S.M., 2011. Annual cycles and spring blooms in phytoplankton: don’t abandon Sverdrup completely. Mar. Ecol. Prog. Ser. 443, 39-50.

Cloern, J.E., 2001. Our evolving conceptual model of the coastal eutrophication problem. Mar. Ecol. Prog. Ser. 210, 223-253.

Cole, J.J., Findlay, S., Pace, M.L., 1988. Bacterial production in fresh and saltwater ecosystems: a crosssystem overview. Mar. Ecol. Prog. Ser. 43, 1-10.

Cushing, D.H., 1975. Marine Ecology and Fisheries. Cambridge University Press, Cambridge.

De Jonge, V.N., Elliott, M., Orive, E., 2002. Causes, historical development, effects and future challenges of a common environmental problem: eutrophication. Hydrobiologia 475/476, 1-19.

Del Giorgio, P.A., Cole, J.J., 1998. Bacterial Growth Efficiency in Natural Aquatic Systems. Annu. Rev. Ecol. Syst. 29, 503-541.

Duarte, B., Saraiva, P.M., Pantelides, C.C., 2004. Combined Mechanistic and Empirical Modelling. Int. J. Chem. React. Eng. 2, A3.

Duarte, C.M., Amthor, J.S., DeAngelis, D.L., Joyce, L.A., Maranger, R.J., Pace, M.L., Pastor, J.J., Running, S.W., 2003. The Limits to Models in Ecology, in: Canham, C., Cole, J., WK, L. (Eds.), Models in Ecosystem Science. Princeton University Press, Princeton, New Jersey, pp. 437-451.

Eppley, R.W., Peterson, B.J., 1979. Particulate organic matter flux and planktonic new production in the deep ocean. Nature.

Evans, G.T., Parslow, J.S., 1985. A model of annual plankton cycles. Biol. Oceanogr. 3, 327-347.

Field, C.B., 1998. Primary Production of the Biosphere: Integrating Terrestrial and Oceanic Components. Science (80-. ). 281, 237-240.

Finnveden, G., Potting, J., 1999. Eutrophication as an impact category - State of the Art and Research Needs. Int. J. Life Cycle Assess. 4, 311-314.

Galloway, J.N., Dentener, F.J., Capone, D.G., Boyer, E.W., Howarth, R.W., Seitzinger, S.P., Asner, G.P., Cleveland, C.C., Green, P.A., Holland, E.A., Karl, D.M., Michaels, A.F., Porter, J.H., Townsend, A.R., Vörösmarty, C.J., 2004. Nitrogen cycles: past, present, and future. Biogeochemistry 70, 153-226. 
Galloway, J.N., Townsend, A.R., Erisman, J.W., Bekunda, M., Cai, Z., Freney, J.R., Martinelli, L.A., Seitzinger, S.P., Sutton, M.A., 2008. Transformation of the Nitrogen Cycle: Recent Trends, Questions, and Potential Solutions. Science (80-. ). 320, 889-892.

Geider, R.J., Delucia, E.H., Falkowski, P.G., Finzi, A.C., Grime, J.P., Grace, J., Kana, T.M., Roche, J.L.A., Long, S.P., Osborne, B.A., Platt, T., Prentice, I.C., Raven, J.A., Schlesinger, W.H., Smetacek, V., Stuart, V., Sathyendranath, S., Thomas, R.B., Vogelman, T.C., Williams, P., Woodward, F.I., 2001. Primary productivity of planet earth: biological determinants and physical constraints in terrestrial and aquatic habitats. Glob. Chang. Biol. 7, 849-882.

Gran, H.H., Braarud, T., 1935. A quantitative study of the phytoplankton in the Bay of Fundy and Gulf of Maine. J. Biol. Board Canada 1, 279-467.

Green, P.A., Vörösmarty, C.J., Meybeck, M., Galloway, J.N., Peterson, B.J., Boyer, E.W., 2004. Preindustrial and contemporary fluxes of nitrogen through rivers: a global assessment based on typology. Biogeochemistry 68, 71-105.

Herbert, R.A., 1999. Nitrogen cycling in coastal marine ecosystems. FEMS Microbiol. Rev. 23, 563-590.

Huisman, J., Arrayás, M., Ebert, U., Sommeijer, B., 2002. How do sinking phytoplankton species manage to persist? Am. Nat. 159, 245-54.

Huisman, J., van Oostveen, P., Weissing, F.J., 1999. Critical depth and critical turbulence: Two different mechanisms for the development of phytoplankton blooms. Limnol. Oceanogr. 44, 1781-1787.

Kitsiou, D., Karydis, M., 2011. Coastal marine eutrophication assessment: a review on data analysis. Environ. Int. 37, 778-801.

Kroeze, C., Bouwman, A.F., Seitzinger, S.P., 2012. Modeling global nutrient export from watersheds. Curr. Opin. Environ. Sustain. 4, 195-202.

Lee, D.S., Köhler, I., Grobler, E., Rohrer, F., Sausen, R., Gallardo-Klenner, L., Olivier, J.G.J., Dentener, F.J., Bouwman, A.F., 1997. Estimations of global NOx emissions and their uncertainties. Atmos. Environ. 31, 1735-1749.

Lemke, P., Ren, J., Alley, R.B., Allison, I., Carrasco, J., Flato, G., Fujii, Y., Kaser, G., Mote, P., Thomas, R.H., Zhang, T., 2007. Observations: Changes in Snow, Ice and Frozen Ground, in: Solomon, S., D. Qin, M. Manning, Z. Chen, M.M., K.B. Averyt, M.T. and H.L.M. (eds. . (Eds.), Climate Change 2007: The Physical Science Basis. Contribution of Working Group I to the Fourth Assessment Report of the Intergovernmental Panel on Climate Change. Cambridge University Press, Cambridge, UK and New York, USA, pp. 337-383.

Longhurst, A.R., 1998. Ecological Geography of the Sea. Academic Press Limited, London, UK.

Mills, E.L., 1975. Benthic Organisms and the Structure of Marine Ecosystems. J. Fish. Res. Board Canada 32, 1657-1663.

Møller, E.F., 2007. Production of dissolved organic carbon by sloppy feeding in the copepods Acartia tonsa, Centropages typicus, and Temora longicornis. Limnol. Oceanogr. 52, 79-84.

Møller, E.F., Nielsen, T.G., 2001. Production of bacterial substrate by marine copepods: Effect of phytoplankton biomass and cell size. J. Plankton Res. 23, 527-536. 
Mulligan, M., Wainwright, J., 2004. Modelling and Model Building, in: Wainwright, J., Mulligan, M. (Eds.), Environmental Modelling: Finding Simplicity in Complexity. John Wiley \& Sons, Ltd., Chichester, pp. $7-73$.

Niemi, G., Wardrop, D., Brooks, R., Anderson, S., Brady, V., Paerl, H.W., Rakocinski, C.F., Brouwer, M., Levinson, B., McDonald, M., 2004. Rationale for a New Generation of Indicators for Coastal Waters. Environ. Health Perspect. 112, 979-986.

Nixon, S.W., 1995. Coastal marine eutrophication: A definition, social causes, and future concerns. Ophelia 41, 199-219.

Pace, M.L., Knauer, G.A., Karl, D.M., Martin, J.H., 1987. Primary production, new production and vertical flux in the eastern Pacific Ocean. Nature 325, 803-804.

Pauly, D., Christensen, V., 1995. Primary production required to sustain global fisheries. Nature.

Peel, M.C., Finlayson, B.L., Mcmahon, T.A., 2007. Updated world map of the Köppen-Geiger climate classification. Hydrol. Earth Syst. Sci. 11, 1633-1644.

Peterson, B.J., McClelland, J., Curry, R., Holmes, R.M., Walsh, J.E., Aagaard, K., 2006. Trajectory Shifts in the Arctic and Subarctic Freshwater Cycle. Science (80-. ). 313, 1061-1066.

Pinckney, J.L., Paerl, H.W., Tester, P., Richardson, T., 2001. The Role of Nutrient Loading and Eutrophication in Estuarine Ecology. Environ. Health Perspect. 109, 699-706.

Platt, T., Bird, D.F., Sathyendranath, S., 1991. Critical Depth and Marine Primary Production. Proc. R. Soc. B Biol. Sci. 246, 205-217.

Rabalais, N.N., 2002. Nitrogen in Aquatic Ecosystems. Ambio 31, 102-112.

Rabalais, N.N., Turner, R.E., Diaz, R.J., Justić, D., 2009. Global change and eutrophication of coastal waters. ICES J. Mar. Sci. 66, 1528-1537.

Reynolds, C.S., 2006. The Ecology of Phytoplankton. Cambridge University Press, Cambridge, UK.

Roy, P.-O., Huijbregts, M.A.J., Deschênes, L., Margni, M., 2012. Spatially-differentiated atmospheric source-receptor relationships for nitrogen oxides, sulfur oxides and ammonia emissions at the global scale for life cycle impact assessment. Atmos. Environ. 62, 74-81.

Ryther, J.H., Dunstan, W.M., 1971. Nitrogen, Phosphorus, and Eutrophication in the Coastal Marine Environment. Science (80-. ). 171, 1008-1013.

Saba, G.K., Steinberg, D.K., Bronk, D. a., 2011. The relative importance of sloppy feeding, excretion, and fecal pellet leaching in the release of dissolved carbon and nitrogen by Acartia tonsa copepods. J. Exp. Mar. Bio. Ecol. 404, 47-56.

Saba, G.K., Steinberg, D.K., Bronk, D.A., 2009. Effects of diet on release of dissolved organic and inorganic nutrients by the copepod Acartia tonsa. Mar. Ecol. Prog. Ser. 386, 147-161.

Seitzinger, S.P., Harrison, J.A., Dumont, E., Beusen, A.H.W., Bouwman, A.F., 2005. Sources and delivery of carbon, nitrogen, and phosphorus to the coastal zone: An overview of Global Nutrient Export from Watersheds (NEWS) models and their application. Global Biogeochem. Cycles 19, n/a-n/a. 
Seitzinger, S.P., Mayorga, E., Bouwman, A.F., Kroeze, C., Beusen, A.H.W., Billen, G., Van Drecht, G., Dumont, E., Fekete, B.M., Garnier, J., Harrison, J.A., 2010. Global river nutrient export: A scenario analysis of past and future trends. Global Biogeochem. Cycles 24.

Sherman, K., Hempel, G., 2009. The UNEP Large Marine Ecosystem Report: A perspective on changing conditions in LMEs of the World's Regional Seas, UNEP Regional Seas Report and Studies No. 182.

Smetacek, V., Passow, U., 1990. Spring bloom initiation and Sverdrup 's critical-depth model. Limnol. Oceanogr. 35, 228-234.

Smith, V.H., 2007. Using primary productivity as an index of coastal eutrophication: the units of measurement matter. J. Plankton Res. 29, 1-6.

Smith, V.H., Joye, S.B., Howarth, R.W., 2006. Eutrophication of freshwater and marine ecosystems. Limnol. Ocean. 51, 351-355.

Smith, V.H., Tilman, G.D., Nekola, J.C., 1999. Eutrophication: impacts of excess nutrient inputs on freshwater, marine, and terrestrial ecosystems. Environ. Pollut. 100, 179-196.

Spalding, M.D., Fox, H.E., Allen, G.R., Davidson, N., Ferdaña, Z.A., Finlayson, M., Halpern, B.S., Jorge, M.A., Lourie, S.A., Martin, K.D., Mcmanus, E., Recchia, C.A., Robertson, J., 2007. Marine Ecoregions of the World: A Bioregionalization of Coastal and Shelf Areas. Bioscience 57, 573-583.

Steen, B., 2002. Impact evaluation in industrial ecology, in: Ayres, R.U., Ayres, L.W. (Eds.), A Handbook of Industrial Ecology. Edward Elgar, Cheltenham, pp. 149-161.

Suess, E., 1980. Particulate organic carbon flux in the oceans - surface productivity and oxygen utilization. Nature 288, 260-263.

Sverdrup, H.U., 1953. On Conditions for the Vernal Blooming of Phytoplankton. J. du Cons. Int. pour l' Explor. la Mer 18, 287-295.

Taylor, J.R., Ferrari, R., 2011. Shutdown of turbulent convection as a new criterion for the onset of spring phytoplankton blooms. Limnol. Oceanogr. 56, 2293-2307.

Tremblay, J.-É., Michel, C., Hobson, K.A., Gosselin, M., Price, N.M., 2006. Bloom dynamics in early opening waters of the Arctic Ocean. Limnol. Oceanogr. 51, 900-912.

UBC, 1999. Sea Around Us Project: Fisheries, Ecosystems \& Biodiversity [WWW Document]. URL http://seaaroundus.org/ (accessed 6.18.14).

Van der Ploeg, R.R., Böhm, W., Kirkham, M.B., 1999. On the Origin of the Theory of Mineral Nutrition of Plants and the Law of the Minimum. Soil Sci. Soc. Am. J. 63, 1055-1062.

Van Drecht, G., Bouwman, A.F., Harrison, J.A., Knoop, J.M., 2009. Global nitrogen and phosphate in urban wastewater for the period 1970 to 2050. Global Biogeochem. Cycles 23, 1-19.

Van Drecht, G., Bouwman, A.F., Knoop, J.M., Beusen, A.H.W., Meinardi, C.R., 2003. Global modeling of the fate of nitrogen from point and nonpoint sources in soils, groundwater, and surface water. Global Biogeochem. Cycles 17, 1-20. 
Van Vuuren, D.P., Bouwman, A.F., Smith, S.J., Dentener, F., 2011. Global projections for anthropogenic reactive nitrogen emissions to the atmosphere : an assessment of scenarios in the scientific literature. Curr. Opin. Environ. Sustain. 3, 359-369.

Vitousek, P.M., Aber, J.D., Howarth, R.W., Likens, G.E., Matson, P.A., Schindler, D.W., Schlesinger, W.H., Tilman, D.G., 1997. Human alteration of the global nitrogen cycle: sources and consequences. Ecol. Appl. 7, 737-750.

Wassmann, P., 1990. Relationship between primary and export production in the boreal coastal zone of the North Atlantic. Limnol. Ocean. 35, 464-471.

Wollheim, W.M., Vörösmarty, C.J., Bouwman, A.F., Green, P.A., Harrison, J.A., Linder, E., Peterson, B.J., Seitzinger, S.P., Syvitski, J.P.M., 2008. Global N removal by freshwater aquatic systems using a spatially distributed, within-basin approach. Global Biogeochem. Cycles 22, 1-14. 